\title{
MÁRCIO CARLOS MACHADO
}

Estudo da expressão do receptor da vasopressina (AVPR1B), do receptor do hormônio liberador de corticotrofina (CRHR1) e do receptor dos secretagogos de GH (GHSR-1a) em pacientes portadores de síndrome de Cushing ACTHdependente: correlação clínico-molecular

Tese apresentada à Faculdade de Medicina da Universidade de São Paulo para obtenção do título de Doutor em Ciências

Área de concentração: Endocrinologia

Orientador: Dr. Luiz Roberto Salgado

SÃO PAULO

2006 
Não me sinto obrigado a acreditar que o mesmo Deus que nos dotou de sentidos, razão e intelecto, pretenda que não os utilizemos.

(Galileo Galilei) 
Dedico...

Aos meus pais, João e Meire, que sempre me apoiaram em todos os momentos da minha vida.

Ofereço...

À minha esposa, Sandra, pelo seu amor (também) sempre tão presente. 


\section{AGRADECIMENTOS}

À Deus, pela oportunidade de viver, amar, e fazer de minha profissão um instrumento de bondade e respeito ao próximo.

Ao Dr. Luiz Roberto Salgado, por seu exemplo de dedicação ao estudo da neuroendocrinologia, significativa contribuição para o meu aprimoramento profissional, pelo apoio incondicional para a realização deste trabalho, mas, principalmente, pela amizade consolidada nesses anos de residência médica e pósgraduação.

Ao Prof. Dr. Daniel Giannella-Neto e à Dra. Maria Lúcia C. Corrêa-Giannella, meu profundo agradecimento, por terem disponibilizado toda a estrutura e suporte do LIM-25, sem os quais não haveria possibilidade da concretização do meu sonho acadêmico.

Ao Prof. Dr. Marcello Delano Bronstein, meu muito obrigado, por ter fornecido juntamente com o $\mathrm{Dr}$. Salgado toda a estrutura de atendimento dos pacientes e incentivo profissional na Unidade de Neuroendocrinologia do $\mathrm{HC}$ e também fora do meio acadêmico.

Ao Prof. Dr. Éder Carlos Rocha Quintão e à Profa. Dra. Berenice Bilharinho de Mendonça, em nome da Disciplina de Endocrinologia do HC/FMUSP, que muito me auxiliaram nesses anos de pós-graduação, principalmente em relação aos incentivos recebidos para ativa participação em congressos nacionais e internacionais. 
Ao biomédico Ricardo Rodrigues Giorgi, que me ensinou as primeiras noções de biologia molecular prática e pela sua amizade. À biomédica Ana Mercedes Cavaleiro Luna e à bióloga Maria Ângela Zanella Fortes, pela amizade e auxílio na prática do laboratório.

À Dra. Nina Rosa Castro Musolino e ao Dr. Malebranche Berardo C. Cunha Neto, por terem também contribuído para o meu aprimoramento profissional e pelo encaminhamento de pacientes que ajudaram a compor minha casuística.

Ao Dr. Valter A. S. Cescato, neurocirurgião que operou os casos de DC, muito me ajudou na coleta dos fragmentos tumorais, sempre com gentileza e cordialidade.

Ao Prof. Dr. Bernardo L. Wajchenberg, à Dra. Maria Adelaide A. Pereira e à Dra. Márcia Nery, pelo encaminhamento de pacientes que ajudaram na construção da casuística.

À Prof. Dra. Ana Maria J. Lengyel da Unidade de Neuroendocrinologia da UNIFESP, pela colaboração e suporte inicial em relação ao uso do GHRP-6.

À Enfermeira Maria Francisca S. Oliveira, em nome da Enfermaria de Endocrinologia do HC/FMUSP, que muito me ajudou na feitura dos testes de estímulo nos pacientes com SC.

À Enfermeira Irene Maria S. Silva e às funcionárias Selma J. Ambrósio, Sebastiana do Amaral Couto e à Tânia Cristina de Oliveira, da sala de testes hormonais do HC/FMUSP, pelo enorme auxílio na realização dos testes de estímulo nos pacientes e indivíduos controles. 
Ao LIM-42, por ter realizado todas as dosagens hormonais dos pacientes e dos indivíduos controles.

Às secretárias Maria Aparecida da Silva e Rosana Zamboni, meu agradecimento pela gentileza nos processos relacionados à pós-graduação.

Ao secretário Rubens José da Silva e à secretária Márcia Helena Monteiro, também pela valiosa ajuda para resolver assuntos burocráticos.

Aos amigos do LIM-25, pelo valioso companheirismo dentro e fora do ambiente de trabalho.

À Norisa A. Herrera, muito mais que secretária, grande amiga e companheira de muitos momentos alegres vividos nos últimos anos.

À Fundação Faculdade de Medicina e CAPES, pelos auxílios financeiros para compras de materiais e auxílio pessoal através de bolsa.

Aos pacientes e indivíduos controles, sem os quais não seria possível a realização deste trabalho.

À minha querida Sandra, inspiração da minha vida, pela sua incansável e inestimável ajuda em várias etapas deste processo especialmente nas reações de PCR quantitativo e na finalização deste trabalho, mas principalmente, por viver ao meu lado, me apoiando incondicionalmente. 
Esta tese está de acordo com:

Referências: adaptado de International Committee of Medical Journals Editors (Vancouver)

Universidade de São Paulo. Faculdade de Medicina. Serviço de Biblioteca e Documentação. Guia de apresentação de dissertações, teses e monografias. Elaborado por Anneliese Carneiro da Cunha, Maria Julia de A. L. Freddi, Maria F. Crestana, Marinalva de Souza Aragão, Suely Campos Cardoso, Valéria Vilhena. São Paulo: Serviço de Biblioteca e Documentação; 2004.

Abreviaturas dos títulos dos periódicos de acordo com List of Journals Indexed in Index Medicus. 


\section{SUMÁRIO}

Lista de Siglas

Lista de Símbolos

Lista de Figuras

Lista de Tabelas

Resumo

Summary

I INTRODUÇÃO

1 Síndrome de Cushing $\quad 01$

$\begin{array}{ll}1.1 \text { Definições } & 01\end{array}$

$\begin{array}{ll}1.2 \text { Histórico } & 02\end{array}$

$\begin{array}{ll}1.3 \text { Classificação } & 03\end{array}$

$\begin{array}{ll}1.4 \text { Epidemiologia } & 06\end{array}$

$\begin{array}{ll}\text { 1.5 Manifestações Clínicas } & 07\end{array}$

$\begin{array}{ll}1.6 \text { Diagnóstico } & 08\end{array}$

1.7 Diagnóstico Diferencial da Síndrome de Cushing ACTH-dependente 13

1.8 Secretagogos de GH (GHS) na Síndrome de Cushing 16

1.8.1 Histórico, Definição e Ações dos GHS 16

1.8.2 GHS e Eixo Hipotálamo-hipófise-adrenal $\quad 19$

1.8.3 GHS na Síndrome de Cushing 19

$\begin{array}{ll}1.9 \text { Tratamento } & 23\end{array}$

$\begin{array}{ll}1.10 \text { Prognóstico } & 24\end{array}$

2 Expressão Gênica na Síndrome de Cushing ACTH-dependente 25

2.1 Receptor do Hormônio Liberador de Corticotrofina (CRHR1) 25

2.2 Receptores da Vasopressina (AVPR1B e AVPR2) 27 


\section{OBJETIVOS}

III CASUÍSTICA E MÉTOdOS 35

1 Pacientes e Amostras $\quad 35$

2 Testes de Estímulo 39

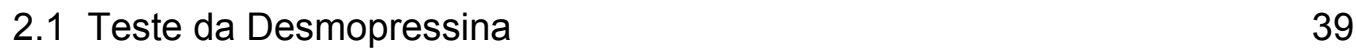

$\begin{array}{ll}2.2 \text { Teste do hCRH } & 40\end{array}$

2.3 Teste do GHRP-6 40

2.4 Ensaios Hormonais $\quad 41$

3 Extração de RNA Total 41

4 Síntese do cDNA e RT-PCR Semi-quantitativa do Gene BCR 42

5 PCR Semi-quantitativa dos Genes PIT1 e BCR 45

6 PCR Quantitativa em Tempo Real (qPCR) dos Genes em Estudo 48

$\begin{array}{lll}7 \text { Análise Estatística } & 55\end{array}$

IV RESULTADOS

1 Teste do GHRP-6 no Grupo Controle 56

2 Testes nos Pacientes com Síndrome de Cushing 58

2.1 Teste do GHRP-6 58

$\begin{array}{ll}2.2 \text { Teste da Desmopressina } & 63\end{array}$

$\begin{array}{ll}2.3 \text { Teste do hCRH } & 63\end{array}$

3 Expressão dos Genes em Estudo $\quad 68$

$\begin{array}{ll}\text { 3.1 Expressão do RNAm do GHSR-1a } & 68\end{array}$

3.2 Expressão do RNAm do AVPR1B 68

3.3 Expressão do RNAm do CRHR1 69

4 Correlações Clínico-moleculares $\quad 69$

$\begin{array}{ll}\text { V DISCUSSÃO } & 88\end{array}$ 
VI CONCLUSÕES

VII ANEXOS

VIII REFERÊNCIAS 


\section{Lista de Siglas}

\begin{tabular}{|c|c|}
\hline aa & aminoácido \\
\hline ACTH & hormônio adrenocorticotrófico \\
\hline AIMAH & hiperplasia adrenal macronodular ACTH-independente \\
\hline AMPc & monofosfato cíclico de adenosina \\
\hline AVP & arginina vasopressina \\
\hline AVPR1B & receptor da arginina vasopressina tipo 1B \\
\hline BCR & gene controle interno - break point cluster region \\
\hline CBSSPI & cateterismo bilateral e simultâneo de seios petrosos inferiores \\
\hline cDNA & ácido desoxirribonucléico complementar \\
\hline $\mathrm{CP}$ & ponto de cruzamento do ciclo - cross point \\
\hline $\mathrm{CRH}$ & hormônio liberador de corticotrofina \\
\hline CRHR1 & receptor do hormônio liberador de corticotrofina tipo 1 \\
\hline CT & limiar do ciclo - threshold cycle \\
\hline DAG & diacilglicerol \\
\hline DC & doença de Cushing \\
\hline DNA & ácido desoxirribonucléico \\
\hline EtBr & brometo de etídio \\
\hline FGF & fator de crescimento de fibroblasto \\
\hline GAPDH & gliceraldeído-3-fostato desidrogenase \\
\hline GABA & ácido gama aminobutírico \\
\hline GC & glicorticorticóide \\
\hline $\mathrm{GH}$ & hormônio do crescimento \\
\hline GHRH & hormônio liberador de hormônio do crescimento \\
\hline GHRP & peptídeo liberador de hormônio do crescimento \\
\hline
\end{tabular}




\begin{tabular}{|c|c|}
\hline GHRP6 & peptídeo liberador de hormônio do crescimento 6 \\
\hline GHS & secretagogos de hormônio do crescimento \\
\hline GHSR & receptor dos secretagogos de hormônio do crescimento \\
\hline $\mathrm{GnRH}$ & hormônio liberador de gonadotrofina \\
\hline GR & receptor de glicocorticóide \\
\hline HC-FMUSP & $\begin{array}{l}\text { Hospital das Clínicas da Faculdade de Medicina da Universidade de } \\
\text { São Paulo }\end{array}$ \\
\hline $\mathrm{hCRH}$ & hormônio liberador de corticotrofina humano \\
\hline IGF1 & fator do crescimento símile à insulina tipo 1 \\
\hline IP3 & inositol-1,4,5-trifosfato \\
\hline IV & intravenoso \\
\hline LIF & fator inibitório de leucemia \\
\hline NEM1 & neoplasia endócrina múltipla tipo 1 \\
\hline NL & normal \\
\hline NR & não realizado \\
\hline $\mathrm{oCRH}$ & hormônio liberador de corticotrofina ovino \\
\hline $\mathrm{pb}$ & par de bases \\
\hline PCR & reação em cadeia da polimerase \\
\hline PIT1 & fator de transcrição específico de hipófise tipo 1 \\
\hline PKC & proteína $\mathrm{C}$ quinase \\
\hline PO & pós-operatório \\
\hline POMC & pró-opiomelanocortina \\
\hline PPNAD & doença adrenal nodular primária pigmentada \\
\hline PRL & prolactina \\
\hline PTTG & gene transformador de tumor hipofisário \\
\hline qPCR & reação em cadeia da polimerase quantitativa em tempo real \\
\hline ras & oncogene homólogo do sarcoma viral de rato \\
\hline
\end{tabular}




$\begin{array}{ll}\text { RM } & \text { ressonância magnética } \\ \text { RNA } & \text { ácido ribonucléico } \\ \text { RNAm } & \text { ácido ribonucléico mensageiro } \\ \text { RT-PCR } & \text { reação em cadeia da polimerase pela transcripatse reversa } \\ \text { SC } & \text { síndrome de Cushing } \\ \text { SEA } & \text { Secreção Ectópica de ACTH } \\ \text { TA } & \text { temperatura ambiente } \\ \text { TRH } & \text { hormônio liberador de tireotropina } \\ \text { UV } & \text { luz ultravioleta } \\ \text { VO } & \text { via oral }\end{array}$




\section{Lista de Símbolos}

\begin{tabular}{|c|c|}
\hline${ }^{\circ} \mathrm{C}$ & grau Celsius \\
\hline$=$ & igual a \\
\hline$>$ & maior que \\
\hline \pm & mais ou menos \\
\hline$<$ & menor que \\
\hline$\mu g$ & micrograma \\
\hline$\mu \mathrm{L}$ & microlitro \\
\hline$\%$ & porcento \\
\hline $\mathrm{dL}$ & decilitro \\
\hline h & hora \\
\hline $\mathrm{kb}$ & quilobase \\
\hline $\mathrm{kg}$ & quilograma \\
\hline L & litro \\
\hline$m^{2}$ & metro quadrado \\
\hline $\mathrm{mg}$ & miligrama \\
\hline $\min$ & minuto \\
\hline $\mathrm{mL}$ & militro \\
\hline $\mathrm{mM}$ & milimolar \\
\hline $\mathrm{ng}$ & nanograma \\
\hline$p$ & significância estatística \\
\hline pg & picograma \\
\hline rpm & rotação por minuto \\
\hline $\mathrm{s}$ & segundo \\
\hline U & unidade \\
\hline
\end{tabular}




\section{Lista de Figuras}

Figura 1. Curva de sobrevida em pacientes com síndrome de Cushing portadores de doença de Cushing (confirmada e não confirmada) e adenomas de adrenal. No primeiro ano, a taxa de mortalidade é maior que na população geral para todas as etiologias da síndrome de Cushing. A longo prazo, só há diferença na mortalidade em relação à taxa esperada nos casos de doença de Cushing não confirmada. Esses últimos casos representam os pacientes que não tiveram remissão pós-operatória, explicando o pior prognóstico. Adaptado de Lindholm et al. (2001)

Figura 2. A) Gel ilustrativo da integridade do RNA total de 4 amostras de hipófise normal (HN3, HN5, HN6 e HN7) e 3 amostras de tumor corticotrófico (ALSJ, GCV e SCC), em gel de agarose $1,2 \%$ com EtBr. B) Gel ilustrativo do produto de RT-PCR semiquantitativa do gene BCR em 5 amostras de tecidos normais (HN3, HN7, HN8, TN2 e PN), 4 tumores corticotróficos (CRS, MNL e PPS) e 2 tumores ectópicos produtores de ACTH (VBJ e JCJ), em gel de agarose 2,0\% com EtBr. Tu, tumor; SEA, Secreção Ectópica de ACTH; HN, hipófise normal; TN, timo normal; PN, pulmão normal; $\mathrm{CN}$, controle negativo; pb, pares de base

Figura 3. Co-amplifcação dos genes $B C R$ e PIT1 por RT-PCR semiquantitativa em amostras de hipófise normal e tecidos tumorais corticotróficos, visualizados em gel de agarose 2,0\% com EtBr. $\mathrm{HN}$, hipófise normal; $\mathrm{CN}$, controle negativo; pb, pares de base

Figura 4. Fluxograma da inclusão final das amostras dos pacientes com síndrome de Cushing ACTH-dependente para o estudo molecular dos genes de interesse (AVPR1B, GHSR-1a e CRHR1)

Figura 5. Curvas de dissociação dos genes GAPDH (A), GHSR-1a (B), AVPR1B (C) e CRHR1 (D)

Figura 6. Representação dos genes alvo (GHSR-1a = 192 pb, AVPR1B $=221 \mathrm{pb}$ e CRHR1=182 pb) e do gene controle $($ GAPDH $=226)$ em gel de agarose $2,0 \%$ com EtBr para verificar a amplificação de produtos inespecíficos. PM, peso molecular, pb, pares de base 
Figura 7. Determinação da eficiência de amplificação (slope) dos genes AVPR1B (A), CRHR1 (B) e GHSR-1a (C), em relação ao gene controle GAPDH

Figura 8. Comparação das respostas de cortisol (A), ACTH (B) e GH (C) no teste do GHRP-6 nos indivíduos controles e nos pacientes com síndrome de Cushing ACTH-dependente. Doença de Cushing: $n=20$; indivíduos controles: $n=21$; síndrome de Cushing ACTH-dependente: $\mathrm{n}=22$; $\mathrm{SC}$, síndrome de Cushing; ${ }^{*} p<0,05$

Figura 9. Respostas individuais ao teste do GHRP-6 dos pacientes com síndrome de Cushing ACTH-dependente e dos indivíduos controles. DC, doença de Cushing; $\Delta$, diferença entre o valor absoluto do hormônio no pico menos o valor absoluto no basal (tempo 0)

Figura 10. Respostas individuais aos testes nos pacientes com Secreção Ectópica de ACTH

Figura 11. Valores individuais de expressão do RNAm do GHSR-1a das amostras dos tecidos normais (hipófises, timos e pulmão) e dos pacientes com síndrome de Cushing ACTH-dependente (Corticotrofinomas e Secreção Ectópica de ACTH); *modelo matemático de Pfaffl (2001); NL, Normal; SEA, Secreção Ectópica de ACTH

Figura 12. Valores individuais de expressão do RNAm do GHSR-1a das amostras de tecidos normais (hipófises, timos e pulmão) e dos pacientes com Secreção Ectópica de ACTH; SEA, Secreção Ectópica de ACTH; NL, Normal; "modelo matemático de Pfaffl (2001)

Figura 13. Expressão do RNAm do GHSR-1a nas amostras dos tumores corticotróficos e hipófises normais; *modelo matemático de Pfaffl (2001)

Figura 14. Valores individuais de expressão do RNAm do AVPR1B das amostras dos tecidos normais (hipófises, timos e pulmão) e dos pacientes com síndrome de Cushing ACTH-dependente (Corticotrofinomas e Secreção Ectópica de ACTH); NL, Normal; SEA, Secreção Ectópica de ACTH 
Figura 15. Valores individuais de expressão do RNAm do AVPR1B das amostras de tecidos normais (hipófises, timos e pulmão) e dos pacientes com SEA; SEA, Secreção Ectópica de ACTH; NL, Normal

Figura 16. Expressão do RNAm do AVPR1B nas amostras dos tumores corticotróficos e hipófises normais

Figura 17. Valores individuais de expressão do RNAm do CRHR1 das amostras dos tecidos normais (hipófises, timos e pulmão) e dos pacientes com síndrome de Cushing ACTH-dependente (Corticotrofinomas e Secreção Ectópica de ACTH); NL, Normal; SEA, Secreção Ectópica de ACTH

Figura 18. Valores individuais de expressão do RNAm do CRHR1 das amostras de tecidos normais (hipófises, timos e pulmão) e dos pacientes com Secreção Ectópica de ACTH; SEA, Secreção Ectópica de ACTH; NL, Normal

Figura 19. Expressão do RNAm do CRHR1 nas amostras dos tumores corticotróficos e hipófises normais

Figura 20. Expressão do RNAm do GHSR-1a nos pacientes com doença de Cushing responsivos e não responsivos ao teste do GHRP-6 e nas hipófises normais; DC, doença de Cushing, *modelo matemático de Pfaffl (2001)

Figura 21. Resultados dos testes de estímulo com GHRP-6, desmopressina e hCRH nos pacientes com Secreção Ectópica de ACTH, e expressão do RNAm dos receptores GHSR-1a (A), AVPR1B (B), e CRHR1 (C) nos respectivos pacientes e nas amostras de tecidos normais (hipófises, timos e pulmão); SEA, Secreção Ectópica de ACTH; NL, Normal, *modelo matemático de Pfaffl (2001)

Figura 22. Expressão do RNAm do AVPR1B nos pacientes com doença de Cushing responsivos e não responsivos ao teste da desmopressina; DC, doença de Cushing 
Figura 23. Expressão do RNAm do CRHR1 nos pacientes com doença de Cushing responsivos e não responsivos ao teste do hCRH; DC, doença de Cushing

Figura 24. Correlação entre a expressão do RNAm dos receptores GHSR-1a e AVPR1B nas amostras de tumores corticotróficos; *modelo matemático de Pfaffl (2001)

Figura 25. Correlação entre a expressão do RNAm dos receptores CRHR1 e GHSR-1a nas amostras de tumores corticotróficos; *modelo matemático de Pfaffl (2001)

Figura 26. Correlação entre a expressão do RNAm dos receptores CRHR1 e AVPR1B nas amostras de tumores corticotróficos

Figura Capa. A) Foto de paciente com síndrome de Cushing (SC) com múltiplas estrias violáceas largas em abdome e coxas; B) Imagem de RM, T1, corte coronal pós gadolíneo, em paciente com SC devido a tumor carcinóide pulmonar, mostrando imagem hipocaptante (seta) na porção mediana da hipófise (incidentaloma); C) Imagem em subtração de cateterismo bilateral de seios petrosos inferiores, mostrando cateteres posicionados nos seios petrosos inferiores e infusão de contraste à esquerda com refluxo para o lado contralateral; D) Visão cirúrgica de acesso transesfenoidal em paciente com macroadenoma hipofisário produtor de ACTH, mostrando abertura da duramáter (dm), lesão amarelada tumoral (TU) e tecido acinzentado à esquerda (tecido hipofisário não tumoral, HNT) 


\section{Lista de Tabelas}

Tabela 1. Etiologias da síndrome de Cushing endógena em adultos. Adaptado de Beauregard et al. (2002)

Tabela 2. Manifestações clínicas da síndrome de Cushing. Adaptado de Aron et al. (2004)

Tabela 3. Sensibilidade e especificidade dos exames utilizados para confirmação da síndrome de Cushing. Adaptado de Liu et al. (2005)

Tabela 4. Exames utilizados no diagnóstico diferencial da síndrome de Cushing ACTH-dependente

Tabela 5. Efeitos dos GHS/ghrelina. Adaptado de Korbonits et al. (2004)

Tabela 6. Casuísticas de GHS/ghrelina na síndrome de Cushing

Tabela 7. Casuísticas de expressão do RNAm do GHSR-1a em adenomas hipofisários e comparação com o tecido hipofisário normal

Tabela 8. Casuísticas de expressão do RNAm do GHSR-1a na síndrome de Cushing ACTH-dependente e em outros tumores neuroendócrinos ACTH negativos e comparação com o tecido hipofisário normal

Tabela 9. Dados clínicos e laboratoriais dos pacientes com síndrome de Cushing ACTH-dependente

Tabela 10. Comparação das casuísticas dos indivíduos controles e dos pacientes com doença de Cushing

Tabela 11. Comparação dos valores de cortisol, ACTH, GH e IGF1 basais e pós estímulo com GHRP-6 nos indivíduos controles e nos pacientes com doença de Cushing 
Tabela 12. Teste do GHRP-6 nos pacientes com tumores ectópicos produtores de $\mathrm{ACTH}$

Tabela 13. Resumo dos testes de estímulo nos pacientes com síndrome de Cushing ACTH-dependente

Tabela 14. Resumo dos testes de estímulo nos pacientes com síndrome de Cushing ACTH-dependente que foram submetidos ao estudo molecular dos genes de interesse

Tabela 15. Resultados dos testes de estímulo e resumo da expressão dos receptores nas amostras estudadas

ANEXO E. Tabela com valores hormonais basais e pós estímulo com GHRP-6 nos indivíduos controles

ANEXO F. Tabela com valores hormonais basais e pós estímulo com desmopressina nos pacientes com síndrome de Cushing ACTH-dependente

ANEXO G. Tabela com valores hormonais basais e pós estímulo com GHRP-6 nos pacientes com síndrome de Cushing ACTHdependente

ANEXO H. Tabela com valores hormonais basais e pós estímulo com hCRH nos pacientes com síndrome de Cushing ACTHdependente 


\section{RESUMO}

Machado MC. Estudo da expressão do receptor da vasopressina (AVPR1B), do receptor do hormônio liberador de corticotrofina (CRHR1) e do receptor dos secretagogos de GH (GHSR-1a) em pacientes portadores de síndrome de Cushing ACTH-dependente: correlação clínico-molecular [tese]. São Paulo: Faculdade de Medicina, Universidade de São Paulo; 2006. 134p.

INTRODUÇÃO: O diagnóstico diferencial da síndrome de Cushing (SC) ACTHdependente é um dos maiores desafios da endocrinologia, devido ao comportamento clínico e laboratorial semelhante de alguns tumores carcinóides com a doença de Cushing (DC). Assim, testes dinâmicos de secreção de ACTH e cortisol têm sido utilizados com o objetivo de identificar respostas que sejam preditivas e específicas no diagnóstico diferencial. O padrão dessas respostas é atribuído à superexpressão de receptores; entretanto, poucos estudos foram realizados para comprovar tal associação. O objetivo deste estudo foi verificar se a secreção de ACTH e cortisol em resposta aos testes do $\mathrm{CRH}$ humano (hCRH), da desmopressina, e do peptídeo liberador do $\mathrm{GH}$ (GHRP-6) é dependente da magnitude de expressão dos seus respectivos receptores (CRHR1, AVPR1B e GHSR-1a) em amostras de tumores de pacientes portadores da SC ACTH-dependente. CASUÍSTICA E MÉTODOS: Entre 2002 e 2004, foram avaliados 22 pacientes (20 com DC e dois com Secreção Ectópica de ACTH [SEA], carcinóide de pulmão e timo), idade mediana de 32 anos (15-54 anos), sendo 18 do sexo feminino e quatro do sexo masculino, provenientes da Disciplina de Endocrinologia e Metabologia da Faculdade de Medicina da Universidade de São Paulo. Os pacientes foram submetidos aos testes do hCRH (100 $\mu \mathrm{g})$, desmopressina $(10 \mu \mathrm{g})$ e GHRP-6 $(1 \mu \mathrm{g} / \mathrm{kg})$ com dosagens de ACTH e cortisol e também de GH no 
caso do GHRP-6. Vinte e um indivíduos controles, pareados por sexo e idade, foram submetidos ao teste do GHRP-6. Durante o ato operatório, fragmentos de tumor foram coletados para posterior extração do RNA total. O estudo da expressão foi feito por meio de PCR quantitativo em tempo real dos genes CRHR1, AVPR1B e GHSR-1a em relação ao GAPDH. Fragmentos de tecidos normais (hipófise, pulmão e timo) procedentes de necropsias foram utilizados como controles. RESULTADOS: Observamos maior expressão de GHSR-1a nos pacientes responsivos ao GHRP-6, tanto naqueles com DC quanto no paciente com carcinóide pulmonar. Não houve maior expressão dos receptores CRHR1 e AVPR1B nos pacientes com DC responsivos aos respectivos testes, observando-se, no entanto, uma forte associação entre respostas in vivo e a expressão desses receptores nos pacientes com SEA. As concentrações de ACTH e cortisol induzidas pela administração de GHRP-6 foram mais elevadas nos pacientes com DC quando comparados aos controles, havendo, no entanto, superposição entre as respostas. Observamos também elevação dos níveis séricos de GH nos indivíduos controles e, em menor intensidade, nos pacientes com DC. CONCLUSÕES: Houve maior expressão do receptor GHSR-1a em pacientes com SC ACTH-dependente responsivos ao GHRP-6, estabelecendo-se uma relação direta entre a expressão do receptor e a resposta in vivo ao secretagogo, tanto em pacientes com DC quanto nos portadores de SEA. Uma associação entre a expressão dos receptores CRHR1 e AVPR1B com a resposta in vivo aos respectivos secretagogos foi observada nos pacientes com SEA e não nos pacientes com DC. Tendo em vista a resposta ao GHRP-6 em paciente com SEA, limita-se o uso desse peptídeo no diagnóstico diferencial da SC ACTH-dependente.

DESCRITORES: Síndrome de Cushing/diagnóstico, Neoplasias hipofisárias, Síndrome de ACTH ectópico, Tumor carcinóide, Expressão gênica, Receptores de vasopressina, Receptores de hormônio liberador de corticotropina 


\section{SUMMARY}

Machado MC. Study of mRNA expression of the receptors for vasopressin (AVPR1B), corticotropin releasing hormone (CRHR1) and $\mathrm{GH}$ secretagogues (GHSR-1a) in patients with ACTH-dependent Cushing's syndrome: clinicalmolecular correlation [thesis]. Sao Paulo: University of Sao Paulo School of Medicine; 2006. 134p.

INTRODUCTION: The differential diagnosis of ACTH-dependent Cushing's syndrome (CS) is one of the major challenges in endocrinology, especially in view of the similar clinical and laboratorial behavior between some carcinoid tumors and Cushing's disease (CD). Hence, dynamic tests of ACTH and cortisol release have been carried out with the aim to identify predictive and specific responses for this differential diagnosis. The pattern of the responses has been attributed to receptors overexpression, yet few studies have been undertaken to confirm such association. The aim of the present study was to verify whether ACTH and cortisol release in response to human $\mathrm{CRH}(\mathrm{hCRH})$, desmopressin, and $\mathrm{GH}$ releasing peptide (GHRP-6) depends on the magnitude of expression of their respective receptors (CRHR1, AVPR1B e GHSR-1a) in samples of tumors from patients with ACTH-dependent CS. PATIENTS AND METHODS: Twenty two patients (20 with CD and 2 with Ectopic ACTH Syndrome [EAS], lung and thymus carcinoid tumors) from the Division of Endocrinology and Metabolism of University of Sao Paulo School of Medicine, median age of 32 years (15-54 years), being 18 females and 4 males, were evaluated between 2002 and 2004. The patients were submitted to dynamic tests with hCRH $(100 \mu \mathrm{g})$, desmopressin $(10 \mu \mathrm{g})$ and GHRP-6 $(1 \mu \mathrm{g} / \mathrm{kg})$, with measurement of $\mathrm{ACTH}$ and cortisol levels, and also of $\mathrm{GH}$ in the case of 
GHRP-6 stimulation. Twenty one age and sex-matched controls were submitted to the GHRP-6 test. During surgery, tumor fragments were collected and subsequently processed for total mRNA extraction. Gene expression of CRHR1, AVPR1B and GHSR-1a relative to GAPDH was quantitated by real-time qPCR. Tissue samples of normal pituitary, lung and thymus from necropsy were used as controls. RESULTS: Greater expression of GHSR-1a was observed in patients responsive to the GHRP-6 test, both in those with CD and in the one with pulmonary carcinoid tumor. No enhanced expression of receptors CRHR1 and AVPR1B was found in CD patients responsive to the respective dynamic tests, yet there was a strong association between the in vivo responses and the expression of those receptors in the two patients with EAS. GHRP-6 -induced ACTH and cortisol release was more marked in patients with $C D$ as compared with control individuals, but there was overlap of the responses. GH stimulation was observed in control individuals and, to a lesser extent, in patients with CD. CONCLUSIONS: There was greater expression of GHSR-1a in patients with ACTH-dependent CS who responded to GHRP-6, establishing a direct association between receptor gene expression and the in vivo response to the secretagogue in both CD patients and those with EAS. An association between expression of CRHR1 and AVPR1B and the in vivo response to the respective secretagogues was found in patients with EAS but not in those with CD. In view of the response to GHRP-6 in a patient with EAS, we considered the use of this peptide in the differential diagnosis of ACTH-dependent CS of limited value.

DESCRIPTORS: Cushing's Syndrome/diagnosis, Pituitary neoplasms, Ectopic ACTH Syndrome, Carcinoid tumor, Gene expression, Vasopressin receptors, Corticotropin-releasing hormone receptors 


\section{INTRODUÇÃO}

\section{Síndrome de Cushing}

\subsection{Definições}

A síndrome de Cushing (SC) é um estado clínico resultante de prolongada e inapropriada exposição à quantidade excessiva de cortisol, determinando concentrações séricas elevadas de cortisol, perda da contra-regulação normal do eixo hipotálamo-hipófise-adrenal e alteração no ritmo circadiano de secreção do cortisol (Trainer et al., 1991; Newell-Price et al., 1998). Essa definição se refere à SC endógena, condição na qual, existe uma fonte endógena responsável pela produção excessiva do hormônio cortisol. Há também a SC causada pela exposição excessiva e prolongada aos glicocorticóides, potentes agentes antiinflamatórios, amplamente utilizados em várias doenças. Nessa situação, a SC é denominada exógena e pode ocorrer com o uso de praticamente todas as apresentações desses fármacos tais como a tópica, inalatória, e principalmente, a oral. A SC exógena é uma condição mais freqüente que a endógena e, na maioria das vezes, facilmente suspeitada e confirmada pelo diagnóstico da doença de base e pela história do uso dessas medicações. Outras condições podem cursar com evidências laboratoriais de excesso de cortisol, porém, não configurando a SC, como em pacientes internados por longos períodos em UTI (Newell-Price et al., 1998). 
A SC endógena pode ser dividida, em relação ao mecanismo fisiopatológico, em dois grupos: ACTH-dependente e ACTH-independente. Cada grupo é composto por algumas doenças, tendo em comum as concentrações plasmáticas de ACTH (baixas ou indetectáveis na SC ACTH-independente e elevadas ou inapropriadamente normais na SC ACTH-dependente).

Em adultos, a etiologia mais freqüente da SC endógena é representada pelos tumores hipofisários (adenomas) produtores de ACTH, denominada doença de Cushing (DC). Por outro lado, existem outras etiologias (principalmente tumorais) originadas em diversos órgãos que produzem ACTH e SC. Nessa situação, o quadro é comumente denominado Secreção Ectópica de ACTH (SEA) ou síndrome de Cushing Ectópica. Alguns autores (Odell et al., 1977 apud Terzolo et al., 2001) questionam essas denominações de produção ectópica, pois vários tecidos, mesmo não endócrinos, mostraram imunoreatividade para $\mathrm{ACTH}$, embora, normalmente não haja secreção de $\mathrm{ACTH}$ detectável proveniente desses tecidos nem importância fisiológica conhecida.

\subsection{Histórico}

Em 1898, William Osler descreveu um caso cujas manifestações clínicas lembravam a síndrome de Cushing (Altschule, 1980). Porém, somente mais de três décadas depois, o neurocirurgião Harvey Cushing publicou uma série de 12 casos (Cushing, 1932 apud Newell-Price et al., 1998), onde correlacionou o conjunto dos sinais e sintomas com o achado anátomo-patológico de basofilismo hipofisário, sendo então, denominada síndrome de Cushing.

Em 1928, foi descrito um caso de tumor pulmonar de pequenas células com sinais e sintomas sugestivos de hipercortisolismo (Brown, 1928 apud Beuschlein e Hammer, 2002). Anos depois, essa associação de SC ACTH-dependente com 
tumores originários de tecidos não-endócrinos foi melhor caracterizada (Meador et al., 1962 apud Beuschlein e Hammer, 2002; Liddle et al., 1962 apud Beuschlein e Hammer, 2002).

Mesmo hoje, mais de setenta anos após a correlação clínico-patológica original (Cushing, 1932 apud Newell-Price et al., 1998), o diagnóstico diferencial da SC permanece por vezes muito difícil, sendo um dos maiores desafios na clínica endocrinológica.

\subsection{Classificação}

Como já mencionado, a SC endógena pode ser classificada de acordo com as concentrações plasmáticas de ACTH em ACTH-dependente e independente. $\mathrm{Na}$ DC e na SEA que representam praticamente a totalidade do primeiro grupo, as concentrações de ACTH são elevadas ou inapropriadamente normais para os níveis de cortisol (Tabela 1). A SC ACTH-independente, menos freqüente, é representada por doenças nas glândulas adrenais, principalmente, por adenomas, hiperplasias e carcinomas. Nesse grupo, a secreção de ACTH hipofisário está habitualmente suprimida, sendo as concentrações plasmáticas de ACTH indetectáveis ou baixas, especialmente $<10 \mathrm{pg} / \mathrm{mL}$ (Arnaldi et al., 2003a; Lindsay e Nieman, 2005).

A maioria dos casos de SC endógena em geral é causada por tumores esporádicos, sejam hipofisários (DC ou carcinoma corticotrófico), tumores ectópicos (ACTH, CRH/ACTH ou cortisol) ou adrenais (adenomas ou carcinomas).

Muito menos freqüente, a SC é causada por hiperplasias, principalmente, das adrenais (Newell-Price et al., 1998), sendo descritas também hiperplasias na hipófise (Beauregard et al., 2002) e em outros órgãos, como o timo (Ohta et al., 2000). As hiperplasias adrenais são, em geral, bilaterais, podendo ser 
macronodulares (AIMAH - ACTH-independent bilateral macronodular adrenal hyperplasia), decorrentes da expressão de receptores adrenais anômalos; e micronodulares, representadas principalmente pela PPNAD (primary pigmented nodular adrenal disease) (Newell-Price et al., 1998). Essa última, comumente familiar e integrante de uma síndrome denominada Complexo de Carney (PPNAD, mixomas cardíacos ou cutâneos, adenomas hipofisários, neoplasia testicular, adenoma ou carcinoma de tireóide, cistos ovarianos e schwanomas), onde mutações no gene da PRKAR1A (protein kinase $A$ type 1a regulatory subunit) que funciona como um gene supressor de tumor, promovem proliferação celular em vários tecidos (Carney et al., 1985; Stratakis et al., 2001).

Outra condição familiar onde a SC pode estar presente é a Neoplasia Endócrina Múltipla - tipo 1 (NEM1), causada por perda de heterozigosidade na região 11q13 (gene menin). Essa associação é pouco frequente (Matsuzaki et al., 2004; Rix et al., 2004), já que os adenomas hipofisários que são componentes da NEM1, são na maioria produtores de PRL e GH (Vergès et al., 2002). Além disso, adenomas de adrenal e tumores ectópicos produtores de ACTH podem ser etiologias da SC na NEM1 (Gardner, 2004). Outra situação que a SC ACTH-independente pode estar associada é a síndrome de McCune-Albright, doença esporádica cujas manifestações clínicas são em parte similares às do Complexo de Carney (Stratakis et al., 2001), decorrente de mutação ativadora na subunidade $\alpha$ da proteína $\mathrm{G}$ levando ativação constitutiva de células adrenais (Weinstein et al., 1991).

Finalmente, a SC pode ser causada por hipersensibilidade ao cortisol devido à expressão periférica aumentada do receptor de cortisol ou afinidade aumentada desse hormônio com o seu receptor. Existem somente duas descrições dessa entidade (Lida et al., 1990; Newfield et al., 2000) e outros estudos são necessários para o melhor entendimento dessa condição. 
Tabela 1. Etiologias da síndrome de Cushing endógena em adultos. Adaptado de Beauregard et al. (2002)

\section{ETIOLOGIA}

\begin{tabular}{lc}
\hline ACTH-DEPENDENTE & $\mathbf{8 0}$ \\
\hline Adenoma corticotrófico (Doença de Cushing) & $60-70$ \\
Secreção ectópica de ACTH & 15 \\
Secreção ectópica de CRH / ACTH & Rara \\
Hiperplasia corticotrófica & Rara \\
Carcinoma corticotrófico & Rara \\
\hline ACTH-INDEPENDENTE & $\mathbf{2 0}$ \\
\hline Adenoma de adrenal & 10 \\
Carcinoma de adrenal & 5 \\
Hiperplasia adrenal micronodular (PPNAD) & Rara \\
Hiperplasia adrenal macronodular (AIMAH) & Rara \\
Síndrome de hipersensibilidade ao cortisol & Muito rara \\
Secreção ectópica de cortisol & Muito rara \\
\hline
\end{tabular}

FREQÜÊNCIA (\%)

PPNAD, primary pigmented nodular adrenal disease; AIMAH, ACTH-independent bilateral macronodular adrenal hyperplasia 


\subsection{Epidemiologia}

Em geral, a SC endógena é uma condição rara, com incidência de 10 casos por 1.000.000/habitantes/ano, acometendo indivíduos em várias faixas etárias, mas com maior prevalência entre 20-30 anos, e mais freqüente no sexo feminino (Beauregard et al., 2002).

Entretanto, estudos recentes em populações de alto risco (obesos portadores de Diabete Melito não controlado) têm mostrado uma prevalência de 2 a 3,3\% de SC (Leibowitz et al., 1996; Catargi et al., 2003) e 7\% numa população de pacientes diabéticos internados (Chiodini et al., 2005), sugerindo que a SC seja mais comum do que previamente conhecida.

A DC é a causa mais comum da SC endógena em adultos, representando $60-70 \%$ de todos os casos, com incidência de 5-6 casos por 1.000.000/habitantes/ano e com predominância no sexo feminino de 8:1 (Beauregard et al., 2002).

A SEA é caracterizada por um grupo heterogêneo de doenças geralmente neoplásicas, acometem vários órgãos e, em geral, são um pouco mais freqüentes nas mulheres na proporção de 1,2:1. Vale ressaltar que algumas doenças em particular, carcinomas pulmonares de pequenas células e os carcinóides tímicos produtores de $\mathrm{ACTH}$, são discretamente mais prevalentes no sexo masculino (52 vs. 48\%) (Beuschlein e Hammer, 2002).

A incidência de tumores adrenais unilaterais que causam a SC é de 2 casos por 1.000.000/habitantes/ano, também com maior freqüência nas mulheres: 4:1. Os carcinomas de adrenal nos adultos, também possuem discreta predileção pelo sexo feminino: 2:1 (Beauregard et al., 2002). Em crianças a prevalência de doenças adrenais é maior que em adultos (65\%) e os carcinomas adrenais mais freqüentes nessa população (Beauregard et al., 2002). 


\subsection{Manifestações Clínicas}

As manifestações clínicas da SC acometem vários órgãos e tecidos, não existindo total especificidade dos sinais e sintomas (Tabela 2). Na verdade, existe uma superposição destas manifestações com outras situações clínicas tais como a síndrome Metabólica e a síndrome dos Ovários Policísticos (SOP), especialmente em casos leves de SC (Findling e Raff, 2001).

Contudo, algumas dessas morbidades são mais específicas da SC: osteoporose, miopatia, atrofia cutânea, desordens neuropsiquiátricas e nefrolitíase (Findling e Raff, 2001). A presença desses achados em um paciente com obesidade, hipertensão arterial, Diabete Melito, alterações menstruais, estrias violácias, entre outras, aumenta a grau de suspeição da SC.

Comumente, o quadro clínico da SC tem início insidioso e se prolonga por vários anos até o seu reconhecimento. Por essa característica insidiosa e inespecífica dos sinais e sintomas, uma revisão recente sugeriu em que situações deveria ser pesquisada a SC (Findling e Raff, 2005): obesidade centrípeta com a presença de face pletórica e em lua cheia, acúmulo de gordura na fossa supraclavicular e giba dorsal, atrofia cutânea com fragilidade capilar, estrias violáceas largas (>1 cm), miopatia proximal, hirsutismo, micoses cutâneas, retardo de crescimento (em crianças); síndrome metabólica com Diabete Melito não controlado (hemoglobina glicosilada A1C > 8\%), hipertensão, dislipidemia, SOP; hipogonadismo hipogonadotrófico, com irregularidade menstrual (oligomenorréia, amenorréia) ou infertilidade, diminuição da libido e disfunção erétil; osteoporose, especialmente com fratura, em pacientes com menos de 65 anos de idade.

As primeiras descrições da SEA relataram quadro clínico diferente das manifestações clássicas da SC, predominando um quadro agressivo de rápida evolução, com hiperpigmentação cutânea, profunda fraqueza muscular, hipocalemia 
e pouco ganho ou até mesmo perda de peso. Esse quadro clínico "aberto" ("overt") da SC foi atribuído ao carcinoma pulmonar de pequenas células (Meador et al., 1962 apud Beuschlein e Hammer, 2002). Entretanto, vários tumores, principalmente os carcinóides bem diferenciados, podem produzir quadro clínico totalmente superponível à DC, dificultando o diagnóstico diferencial.

Em crianças, os estigmas clássicos da SC podem não estar presentes e o ganho de peso associado ao retardo de crescimento são os achados mais proeminentes para a suspeita da síndrome (Magiakou et al., 1994; Leinung e Zimmerman, 1994).

Apesar da pletora de sinais, sintomas e morbidades que compõem a SC, raros pacientes portadores de adenomas corticotróficos não exibem fenótipo cushingóide mesmo na fase ativa da doença. Há descrição de defeito na conversão da cortisona em cortisol, mediada pela enzima 11-beta-hidroxiesteroide dehidrogenase tipo 1 (11ß-HSD1) (Tomlinson et al., 2002), e secreção de molécula de ACTH biologicamente inativa de alto peso molecular (Matsuno et al., 2004), situações raras que explicam essa ausência de fenótipo cushingóide em pacientes com tumores corticotróficos.

\subsection{Diagnóstico}

Após a suspeita clínica, se possível com a presença de algum sinal ou sintoma de maior especificidade para a SC e da exclusão de fonte exógena, o diagnóstico apresenta duas etapas seqüenciais importantes que não devem ser negligenciadas. A primeira etapa consiste de exames para a confirmação do hipercortisolismo, não importando nesse momento a etiologia da SC. 
Tabela 2. Manifestações clínicas da síndrome de Cushing. Adaptado de Aron et al. (2004)

\begin{tabular}{|c|c|}
\hline MANIFESTAÇÃO CLÍNICA & FREQÜÊNCIA (\%) \\
\hline Obesidade* & 90 \\
\hline Face em lua cheia ${ }^{*}$ & 90 \\
\hline Hipertensão arterial & 85 \\
\hline Manifestações neuropsiquiátricas & 85 \\
\hline Impotência/diminuição libido & 85 \\
\hline Osteopenia & 80 \\
\hline Intolerância a glicose & 75 \\
\hline Hirsutismo & 75 \\
\hline Pletora facial & 70 \\
\hline Dislipidemia & 70 \\
\hline Desordens menstruais & 70 \\
\hline Fraqueza muscular & 65 \\
\hline Edema $^{*}$ & 55 \\
\hline Estrias & 50 \\
\hline Infecções fúngicas & 50 \\
\hline Osteoporose/fratura & 50 \\
\hline Exoftalmo ${ }^{\S}$ & 45 \\
\hline Acne & 35 \\
\hline Fragilidade capilar & 35 \\
\hline Poliúria & 30 \\
\hline Diabete Melito & 20 \\
\hline Nefrolitíase & 15 \\
\hline Hiperpigmentação & 10 \\
\hline Cefaléia & 10 \\
\hline
\end{tabular}

*Especialmente a obesidade centrípeta com preenchimento de fossas supraclaviculares e giba dorsal ("buffalo hump"); ${ }^{*}$ Newell-Price et al. (1998); §Kelly (1996) 
A primeira linha de exames utilizados para a confirmação, segundo Arnaldi et al. (2003a), consiste de: cortisol urinário livre de 24 h; supressão de cortisol com dose baixa de dexametasona; e cortisol salivar noturno (2400 h). Outros exames tradicionalmente usados são: cortisol sérico noturno $(2400 \mathrm{~h})$ e teste do $\mathrm{CRH}$ ovino (oCRH) após dexametasona.

O cortisol urinário livre de 24 h reflete um índice integrado da secreção de cortisol que circula no sangue nesse período, representando um exame com alta sensibilidade e especificidade para o diagnóstico da SC (Tabela 3). Recomenda-se a coleta de três a quatro amostras, pois pode ocorrer secreção variável de cortisol.

Um estudo mostrou pelo menos uma amostra de cortisol urinário normal dentre quatro, em $11 \%$ dos pacientes (Nieman e Cutler, $1990^{1}$ ). Valores pouco acima da referência do método podem estar presentes em quadros leves da SC como também em situações conhecidas como pseudo-Cushing. Classicamente, a depressão e o alcoolismo são as causas mais atribuídas ao pseudo-Cushing. Nessas situações, existe uma hiper-ativação do eixo hipotálamo-hipófise-adrenal com secreção aumentada de $\mathrm{CRH}$. Outras situações, como a gestação, estresse, anorexia nervosa, resistência aos glicocorticóides e artefatos laboratoriais (carbamazepina ou fenofibrato), também podem ser considerados estados de pseudo-Cushing, já que produzem alterações superponíveis às da SC. Assim, alguns autores valorizam mais o cortisol urinário quando os valores estão 3 a 4 vezes acima do normal (Newell-Price et al., 1998). Falso-negativos podem ocorrer com a função renal alterada (taxa de filtração glomerular $<30 \mathrm{~mL} / \mathrm{min}$ ). Por isso, é recomendável a concomitante mensuração da creatinúria de 24 h. Em crianças, os valores

\footnotetext{
${ }^{1}$ Nieman LK, Cutler Jr GB. (National Institutes of Health, Bethesda, Maryland, USA). The sensitivity of the urine free cortisol measurement as a screening test for Cushing's syndrome. (Presented at 72nd Annual Meeting of The Endocrine Society; 1990 June 16-19; Atlanta, USA. Abstracts).
} 
devem ser corrigidos para a superfície corpórea/1,72 $\mathrm{m}^{2}$ (Newell-Price et al., 1998). Uma forma simplificada é a determinação do cortisol urinário noturno (2000h às 800 h). Entretanto, essa variante do método não é utilizada rotineiramente e outros estudos são necessários para sua validação (Corcuff et al., 1998).

O teste de supressão do cortisol com dose baixa de dexametasona mais utilizado, consiste na determinação do cortisol sérico às 800 h após ingesta de 1 mg de dexametasona entre 2300 h e 2400 h (overnight). O critério original para a supressão normal do cortisol era $<5 \mu \mathrm{g} / \mathrm{dL}$. Atualmente, o valor de corte é $<1,8 \mu \mathrm{g} / \mathrm{dL}$, aumentando a sensibilidade desse método, principalmente, pela identificação de casos leves da SC. Falso-positivos podem ocorrer quando existe: metabolização aumentada da dexametasona (uso de barbitúricos, fenitoína, carbamazepina, rifampicina, meprobamate, aminoglutetimide ou metaqualone), absorção diminuída da dexametasona, aumento da globulina ligadora de cortisol (CBG) (tratamento com estrógeno ou gestação), e nos estados de pseudo-Cushing (Arnaldi et al., 2003a). Ainda, recomenda-se o uso de ensaios do cortisol com sensibilidade de $1 \mu \mathrm{g} / \mathrm{dL}$ ou menos (Trainer et al., 1991; Newell-Price et al., 1998).

O cortisol salivar noturno $(2400 \mathrm{~h})$ tem sido considerado um exame tão sensível quanto o cortisol urinário (Arnaldi et al., 2003a), refletindo porcentagem do cortisol sérico total (65\%) e do cortisol sérico livre (5\%) (Barrou et al., 1996). Dentre as vantagens estão a facilidade de coleta e estabilidade da amostra em temperatura ambiente. Vários trabalhos têm analisado esse método e recentemente uma importante revisão diagnóstica, sugeriu que o cortisol salivar noturno seja o primeiro exame solicitado na suspeita da SC (Findling e Raff, 2005). Também tem sido estudado o cortisol salivar (800 h) após dose baixa de dexametasona (Castro et al., 2003; Liu et al., 2005), sendo necessários mais estudos para validação desse método. 
Tabela 3. Sensibilidade e especificidade dos exames utilizados para confirmação da síndrome de Cushing. Adaptado de Liu et al. (2005)

\begin{tabular}{|c|c|c|}
\hline EXAME & SENSIBILIDADE (\%) & ESPECIFICIDADE (\%) \\
\hline Cortisol urinário livre de $24 \mathrm{~h}$ & 76 a 100 & 95 a 98 \\
\hline $\begin{array}{l}\text { Supressão de cortisol sérico com } \\
\text { dose baixa de dexametasona* }\end{array}$ & 93 a 100 & NR \\
\hline Cortisol salivar noturno (2400 h) & 92,7 a 100 & 84,8 a 100 \\
\hline Cortisol sérico noturno (2400 h) & 90,2 a 100 & 82,9 a 100 \\
\hline $\begin{array}{l}\text { Cortisol salivar }(800 \mathrm{~h}) \text { após } \\
\text { dose baixa de dexametasona }\end{array}$ & 91,4 a 100 & 94 a 100 \\
\hline oCRH pós dexametasona & $100^{*}$ & $100^{*}$ \\
\hline
\end{tabular}


Outro exame, utilizado com o mesmo racional de verificar as concentrações de cortisol no momento de nadir do ritmo circadiano normal, é a mensuração do cortisol sérico noturno (2400 h). As desvantagens principais, em relação ao cortisol salivar, são as necessidades de coleta geralmente após 48 h de internação hospitalar e da coleta em repouso.

Finalmente, o teste do oCRH após dexametasona é considerado o melhor método para o diagnóstico diferencial entre a SC e o estado de pseudo-Cushing (Newell-Price et al., 1998). A dexametasona é administrada VO de 6/6 h por 2 dias na dose de $0,5 \mathrm{mg}$. Após $2 \mathrm{~h}$ da última dose $\left(600 \mathrm{~h}\right.$ do $2^{\circ}$ dia $)$ o oCRH é infundido na quantidade de $1 \mu \mathrm{g} / \mathrm{kg} \mathrm{IV}$. O cortisol sérico $>1,4 \mu \mathrm{g} / \mathrm{dL} 15 \mathrm{~min}$ após a infusão do oCRH confirma o diagnóstico da SC (Yanovski et al., 1993). Não há padronização desse teste com o $\mathrm{CRH}$ humano $(\mathrm{hCRH})$.

Apesar de todos os métodos citados, o diagnóstico é por vezes bastante difícil. Outro fator que dificulta esse diagnóstico é a incomum secreção cíclica de cortisol que pode ocorrer com quaisquer etiologias da SC. Essa condição também é denominada Cushing intermitente ou hormonogênese periódica (Bailey, 1971 apud Newell-Price et al., 1998). Nessa situação, coletas seriadas de exames como o cortisol urinário de $24 \mathrm{~h}$ e o cortisol salivar notuno (2400 h) podem ajudar na investigação.

\subsection{Diagnóstico Diferencial da Síndrome de Cushing ACTH-dependente}

O diagnóstico diferencial da SC ACTH-dependente é, frequentemente difícil, demorado e oneroso. Isso ocorre, entre outros motivos, pela limitação da ressonância magnética $(\mathrm{RM})$ da região hipofisária que evidencia apenas $50 \%$ dos tumores corticotróficos, baixa especificidade dos testes dinâmicos de ACTH e cortisol, e principalmente, pelo comportamento clínico e laboratorial semelhante de alguns tumores carcinóides bem diferenciados com a DC. 
Desse modo, são utilizados diversos exames, desde métodos simples como a determinação do potássio sérico até exames de imagem sofisticados como o tomografia por emissão de positrons com 18F-fluoro-2-deoxy-D-glucose (PET-FDG) (Tabela 4), sendo o cateterismo bilateral e simultâneo de seios petrosos inferiores (CBSSPI) considerado o teste padrão-ouro com acurácia em torno de 94\% (Lindsay e Nieman, 2005).

Apesar do arsenal de exames disponíveis, $12,5 \%$ dos casos permaneceram com o diagnóstico etiológico desconhecido em um centro de referência após anos de inúmeros procedimentos diagnósticos e terapêuticos (Isidori et al., 2006), sendo chamados de secreção ectópica oculta de ACTH.

O hormônio liberador do ACTH (CRH), identificado por Vale et al. (1981), tem sido extensamente estudado nesse contexto. A maioria dos casos de DC responde significativamente ao $\mathrm{CRH}$ enquanto que na SEA só raramente (NewellPrice et al., 1998). O teste é realizado com oCRH ou $h C R H$, sendo o primeiro peptídeo mais estudado, com estímulo mais potente e prolongado. É difícil a comparação dos peptídeos, entretanto os dados disponíveis atualmente sugerem uma melhor acurácia com o oCRH (Lindsay e Nieman, 2005).

Mais comumente, é definido como resposta positiva específica para a doença de Cushing um incremento em relação ao basal de $>20 \%$ de cortisol e $>35 \%$ de ACTH com oCRH (Nieman et al., 1993), e > 14\% de cortisol e $>105 \%$ de ACTH para hCRH (Newell-Price et al., 2002).

Há tempos é conhecido o efeito estimulador da vasopressina sobre a secreção de $\mathrm{ACTH}$, particularmente potencializando os efeitos do CRH (DeBold et al., 1984). A arginina vasopressina (AVP) e a lisina vasopressina (LVP) foram utilizadas no diagnóstico diferencial da SC ACTH-dependente, apresentando respostas positivas em $70 \%$ dos pacientes com DC. Entretanto, esses peptídeos produziam efeitos colaterais como dores abdominais e náuseas, limitando seu uso (Newell-Price et al., 2002). 
Tabela 4. Exames utilizados no diagnóstico diferencial da síndrome de Cushing ACTH-dependente

\begin{tabular}{|c|c|c|}
\hline EXAME & DOENÇA DE CUSHING* & $\begin{array}{c}\text { SECREÇÃO } \\
\text { ECTÓPICA DE ACTH* }\end{array}$ \\
\hline Potássio & NL & Hipocalemia \\
\hline АСТН & NL ou pouco elevado & NL ou elevado \\
\hline $\begin{array}{l}\text { Supressão de cortisol com dose } \\
\text { alta }(8 \mathrm{mg}) \text { de dexametasona }\end{array}$ & Suprime & Não suprime \\
\hline Teste do oCRH & Responsivo & Não responsivo \\
\hline Teste do hCRH & Responsivo & Não responsivo \\
\hline Teste da desmopressina & Responsivo & Não responsivo \\
\hline $\begin{array}{l}\text { Teste dos GHS (hexarelina, } \\
\text { GHRP-6) }\end{array}$ & Responsivo & Não responsivo \\
\hline Marcadores tumorais ${ }^{*}$ & Ausentes & Podem estar presentes \\
\hline RM hipófise & Positiva em 50-60\% & Incidentaloma em $10 \%$ \\
\hline $\begin{array}{l}\text { TC/RM - tórax / abdome / região } \\
\text { cervical }\end{array}$ & NL & Positivo \\
\hline $\begin{array}{l}\text { Cintilografia de receptores de } \\
\text { somatostatina }\left({ }^{111} \text { In-pentreotide) }\right.\end{array}$ & Negativo & Positivo \\
\hline Gradiente de ACTH & $\ldots$ & Gradiente positivo \\
\hline FDG-PET & $\ldots$ & $\begin{array}{l}\text { Positivo em alguns } \\
\text { casos }\end{array}$ \\
\hline $\begin{array}{l}\text { Cateterismo bilateral e simultâneo } \\
\text { dos seios petrosos inferiores }\end{array}$ & $\begin{array}{l}\text { Gradiente centro- } \\
\text { periferia }\end{array}$ & $\begin{array}{l}\text { Sem gradiente } \\
\text { centro-periferia }\end{array}$ \\
\hline
\end{tabular}

${ }^{*}$ Resultados encontrados mais comuns; ${ }^{7}$ Marcadores tumorais mais comuns: calcitonina, gastrina, antígeno carcinogênico embrionário (CEA), gonadotrofina coriônica humana fração beta ( $\beta$ hCG), $\alpha$-fetoproteína (Howlett et al., 1986 apud Wajchenberg et al., 1994); NL, normal 
Desde então, a desmopressina que é um análogo sintético de longa duração da vasopressina, tem sido usada no diagnóstico diferencial (Malerbi et al., 1993). Nesse estudo original com a desmopressina, ocorreram respostas exageradas de cortisol em 15/16 pacientes com DC, e respostas ausentes em indivíduos normais e em um paciente com SEA. Posteriormente, outras casuísticas mostraram respostas positivas em indivíduos normais (Scott et al., 1999) e também em tumores ectópicos, com porcentagem maior do que com CRH (Newell-Price et al., 1998).

O critério de resposta mais utilizado para a desmopressina (10 $\mu \mathrm{g}$ IV) é o mesmo do oCRH, incremento de $>20 \%$ de cortisol e $>35 \%$ de ACTH em relação aos valores basais (Nieman et al., 1993).

Esse padrão de respostas exageradas de $\mathrm{ACTH}$ e cortisol com o $\mathrm{CRH}$ e desmopressina tem sido atribuído à maior expressão dos respectivos receptores nos tumores, sendo que diferenças de expressão podem explicar as diferentes respostas nos pacientes com SC ACTH-dependente. Entretanto, nenhum estudo sistemático foi feito até o momento para confirmar tal associação.

\subsection{Secretagogos de GH (GHS) na Síndrome de Cushing}

\subsubsection{Histórico, Definição e Ações dos GHS}

Em 1977, Bowers et al. apud Korbonits et al. (2004) descreveram um peptídeo sintético, análogo das metencefalinas, com potente efeito estimulatório de GH em animais e humanos. Essa substância faz parte de uma família de secretagogos de GH (GHS), peptídicos (GHRP - peptídeo liberador de $\mathrm{GH}$ ) e não peptídicos (exemplo: MK-0677). Os GHS não possuem homologia com o GHRH e atuam em receptor específico, diferente do receptor do GHRH (Korbonits et al., 2004; van der Lely et al., 2004; Lengyel, 2006). 
Em 1996 foi clonado o receptor dos GHS (GHSR) (Howard et al.) e somente em 1999, foi descoberto o seu ligante natural denominado ghrelina (Kojima et al.).

Os GHS são potentes estimuladores de $\mathrm{GH}$, administrados tanto por via parenteral quanto por VO (Smith et al., 1997). Entretanto, foram usados no tratamento da baixa estatura e, também, na deficiência de $\mathrm{GH}$ com resultados apenas modestos, nitidamente inferiores à administração do $\mathrm{GH}$ exógeno humano (hGH) (Mericq et al., 2003; Korbonits et al., 2004).

Os GHS estimulam a secreção de GH pela ação direta em seu receptor ativo (GHSR-1a), expresso principalmente no hipotálamo (núcleo arqueado) (Kojima et al., 1999). Desta maneira, possuem ação sinérgica ao GHRH e ação antagônica à somatostatina (Korbonits et al., 2004; van der Lely et al., 2004; Lengyel, 2006). Porém, também possuem ação direta na hipófise, mediada pelo seu receptor e, mesmo em casos de lesão de haste hipofisária em animais, ainda produzem pequena secreção de GH (Fletcher et al., 1994). Entretanto, pacientes portadores de desconexão hipotálamo-hipofisária não secretaram GH com estímulo de ghrelina (Popovic et al., 2003).

A ghrelina, ligante natural dos receptores dos GHS, expressa em vários tecidos, principalmente no estômago, constitui uma nova via na fisiologia da secreção do $\mathrm{GH}$, além do $\mathrm{GHRH}$ e da somatostatina. Entretanto, admite-se atualmente, que a ghrelina possui importância apenas secundária para a secreção fisiológica do $\mathrm{GH}$, provavelmente por amplificar o padrão de secreção de $\mathrm{GH}$, ampliando a resposta do somatotrofo ao $\mathrm{GHRH}$ (Lengyel, 2006)

Por outro lado, foram descritas até o momento, várias ações da ghrelina e dos GHS, ligadas principalmente à homeostase energética do organismo (Korbonits et al., 2004; van der Lely et al., 2004) (Tabela 5). 
Tabela 5. Efeitos dos GHS/ghrelina. Adaptado de Korbonits et al. (2004)

\begin{tabular}{lc}
\hline \multicolumn{1}{c}{ AÇÃo } & EFEITO \\
\hline Liberação de GH & $\uparrow$ \\
Liberação de ACTH e cortisol & $\uparrow$ \\
Liberação de PRL & $\uparrow$ \\
Apetite & $\uparrow$ \\
Metabolismo de carboidrato & $\uparrow \downarrow$ \\
Motilidade gástrica & $\uparrow$ \\
Sono & $\uparrow$ \\
Metabolismo ósseo* & $\uparrow$ \\
Coração (inotropismo) & $\uparrow$ \\
Vasodilatação & $\uparrow$ \\
Proliferação celular & $\uparrow$ \\
Sistema nervoso autônomo & $\uparrow \downarrow$ \\
Termoregulação & $\uparrow \downarrow$ \\
\hline Possivelment via GH & $\downarrow$ \\
\hline
\end{tabular}

${ }^{*}$ Possivelmente via GH 


\subsubsection{GHS e Eixo Hipotálamo-hipófise-adrenal}

Apesar do nome, os GHS estimulam a secreção de ACTH, cortisol e PRL em indivídiuos normais, sendo que com a ghrelina, pode haver também secreção de aldosterona (Arvat et al., 2001).

Entretanto, ao contrário da secreção de $\mathrm{GH}$, há necessidade do eixo hipotálamo-hipófisário íntegro para que ocorra a secreção de ACTH. Em casos de desconexão, essa resposta é totalmente abolida. Desta maneira, admite-se que o mecanismo da resposta do ACTH seja mediado por centros superiores à hipófise, provavelmente mediado pela arginina-vasopressina (Korbonits et al., 2004).

A secreção de cortisol pelos GHS é secundária à estimulação do $A C T H$, apesar de existir expressão do receptor GHSR-1a na adrenal. Ainda é pouco conhecido o papel fisiológico da ghrelina no eixo hipotálamo-hipófise-adrenal (Korbonits et al., 2004).

Por sua vez, a PRL é secretada pelos GHS/ghrelina supostamente por ativação de células mamo-somatotróficas, embora a ação no hipotálamo não possa ser excluída (Korbonits et al., 2004).

\subsubsection{GHS na Síndrome de Cushing}

Os GHS são utilizados no diagnóstico diferencial da SC ACTH-dependente desde 1997b (Ghigo et al.). As casuísticas relatadas até o momento (Tabela 6), mostram respostas exageradas de ACTH e cortisol nos pacientes com DC, sendo essas respostas bloqueadas ou achatadas em pacientes com adenomas de adrenal e em tumores ectópicos produtores de ACTH (Ghigo et al., 1997b). 
Tabela 6. Casuísticas de GHS/ghrelina na síndrome de Cushing

\begin{tabular}{|c|c|c|c|c|}
\hline CASUÍSTICA & GHS & $\begin{array}{c}\text { DOENÇA DE } \\
\text { CUSHING } \\
(\mathrm{N})\end{array}$ & $\begin{array}{c}\text { TUMOR } \\
\text { ECTÓPICO } \\
(\mathrm{N})\end{array}$ & $\begin{array}{c}\text { ADENOMA } \\
\text { DE ADRENAL } \\
(\mathrm{N})\end{array}$ \\
\hline Ghigo et al. (1997b) & Hexarelina & 10 & $0 * / 2$ & $0 * / 5$ \\
\hline Arvat et al. (1998) & Hexarelina & $13^{*} / 21$ & $\ldots$ & $\ldots$ \\
\hline Grottoli et al. (1999) & Hexarelina & 9 & $\ldots$ & $\ldots$ \\
\hline Arvat et al. (1999) & Hexarelina & 6 & $\ldots$ & $\ldots$ \\
\hline Coiro et al. (2000) & Hexarelina & 6 & $\ldots$ & $\ldots$ \\
\hline Leal-Cerro et al. (2002) & Ghrelina & 10 & $\ldots$ & $\ldots$ \\
\hline Oliveira et al. (2003) & GHRP-6 & 10 & $\ldots$ & $\ldots$ \\
\hline \multirow[t]{2}{*}{ Correa-Silva et al. (2004) } & Ghrelina / & 12 & $\ldots$ & $\ldots$ \\
\hline & GHRP-6 & & & \\
\hline \multirow[t]{2}{*}{ Silva et al. (2006) } & Ghrelina / & 6 & $\ldots$ & $\ldots$ \\
\hline & GHRP-6 & & & \\
\hline
\end{tabular}

*número de pacientes responsivos/número total de pacientes; $\mathrm{N}$, número de pacientes 
Mesmo após a publicação dessas séries, não existe ainda padronização da resposta de ACTH e cortisol nos testes de estímulo com GHS em indivíduos normais e em pacientes com SC ACTH-dependente. Nesses estudos, as respostas positivas foram definidas após comparação dos valores médios dos hormônios (pico de resposta, área sob a curva ou $\Delta$ de incremento) dos grupos controles com os pacientes. Portanto, não é conhecido o padrão de resposta individual na maioria desses indivíduos.

Outro estudo mostrou resposta positiva à hexarelina mais freqüente naqueles pacientes com DC portadores de microadenomas quando comparados com alguns pacientes com macroadenomas (Arvat et al., 1998). Em outras séries, essas correlações são limitadas pela não especificação das respostas individuais e da prevalência de micro e macroadenomas nos pacientes.

Os mecanismos pelos quais ocorrem as respostas de ACTH e cortisol com os GHS nos pacientes com DC não estão totalmente esclarecidos. Um estudo mostrou intensidade semelhante de resposta de ACTH e cortisol com GHRP-6 $(2 \mu \mathrm{g} / \mathrm{kg})$ e desmopressina $(10 \mu \mathrm{g})$ e correlação do pico de cortisol com os dois secretagogos, sugerindo que o mecanismo de resposta possa ser semelhante (Oliveira et al., 2003).

Outra hipótese, seria a ação do GHS diretamente no tumor corticotrófico, via seu receptor ativo GHSR-1a. Um estudo mostrou secreção de ACTH dosedependente após estímulo direto com o MK-0677 em culturas de células de tumores corticotróficos (Barlier et al., 1999). Outro autor não observou essa ação direta também em culturas de células de adenomas corticotróficos pela mensuração do fluxo de cálcio intracelular (Lania et al., 1998).

Em 1998, foi relatado um paciente portador de tumor carcinóide tímico produtor de GHRH e ACTH, com os quadros clínicos de acromegalia e SC. Os autores observaram resposta in vitro ao GHRP-6, pela mensuração de cálcio 
intracelular (Jansson et al., 1998). Essa publicação não definiu se poderia ocorrer resposta in vivo aos GHS em pacientes com SEA, ressaltando-se que, outros autores demonstraram a mesma resposta in vitro, com metodologia semelhante, em tumores sabidamente não secretores (adenomas hipofisários não-funcionantes) (Lania et al., 1998). Porém, recentemente, foi publicado o caso de um paciente com tumor carcinóide brônquico com SC cíclica com resposta in vivo a hexarelina com secreção de ACTH (Arnaldi et al., 2003b).

Assim, são necessários estudos com maior número de pacientes, incluindo outros casos de tumores ectópicos, para definir a sensibilidade e especificidade desse teste no diagnóstico diferencial da SC ACTH-dependente. Além disso, não há casuística até então que tenha correlacionado as respostas de ACTH e cortisol in vivo aos GHS com o estudo molecular do receptor GHSR-1a.

Sabe-se que a secreção de GH é bastante prejudicada na SC levando à diminuição da velocidade de crescimento dos pacientes pediátricos (Magiakou et al., 1994; Leinung e Zimmerman, 1994). Além disso, os testes de estímulo de GH, comumente utilizados (teste de tolerância à insulina, entre outros), geralmente não são capazes de produzir resposta em vigência de hipercortisolismo. Entretanto, algumas casuísticas com o uso de GHS em SC têm mostrado capacidade de secreção de $\mathrm{GH}$, porém, menor do que nos indivíduos controles. O potente efeito estímulatório dessas substâncias em alguns casos sobrepuja o bloqueio do hipercortisolismo. Um estudo mostrou secreção de GH mais intensa da ghrelina quando comparada ao GHRP-6 em pacientes portadores de DC, ainda que menor que nos indivíduos controles (Correa-Silva et al., $2004^{1}$ ).

\footnotetext{
${ }^{1}$ Correa-Silva SRC, Nascif SO, Silva MR, Senger MH, Miranda WL, Machado AF, Lengyel AMJ. (Divisão de Endocrinologia, Universidade Federal de São Paulo, UNIFESP/EPM, São Paulo, SP). Decreased $\mathrm{GH}$ secretion and enhanced ACTH and cortisol release after ghrelin administration in Cushing's disease: comparison with GHRP-6. (Presented at $12 \mathrm{~h}$ International Congress of Endocrinology (ICE), 2004 August 31-September 4; Lisbon, Portugal. Abstracts p913-917).
} 


\subsection{Tratamento}

O tratamento cirúrgico é a principal opção terapêutica da SC, tanto para os tumores corticotróficos, quanto para as causas adrenais e da SEA. Na falha desse tratamento ou na sua impossibilidade, seja por falta de condições clínicas, recusa à cirurgia ou não localização do tumor, várias opções são consideradas para controlar o quadro de hipercortisolismo, principalmente o tratamento medicamentoso e a adrenalectomia bilateral. Para a DC, também são opções o tratamento radioterápico (convencional ou conformacional) e a adrenalectomia unilateral mais radioterapia (Nagesser et al., 1995).

Na DC, mesmo sem imagem tumoral visível na RM, a presença do gradiente centro-periferia no CBSSPI é condição suficiente para a abordagem cirúrgica. Comumente, a cirurgia é realizada pela via transesfenoidal, com visualização do tumor na maioria dos casos e com $78 \%(50-100 \%)$ de confirmação com o lado presumido pelo cateterismo (Newell-Price et al., 1998). A taxa de remissão pósoperatória (PO) é muito variável, pois, depende da casuística analisada (experiência do cirurgião, critério de remissão e follow-up) e das características do tumor (tamanho e extensão). A maior casuística publicada $(n=510)$ relata remissão PO em 76,3\% dos casos (Bochicchio et al., 1995).

Embora não haja consenso nos critérios de cura da DC, sabe-se que quanto mais rigoroso for o critério (menor cortisol sérico PO), menor serão as taxas de remissão e recidiva das séries, embora essa última possa ocorrer mesmo com níveis de cortisol PO < $1 \mu \mathrm{g} / \mathrm{dL}$ (Bochicchio et al., 1995; Yap et al., 2002).

A recidiva da DC acontece em torno de 12,7\% (Bochicchio et al., 1995). Alguns fatores são preditivos para a recidiva, como: cortisol normal PO; níveis baixos de cortisol PO, mas com resposta significativa após estímulo (oCRH, metirapona, desmopressina, GnRH, TRH ou loperamida); curto período de reposição de 
glicocorticóide; e não retorno do ritmo circadiano normal do cortisol; não existindo portanto, um marcador ideal (Bochicchio et al., 1995; Colombo et al., 2000; Barbetta et al., 2001; Losa et al., 2001; Estrada et al., 2001; Valéro et al., 2004).

Ao contrário do tratamento clínico dos prolactinomas com os agonistas dopaminérgicos, não há medicamento tão eficiente para controlar a secreção hormonal e diminuir o tamanho tumoral na DC. Classicamente, o tratamento medicamentoso pode ser dividido em três grupos de acordo com o mecanismo de ação: drogas que inibem a esteroidogênese adrenal (cetoconazol, mitotane, metirapona, aminoglutetimide e etomidato); drogas que modulam a secreção de ACTH (agonistas dopaminérgicos, análogos da somatostatina, ciproheptadina, carbamazepina e ácido valpróico); e antagonista do receptor de glicocorticóide (mifepristone/RU-486) (Beauregard et al., 2002; Utz et al., 2005).

Recentemente, os agonistas do receptor ativado do proliferador de peroxisoma gama (PPAR $\gamma$ ), rosiglitazone e pioglitazone, também foram utilizados nos pacientes com DC com resposta satisfatória em alguns pacientes (Ambrosi et al., 2004; Suri e Weiss, 2005; Cannavo et al., 2005; Hull et al., 2005; Barbaro et al., 2005). O racional proposto dessas medicações seria um efeito pró-apoptótico nas células tumorais (Heaney et al., 2002).

O tratamento quimioterápico é pouco usado no contexto da SC, principalmente em carcinomas e em tumores ectópicos produtores de ACTH. Os resultados são geralmente parciais e insatisfatórios.

\subsection{Prognóstico}

Pacientes com síndrome de Cushing tem uma taxa de mortalidade 4 vezes superior a indivíduos controles pareados em sexo e idade (Etxabe e Vazquez, 1994), 
devido às morbidades da síndrome que são correlacionadas direta ou indiretamente com o excesso de cortisol. Portanto, o objetivo primário na prevenção e tratamento dessas complicações é o controle do hipercortisolismo (Arnaldi et al., 2003a).

O hipercortisolismo crônico está associado a um aumento nos fatores de risco cardiovasculares, como hipertensão arterial, intolerância à glicose ou Diabete Melito, obesidade centrípeta, dislipidemia e hipercoagubilidade. A alta taxa de mortalidade é decorrente das complicações cardiovasculares. (Arnaldi et al., 2003a).

Um estudo revelou que mesmo após cinco anos da resolução do hipercortisolismo na DC, ainda existe aumento dos fatores de risco cardiovasculares (Colao et al., 1999). Entretanto, um trabalho mostrou que a longo prazo, a taxa de mortalidade dos pacientes curados por adenomas de adrenal ou DC não era diferente da população geral (Lindholm et al., 2001) (Figura 1).

Por outro lado, o prognóstico e a taxa de mortalidade podem ser piores nos casos de SC associados a neoplasias, como nos tumores pulmonares de pequenas células produtores de ACTH (Lindholm et al., 2001).

\section{Expressão Gênica na Síndrome de Cushing ACTH-dependente}

\subsection{Receptor do Hormônio Liberador de Corticotrofina (CRHR1)}

São descritos dois receptores de CRH: CRHR1 e CRHR2. O receptor CRHR1 está presente em várias regiões do cérebro, hipófise (corticotrofos), e pouco em tecidos periféricos (adrenais) (Catalano et al., 2003). É o principal responsável pela ação do hormônio hipotalâmico $\mathrm{CRH}$, mediando a resposta ao stress, dentre outras (Chen et al., 1993). O CRHR2 é expresso principalmente no cérebro (Liaw et al., 1996), com função ainda pouco conhecida. 


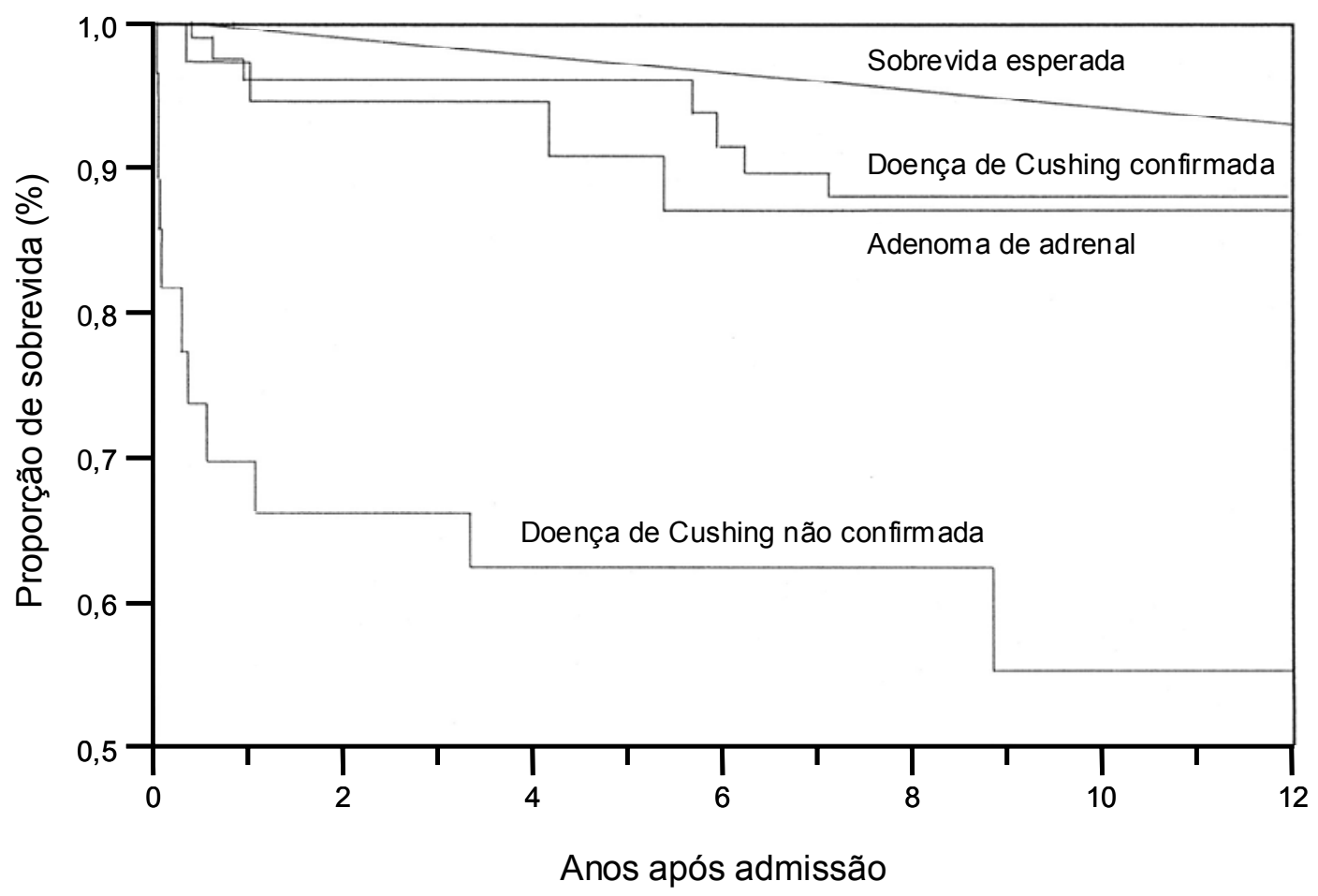

Figura 1. Curva de sobrevida em pacientes com síndrome de Cushing portadores de doença de Cushing (confirmada e não confirmada) e adenomas de adrenal. No primeiro ano, a taxa de mortalidade é maior que na população geral para todas as etiologias da síndrome de Cushing. A longo prazo, só há diferença na mortalidade em relação à taxa esperada nos casos de doença de Cushing não confirmada. Esses últimos casos representam os pacientes que não tiveram remissão pós-operatória, explicando o pior prognóstico. Adaptado de Lindholm et al. (2001) 
O gene do CRHR1 foi clonado em 1993 (Chen et al.) e está localizado no cromossomo 17q12-q22. Apresenta 14 exons e codifica uma proteína de 415 aa. Faz parte do grupo de receptores de superfície acoplados à proteína G (subfamília $\mathrm{G}_{\mathrm{s}}$ - ativa adenilciclase, $2^{\circ}$ mensageiro $\left.A M P c\right)$.

O receptor CRHR2, clonado mais recentemente (Liaw et al., 1996), é codificado por gene localizado em 7p21-p15 que contém 12 exons. Esse receptor também é de superfície, acoplado à proteína $G$ (subfamília $G_{s}-2^{\circ}$ mensageiro AMPc). Sua proteína, com 411 aa, apresenta $70 \%$ de homologia com o receptor CRHR1.

Estudos de expressão de RNAm demonstraram a presença do CRHR1 em adenomas corticotróficos e também em tumores ectópicos produtores de ACTH (de Keyzer et al., 1996). Esses relatos são concordantes em demonstrar que a intensidade de expressão geralmente é maior nos tumores quando comparados à hipófise normal (de Keyzer et al., 1996; de Keyzer et al., 1998; Dieterich et al., 1998).

Não há estudo correlacionando o padrão de expressão do RNAm do CRHR1 nos tumores com as respostas in vivo ao $\mathrm{CRH}$ em pacientes com SC ACTH-dependente.

\subsection{Receptores da Vasopressina (AVPR1B e AVPR2)}

Existem três tipos de receptores da vasopressina, responsáveis por funções distintas: AVPR1A, AVPR1B e AVPR2. O receptor AVPR1A está localizado principalmente no fígado, musculatura lisa vascular, cérebro e plaquetas. Sua função é mediar a vasoconstricção em situações de hipotensão arterial e estímulo da glicogenólise hepática. Além disso, auxilia na hemostasia por contribuir para a agregação plaquetária. O AVPR2, expresso principalmente 
nos túbulos contornados distais e dutos coletores renais, é responsável pelo efeito antidiurético da vasopressina, também conhecida como hormônio antidiurético $(A D H)$. O receptor AVPR1B está localizado na hipófise, particularmente no corticotrofo, conhecido como um dos marcadores do "fenótipo corticotrofo". Juntamente com o $\mathrm{CRH}$, participa do estímulo de $\mathrm{ACTH}$ e cortisol em situações de stress (Sugimoto et al., 1994).

O receptor AVPR2, membro da família dos receptores de superfície acoplados à proteína $\mathrm{G}$ (subfamília $\mathrm{G}_{\mathrm{S}}$ - ativa adenilciclase), é codificado pelo gene localizado no cromossomo Xq28, com 3 exons (van den Ouweland et al., 1992). O AVPR1B, também conhecido como AVPR3 ou V3R, também é membro dos receptores acoplados à proteína $G$ (subfamília $G_{q}$ - ativa fosfolipase $C$ ). Seu gene foi clonado em 1994 (Sugimoto et al.), está localizado em 1q32 com 2 exons e codifica uma proteína de 424 aa.

Existem vários relatos de maior expressão do gene AVPR1B em tumores corticotróficos e em tumores neuroendócrinos, quando comparado com tecidos normais (de Keyzer et al., 1996; Dahia et al., 1996; de Keyzer et al., 1998; Arlt et al., 1997; Chabot et al., 1998; Tsagarakis et al., 2002). Além disso, foi reportada expressão do AVPR2 na SC, em casos de DC e SEA (Dahia et al., 1996; Arlt et al., 1997; Tsagarakis et al., 2002). Um estudo demonstrou que 3 de 5 pacientes com tumores ectópicos produtores de ACTH exibiam resposta in vivo à desmopressina, o que poderia ser justificado pela superexpressão do AVPR2 encontrado em 4 dos 4 tumores avaliados (Tsagarakis et al., 2002).

Contudo, poucos trabalhos têm tentado correlacionar as respostas in vivo com a análise molecular do receptor AVPR1B. Dahia et al. (1996) não encontrou mutações nesse gene, fato que acontece em outras doenças associadas a receptores acoplados à proteína G (exemplo: síndrome de McCune Albright, testotoxicose, entre outras) (Antonini et al., 2004). Outro estudo não mostrou 
correlação entre as respostas in vivo e in vitro com a desmopressina, sugerindo que a secreção de ACTH e cortisol seja mediada por fatores extra-hipofisários (Pecori Giraldi et al., 2003).

\subsection{Receptores dos GHS (GHSR-1a e GHSR-1b)}

O gene dos receptores dos GHS/ghrelina humano (GHSR), clonado em 1996 (Howard et al.), está localizado no cromossomo 3q26.2 e apresenta 4,3 kb com dois exons. Esse gene codifica proteína de 366 aa, denominado receptor do GHS tipo 1a (GHSR-1a), que representa a forma ativa do receptor dos GHS. Pelo processamento alternativo do mesmo gene, há um transcrito formado pelo primeiro exon e um segmento de 74 pb do intron (289 aa), denominado GHSR-1b. Essa última proteína é truncada e biologicamente inativa (Howard et al., 1996).

Os GHSRs fazem parte da família dos receptores acoplados à proteína G, sendo da subfamília $\mathrm{G}_{\mathrm{q}}$ (assim como receptores da angiotensina II, endotelinas, entre outros) com sete domínios transmembrana. $O$ transcrito GHSR-1b supostamente produz um receptor com 5 domínios transmembrana, diferindo do GHSR-1a na porção carboxiterminal (Petersenn, 2002). A ligação com o receptor GHSR-1a produz ativação da fosfolipase C, cliva o fosfoinositol-4,5-bifosfato e gera inositol-1,4,5-trifosfato (IP3) e diacilglicerol (DAG). O IP3 age no retículo endoplasmático promovendo liberação de cálcio livre para o meio citoplasmático, importante para ativar outras proteínas cinases e para a secreção hormonal (como do GH). O DAG ativa diretamente a PKC. Além disso, a fosfolipase C pode ativar a fosforilação do canal de $\mathrm{K}$, resultando em inibição do canal, despolarização da membrana celular e ativação do canal de cálcio voltagem-dependente (Korbonits et al., 2004; van der Lely et al., 2004). 
O GHSR-1a está expresso principalmente no hipotálamo (núcleo arqueado) e hipófise (Howard et al., 1996). Perifericamente, o RNAm do GHSR-1a foi demonstrado em alguns tecidos como a tireóide, pâncreas, baço, coração (miocárdio), estômago, intestino, rim, adrenal (Gnanapavan et al., 2002), e também no testículo (Gaytan et al., 2004) e ovário (Gaytan et al., 2005). Por outro lado, a ghrelina está expressa virtualmente em todos os tecidos estudados, assim como o RNAm do GHSR-1b, sugerindo que possam existir outros GHSRs não descritos até o momento (Gnanapavan et al., 2002).

Foi demonstrada a expressão dos GHSRs também em tecidos tumorais: ovário, testículo, pulmão, estômago, mama, pâncreas e principalmente, nos adenomas hipofisários (Korbonits et al., 2004; van der Lely et al., 2004).

Algumas séries relataram a expressão dos GHSRs em vários tipos de adenomas hipofisários, desde os produtores (principalmente nos adenomas somatotróficos) até nos adenomas clinicamente não-funcionantes. Nos somatotrofinomas, a expressão é comumente maior que na hipófise normal, enquanto que nos outros tipos histológicos, a expressão dos GHSRs é em geral, de mesma intensidade que a hipófise normal (Tabela 7).

Há discordância quanto à magnitude de expressão dos GHSRs nos tumores corticotróficos em relação ao tecido hipofisário normal, já que alguns trabalhos mostram superexpressão e outros mostram expressão semelhante (Tabela 8). Esses resultados conflitantes decorrem de diferentes técnicas empregadas, sensibilidade dos métodos de quantificação, tipo de tumor analisado (micro e macroadenomas) e, principalmente, pelos iniciadores utilizados (“GHSR” vs. GHSR1a), já que podem analisar somente o receptor ativo (GHSR-1a) ou não serem específicos (“GHSR").

Além disso, foi verificada a expressão dos GHSRs em outros tumores neuroendócrinos produtores de $\mathrm{ACTH}$, principalmente em carcinóides e tumores 
pulmonares de pequenas células e também, em outros tumores neuroendócrinos mesmo sem a ocorrência de SC (Tabela 8).

Assim, a simples presença do receptor ativo GHSR-1a nesses tumores, não poderia explicar totalmente as respostas exageradas de ACTH e cortisol nos pacientes com a DC. Outra hipótese aventada para explicar a magnitude das respostas seria a ocorrência de cross-talk entre os receptores da vasopressina, CRH e GHSR-1a (de Keyser et al., 1997), todos receptores de superfície acoplados à proteína G, assim como acontece com os receptores da somatostatina (Rocheville et al., 2000). 
Tabela 7. Casuísticas de expressão do RNAm do GHSR-1a em adenomas hipofisários e comparação com o tecido hipofisário normal

\begin{tabular}{|c|c|c|c|c|c|c|}
\hline AUTOR & $\begin{array}{c}\text { TÉCNICA } \\
\text { GHSR-1a / "GHSR” }\end{array}$ & $\mathbf{G H}^{*}$ & PRL* & $\mathrm{CNF}^{*}$ & LH/FSH* & $\mathrm{TSH}^{*}$ \\
\hline $\begin{array}{c}\text { de Keyzer et al. } \\
\text { (1997) }\end{array}$ & $\begin{array}{l}\text { RT-PCR } \\
\text { GHSR-1a }\end{array}$ & $\begin{array}{l}\cdots \\
\cdots\end{array}$ & $\begin{array}{c}2 / 3 \\
\ldots\end{array}$ & $\begin{array}{l}1 / 2 \\
\ldots\end{array}$ & $\begin{array}{l}\cdots \\
\cdots\end{array}$ & $\begin{array}{l}\cdots \\
\cdots\end{array}$ \\
\hline $\begin{array}{l}\text { Korbonits et al. } \\
\text { (1998) }\end{array}$ & $\begin{array}{l}\text { RT-PCR } \\
\text { "GHSR" }\end{array}$ & $\begin{array}{c}8 / 8 \\
8>\mathrm{HN}\end{array}$ & $\begin{array}{c}4 / 4 \\
1>\mathrm{HN}\end{array}$ & $\begin{array}{c}3 / 7 \\
3<\mathrm{HN}\end{array}$ & $\begin{array}{c}0 / 1 \\
\ldots\end{array}$ & $\begin{array}{l}\cdots \\
\cdots\end{array}$ \\
\hline $\begin{array}{c}\text { Skinner et al. } \\
\text { (1998) }\end{array}$ & $\begin{array}{l}\text { RT-PCR } \\
\text { "GHSR" }\end{array}$ & $\begin{array}{c}10 / 10 \\
10>\mathrm{HN}\end{array}$ & $\begin{array}{l}\cdots \\
\cdots\end{array}$ & $\begin{array}{c}3 / 9 \\
3=\mathrm{HN}\end{array}$ & $\begin{array}{l}\cdots \\
\cdots\end{array}$ & $\begin{array}{c}1 / 1 \\
> \\
\mathrm{HN}\end{array}$ \\
\hline $\begin{array}{l}\text { Adams et al. } \\
\quad(1998)\end{array}$ & $\begin{array}{l}\text { RT-PCR } \\
\text { "GHSR" }\end{array}$ & $\begin{array}{c}6 / 6 \\
\ldots\end{array}$ & $\begin{array}{l}3 / 3 \\
\ldots\end{array}$ & $\begin{array}{c}0 / 8 \\
\ldots\end{array}$ & $\begin{array}{l}\cdots \\
\cdots\end{array}$ & $\begin{array}{l}\cdots \\
\cdots\end{array}$ \\
\hline $\begin{array}{l}\text { Nielsen et al. } \\
\text { (1998) }\end{array}$ & $\begin{array}{l}\text { RT-PCR } \\
\text { "GHSR" }\end{array}$ & $\begin{array}{c}10 / 11 \\
\ldots\end{array}$ & $\begin{array}{c}2 / 2 \\
\ldots\end{array}$ & $\begin{array}{c}2 / 14 \\
\ldots\end{array}$ & $\begin{array}{l}\cdots \\
\cdots\end{array}$ & $\begin{array}{l}\cdots \\
\cdots\end{array}$ \\
\hline $\begin{array}{l}\text { Barlier et al. } \\
\quad(1999)\end{array}$ & $\begin{array}{l}\text { RT-PCR } \\
\text { GHSR-1a }\end{array}$ & $\begin{array}{c}6 / 6 \\
6=\mathrm{HN}\end{array}$ & $\begin{array}{c}6 / 6 \\
6=\mathrm{HN}\end{array}$ & $\begin{array}{l}1 / 5 \\
\ldots\end{array}$ & $\begin{array}{c}2 / 4 \\
\ldots\end{array}$ & $\begin{array}{c}0 / 1 \\
\ldots\end{array}$ \\
\hline $\begin{array}{c}\text { Kim et al. } \\
(2001)\end{array}$ & $\begin{array}{l}\text { RT-PCR } \\
\text { GHSR-1a }\end{array}$ & $\begin{array}{c}13 / 13 \\
13>\mathrm{HN}\end{array}$ & $\begin{array}{c}4 / 4 \\
\ldots\end{array}$ & $\begin{array}{c}4 / 4 \\
\ldots\end{array}$ & $\begin{array}{c}5 / 5 \\
\ldots\end{array}$ & $\begin{array}{c}2 / 2 \\
\ldots\end{array}$ \\
\hline $\begin{array}{l}\text { Korbonits et al. } \\
\qquad(2001)\end{array}$ & $\begin{array}{c}\text { qPCR } \\
\text { GHSR-1a }\end{array}$ & $\begin{array}{c}22 / 22 \\
22>\mathrm{HN}\end{array}$ & $\begin{array}{c}4 / 4 \\
\ldots\end{array}$ & $\begin{array}{c}12 / 12 \\
\ldots\end{array}$ & $\begin{array}{c}5 / 5 \\
\ldots\end{array}$ & $\begin{array}{l}\cdots \\
\cdots\end{array}$ \\
\hline $\begin{array}{l}\text { Kim et al. } \\
(2003)\end{array}$ & $\begin{array}{c}\text { qPCR } \\
\text { GHSR-1a }\end{array}$ & $\begin{array}{c}20 / 20 \\
\ldots\end{array}$ & $\begin{array}{l}\cdots \\
\cdots\end{array}$ & $\begin{array}{l}\ldots \\
\ldots\end{array}$ & $\begin{array}{l}\cdots \\
\cdots\end{array}$ & $\begin{array}{l}\cdots \\
\cdots\end{array}$ \\
\hline
\end{tabular}

RT-PCR, reação em cadeia da polimerase por transcriptase reversa; qPCR, reação em cadeia da polimerase quantitativa; $\mathrm{GH}$, adenomas somatotrofos; PRL, prolactinomas; $\mathrm{CNF}$, adenomas clinicamente não-funcionantes; LH/FSH, adenomas produtores de LF/FSH; TSH, tireotropinomas; *número de amostras positivas/número total de amostras, expressão comparativa (número de amostras estudadas) em relação à hipófise normal; HN, hipófise normal 
Tabela 8. Casuísticas de expressão do RNAm do GHSR-1a na síndrome de Cushing ACTH-dependente e em outros tumores neuroendócrinos ACTH negativos e comparação com o tecido hipofisário normal

\begin{tabular}{|c|c|c|c|c|}
\hline AUTOR & $\begin{array}{c}\text { TÉCNICA } \\
\text { GHSR-1a / “GHSR” }\end{array}$ & $\begin{array}{c}\text { DOENÇA DE } \\
\text { CUSHING* }\end{array}$ & $\begin{array}{l}\text { SECREÇÃO } \\
\text { ECTÓPICA } \\
\text { DE ACTH }^{*}\end{array}$ & $\begin{array}{c}\text { OUTROS TNE } \\
\text { ACTH } \\
\text { NEGATIVOS* }\end{array}$ \\
\hline $\begin{array}{c}\text { de Keyzer et al. } \\
\text { (1997) }\end{array}$ & $\begin{array}{l}\text { RT-PCR } \\
\text { GHSR-1a }\end{array}$ & $\begin{array}{c}18 / 18 \\
18>\mathrm{HN}\end{array}$ & $\begin{array}{c}8 / 10 \\
\ldots\end{array}$ & $\begin{array}{c}8 / 10 \\
\ldots\end{array}$ \\
\hline $\begin{array}{c}\text { Korbonits et al. } \\
\text { (1998) }\end{array}$ & $\begin{array}{l}\text { RT-PCR } \\
\text { "GHSR" }\end{array}$ & $\begin{array}{c}16 / 18 \\
5>\mathrm{HN}\end{array}$ & $\begin{array}{c}3 / 3 \\
1>\mathrm{HN}\end{array}$ & $\begin{array}{c}0 / 1 \\
\ldots\end{array}$ \\
\hline $\begin{array}{c}\text { Skinner et al. } \\
(1998)\end{array}$ & $\begin{array}{l}\text { RT-PCR } \\
\text { "GHSR" }\end{array}$ & $\begin{array}{c}3 / 4 \\
3>\mathrm{HN}\end{array}$ & $\begin{array}{l}\ldots \\
\ldots\end{array}$ & $\begin{array}{l}\ldots \\
\ldots\end{array}$ \\
\hline $\begin{array}{l}\text { Nielsen et al. } \\
\quad(1998)\end{array}$ & $\begin{array}{l}\text { RT-PCR } \\
\text { "GHSR" }\end{array}$ & $\begin{array}{c}0 / 1 \\
\ldots\end{array}$ & $\begin{array}{l}\ldots \\
\ldots\end{array}$ & $\begin{array}{l}\ldots \\
\ldots\end{array}$ \\
\hline $\begin{array}{l}\text { Barlier et al. } \\
\quad(1999)\end{array}$ & $\begin{array}{l}\text { RT-PCR } \\
\text { GHSR-1a }\end{array}$ & $\begin{array}{c}2 / 3 \\
\ldots\end{array}$ & $\begin{array}{l}\ldots \\
\ldots\end{array}$ & $\begin{array}{l}\ldots \\
\ldots\end{array}$ \\
\hline $\begin{array}{c}\text { Kim et al. } \\
(2001)\end{array}$ & $\begin{array}{l}\text { RT-PCR } \\
\text { GHSR-1a }\end{array}$ & $\begin{array}{c}2 / 2 \\
\ldots\end{array}$ & $\begin{array}{l}\ldots \\
\ldots\end{array}$ & $\begin{array}{l}\ldots \\
\ldots\end{array}$ \\
\hline $\begin{array}{c}\text { Korbonits et al. } \\
(2001)\end{array}$ & $\begin{array}{c}\text { qPCR } \\
\text { GHSR-1a }\end{array}$ & $\begin{array}{c}12 / 12 \\
12=\mathrm{HN}\end{array}$ & $\begin{array}{c}2 / 2 \\
2<\mathrm{HN}\end{array}$ & $\begin{array}{c}4 / 4 \\
4<\mathrm{HN}\end{array}$ \\
\hline
\end{tabular}




\section{OBJETIVOS}

O presente estudo teve como objetivo primário verificar se a resposta do ACTH e cortisol à desmopressina, hCRH e GHRP-6 depende da magnitude de expressão do receptor da vasopressina (AVPR1B), do receptor do hormônio liberador de corticotrofina $(\mathrm{CRHR} 1)$ e do receptor dos secretagogos de $\mathrm{GH}$ (GHSR-1a), respectivamente, pela quantificação do RNAm desses receptores em amostras de tumores de pacientes portadores da síndrome de Cushing ACTHdependente.

O objetivo secundário foi avaliar o uso do GHRP-6 no diagnóstico diferencial da síndrome de Cushing ACTH-dependente, comparando os resultados com indivíduos controles pareados em sexo e idade. 


\section{CASUÍSTICA E MÉTODOS}

\section{Pacientes e Amostras}

Entre abril de 2002 e agosto de 2004, foram avaliados 22 pacientes com SC ACTH-dependente, mediana de 32 anos (variação: 15-54 anos), 18 do sexo feminino e quatro do sexo masculino (Tabela 9). Os pacientes foram provenientes principalmente da Unidade de Neuroendocrinologia da Disciplina de Endocrinologia e Metabologia do Hospital das Clínicas da Faculdade de Medicina da Universidade de São Paulo (HC-FMUSP) e da Unidade de Neuroendocrinologia da Divisão de Neurocirurgia do HC-FMUSP.

Todos os pacientes, indivíduos normais (grupo controle) ou seus representantes legais assinaram o Termo de Consentimento Pós-informação (Anexo A). O projeto foi aprovado pela Comissão de Pesquisa e Pós-graduação do Departamento de Clínica Médica da FMUSP e pela Comissão de Ética para a Análise de Projetos de Pesquisa (CAPPesq) do HC-FMUSP (Anexo B).

O diagnóstico laboratorial da SC ACTH-dependente foi estabelecido pela dosagem do cortisol urinário de 24 h (média de 03 amostras), perda do ritmo circadiano de secreção do cortisol (dosagem do cortisol sérico e salivar às 2400 h), ausência de supressão do cortisol com $1 \mathrm{mg}$ de dexametasona, e pela determinação plasmática do ACTH (Tabela 9). No diagnóstico diferencial da SC ACTH-dependente foram realizados RM da região hipofisária, tomografia axial 
computadorizada de abdômen, tórax e região cervical, além dos testes da desmopressina, GHRP-6 e CRH humano (hCRH).

Nos casos duvidosos ou negativos para tumor hipofisário no exame de RM, foi indicado o CBSSPI, sendo definido como gradiente centro-periferia a relação das concentrações plasmáticas de $\mathrm{ACTH}>2$ no basal e $>3$ no pós-estímulo e a lateralização definida quando o gradiente interseios petrosos de $\mathrm{ACTH}$ foi $>1,4$ (Oldfield et al., 1991).

Dos 22 pacientes avaliados, 20 tiveram o diagnóstico de DC e 2 com SEA (tumor carcinóide de timo e tumor carcinóide de pulmão). Os critérios utilizados para a confirmação do diagnóstico foram: achados histopatológicos de tumor (adenoma hipofisário ou tumor carcinóide) com imunohistoquímica positiva para ACTH; hipófise normal, mas com remissão clínica e laboratorial pós-operatória; e cirurgia anterior com confirmação histológica de adenoma hipofisário. Todos os tumores hipofisários foram analisados pelo mesmo patologista, no Serviço de Anatomia Patológica do HC-FMUSP.

Vinte e um indivíduos normais, pareados em sexo e idade (mediana de 33 anos; variação: $16-54$ anos; 18F/3M) com os pacientes com DC, foram submetidos ao teste do GHRP-6 para efeito comparativo (grupo controle) (Tabela 10).

Durante o ato operatório, fragmentos do tumor foram coletados a fresco em condições estéreis em tubos de prolipropileno para congelamento de 2,0 mL, contendo $1,0 \mathrm{~mL}$ do reagente TRIzol ${ }^{\circledR}$ (Invitrogen, Life Technologies, Gaithersburg, EUA) e, em seguida, hermeticamente fechados e acondicionados em nitrogênio líquido, armazenados $\mathrm{a}-80^{\circ} \mathrm{C}$ para posterior análise. Outro fragmento tumoral foi enviado para análise anátomo-patológica, complementada com estudo imunohistoquímico. 
Tabela 9. D ados clínicos e laboratoriais dos pacientes com síndrome de Cushing ACTH-dependente

\begin{tabular}{|c|c|c|c|c|c|c|c|c|c|c|c|c|c|c|c|c|c|}
\hline $\mathbf{N}^{\circ}$ & Nome & Sexo & $\begin{array}{l}\text { Idade } \\
\text { anos }\end{array}$ & $\begin{array}{c}\text { Sintomas } \\
\text { meses }\end{array}$ & $\begin{array}{l}\text { IMC } \\
\mathrm{kg} / \mathrm{m}^{2}\end{array}$ & $\begin{array}{c}\text { Fs } \\
\mu \mathrm{g} / \mathrm{dL}\end{array}$ & $\begin{array}{c}\text { Fs } \\
2400 \mathrm{~h} \\
\mu \mathrm{g} / \mathrm{dL} \\
\end{array}$ & $\begin{array}{c}\text { Fs } \\
1 \mathrm{mg} \\
\mu \mathrm{g} / \mathrm{dL} \\
\end{array}$ & $\begin{array}{c}\mathrm{Fu} \\
\text { (média) } \\
\mu \mathrm{g} / 24 \mathrm{~h}\end{array}$ & $\begin{array}{c}\text { F saliv } \\
2400 \mathrm{~h} \\
\mathrm{ng} / \mathrm{dL}\end{array}$ & $\begin{array}{l}\text { ACTH } \\
\mathrm{pg} / \mathrm{mL}\end{array}$ & K & $\begin{array}{l}\text { RM } \\
\text { sela }\end{array}$ & $\begin{array}{l}\text { CBSSPI } \\
\text { (CEN:PER) }\end{array}$ & $A P+I H$ & Rem & Diagnóstico \\
\hline 1 & ALSJ & $\mathrm{F}$ & 33 & 60 & 41,1 & 34,3 & $\ldots$ & $\ldots$ & 1990 & $\ldots$ & 129 & 5,0 & Micro & $\ldots$ & Adenoma, ACTH + & Não & Dç. de Cushing \\
\hline 2 & GCV & $\mathrm{F}$ & 33 & 36 & 32,4 & 17,9 & 9,2 & 19,8 & 745 & $\ldots$ & 69 & 4,3 & Micro & $\ldots$ & Adenoma, ACTH + & Sim & Dç. de Cushing \\
\hline 3 & scc & $\mathrm{F}$ & 26 & 24 & 23,7 & 19,3 & $\ldots$ & 3,6 & 755 & $\ldots$ & 107 & 4,5 & Micro & Presente & Adenoma, ACTH + & Sim & Dç. de Cushing \\
\hline 4 & JMS & $\mathrm{F}$ & 30 & 24 & 22,8 & 22,2 & 20,0 & 20,1 & 1493 & $\ldots$ & 121 & 3,4 & Cp Heter & Presente & Adenoma, ACTH + & Não & Dç. de Cushing \\
\hline 5 & NMSS & $\mathrm{F}$ & 54 & 8 & 30,0 & 23,3 & 14,5 & 8,6 & 465 & $\ldots$ & 33 & 4,2 & Micro & $\ldots$ & Hipófise normal & Sim & Dç. de Cushing \\
\hline 6 & CRS & M & 30 & 60 & 27,0 & 18,2 & 13,7 & 9,2 & 979 & $\ldots$ & 64 & 4,3 & $\mathrm{NL}$ & Presente & Adenoma, ACTH + & Sim & Dç. de Cushing \\
\hline 7 & CNCL & $\mathrm{F}$ & 34 & 24 & 26,5 & 22,4 & $\ldots$ & $\ldots$ & 1075 & $\ldots$ & 53 & 4,1 & Micro & $\ldots$ & Adenoma, ACTH + & Sim & Dç. de Cushing \\
\hline 8 & ITS & $\mathrm{F}$ & 47 & 120 & 35,7 & 33,8 & 18,0 & 11,8 & 793 & 172 & 48 & 4,2 & $\mathrm{NL}$ & Presente & Hipófise normal & Sim & Dç. de Cushing \\
\hline 9 & MAS & $\mathrm{F}$ & 35 & 72 & 31,0 & 28,8 & 16,5 & 19,9 & 568 & 422 & 178 & 4,5 & Micro & $\ldots$ & Adenoma, $\mathrm{ACTH}+$ & Sim & Dç. de Cushing \\
\hline 10 & JAMO & $\mathrm{F}$ & 16 & 60 & 48,3 & 21,8 & 13,0 & $\ldots$ & 799 & 420 & 53 & 4,2 & Micro & $\ldots$ & Adenoma, ACTH + & Sim & Dç. de Cushing \\
\hline 11 & ECM & $\mathrm{F}$ & 30 & 108 & 37,5 & 19,5 & 17,0 & $\ldots$ & 618 & 330 & 77 & 4,1 & $\mathrm{NL}$ & Presente & Hipófise normal & Sim & Dç. de Cushing \\
\hline 12 & ASM & $\mathrm{F}$ & 34 & 48 & 22,5 & 30,2 & 28,4 & $\ldots$ & 1049 & 4280 & 34 & 4,7 & Cp heter & Presente & Adenoma, $\mathrm{ACTH}+$ & Sim & Dç. de Cushing \\
\hline 13 & MNL & $\mathrm{F}$ & 38 & 48 & 35,2 & 26,7 & $\ldots$ & $\ldots$ & 663 & $\ldots$ & 93 & 4,4 & Micro & Presente & Adenoma, ACTH + & Não & Dç. de Cushing \\
\hline 14 & $J O Q$ & M & 32 & 72 & 25,0 & 25,2 & 24,2 & $\ldots$ & 671 & 667 & 356 & 4,4 & Micro & Presente & Adenoma, ACTH + & $\operatorname{Sim}$ & Dç. de Cushing \\
\hline 15 & PPS & $\mathrm{F}$ & 32 & 120 & 26,7 & 16,9 & $\ldots$ & $\ldots$ & 576 & $\ldots$ & 23 & 3,2 & $\mathrm{Cp}$ Heter & Presente & Adenoma, ACTH + & Sim & Dç. de Cushing \\
\hline 16 & MLMS & $\mathrm{F}$ & 46 & 84 & 31,7 & 19,5 & 26,4 & $\ldots$ & 477 & 436 & 26 & 4,2 & Micro & $\ldots$ & Adenoma, ACTH + & $\operatorname{Sim}$ & Dç. de Cushing \\
\hline 17 & RSRR & $\mathrm{F}$ & 19 & 36 & 47,4 & 19,0 & 21,0 & 19,0 & 1707 & 346 & 23 & 3,8 & Micro & $\ldots$ & Hipófise normal & Não ${ }^{\S}$ & Dç. de Cushing \\
\hline 18 & RMS & $\mathrm{F}$ & 24 & 12 & 28,0 & 19,5 & 16,5 & $\ldots$ & 894 & 349 & 56 & 4,2 & $\mathrm{NL}$ & Presente & Hipófise normal & $\operatorname{Sim}$ & Dç. de Cushing \\
\hline 19 & ZFS & $\mathrm{F}$ & 48 & 12 & 46,0 & 28,9 & 17,3 & 20,0 & 1742 & $\ldots$ & 328 & 4,1 & MACRO & $\ldots$ & Adenoma, ACTH + & Não & Dç. de Cushing \\
\hline 20 & MAMA & M & 15 & 48 & 30,0 & 22,6 & $\ldots$ & $\ldots$ & 770 & 367 & 147 & 4,0 & MACRO & - & Adenoma, ACTH + & Sim & Dç. de Cushing \\
\hline 21 & VBJ & $\mathrm{F}$ & 18 & 24 & 31,1 & 43,7 & 41,3 & $\ldots$ & 3794 & $\ldots$ & 464 & 2,3 & $\mathrm{NL}$ & $\ldots$ & Carcinóide tímico* & Sim & SEA \\
\hline 22 & $\mathrm{JCJ}$ & $M$ & 26 & 10 & 21,6 & 72,5 & 49,2 & & 8172 & 899 & 425 & 2,2 & Micro $^{*}$ & Ausente & Carcinóide pulmonar* & Sim & SEA \\
\hline
\end{tabular}

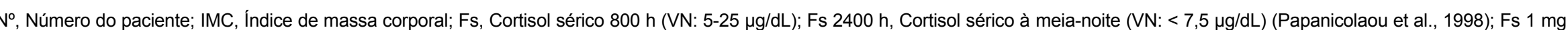
Cortisol sérico $800 \mathrm{~h}$ pós $1 \mathrm{mg}$ de dexametasona overnight (VN: < 1,8 $\mu \mathrm{g} / \mathrm{dL}$ ); Fu, Cortisol urinário de $24 \mathrm{~h}$ (VN: 30-300 $\mu \mathrm{g} / 24 \mathrm{~h}$, não extraído); F sal $2400 \mathrm{~h}$, Cortisol salivar a meia noite (VN: < 130 $\mathrm{ng} / \mathrm{dL})$; ACTH, hormônio adrenocorticotrófico plasmático (VN: < $60 \mathrm{pg} / \mathrm{mL}$ ); K, potássio; RM, Ressonância magnética; NL, normal; Cap Heter, Captação heterogêna do parênquima hipofisário após contraste gadolíneo; Micro, Microadenoma; MACRO, Macroadenoma; CBSSPI, Cateterismo bilateral e simultâneo dos seios petrosos inferiores; CEN:PER, gradiente centro-periferia; NR, Não realizada; AP + IH, Anátomo-patolológico e imunohistoquímica; *Imunohistoquímica positiva para ACTH; Rem, Remissão pós-operatória; SEA, Secreção Ectópica de ACTH; ${ }^{*}$ Incidentaloma de hipófise; 'Diagnóstico confirmado em cirurgia anterior com anátomo-patológico com adenoma hipofisário 
Tabela 10. Comparação das casuísticas dos indivíduos controles e dos pacientes com doença de Cushing

\begin{tabular}{|c|c|c|c|}
\hline & CONTROLES & DOENÇA DE CUSHING & $p$ \\
\hline $\mathbf{N}$ & 21 & 20 & NS \\
\hline $\begin{array}{l}\text { Idade* }^{*} \\
\text { (anos) }\end{array}$ & $33(16-54)$ & $32(15-54)$ & NS \\
\hline $\begin{array}{l}\text { Sexo } \\
(F / M)\end{array}$ & $18 \mathrm{~F} / 3 \mathrm{M}$ & $17 \mathrm{~F} / 3 \mathrm{M}$ & NS \\
\hline $\begin{array}{c}\text { IMC } \\
\left(\mathrm{kg} / \mathrm{m}^{2}\right)\end{array}$ & $23,7 \pm 3,9$ & $32,4 \pm 8,1$ & $<0,001$ \\
\hline
\end{tabular}


Cinco casos de DC foram excluídos do estudo molecular por terem apresentado histologia de hipófise normal (Tabela 9). Todos os pacientes foram submetidos à cirurgia hipofisária transesfenoidal pelo mesmo neurocirurgião, na Unidade de Neuroendocrinologia da Divisão de Neurocirurgia do HC-FMUSP.

Foram coletados também fragmentos de tecidos sem evidências de quaisquer patologias (oito hipófises, dois timos e um pulmão), provenientes de produtos de necropsias que foram usados como controles, cuja autorização foi concedida pelo Serviço de Verificação de Óbitos da Cidade de São Paulo (Anexo C).

2 Testes de Estímulo

\subsection{Teste da Desmopressina}

Os testes foram realizados em dias separados com intervalo de pelo menos $48 \mathrm{~h}$.

O teste da desmopressina foi realizado pela manhã, com o paciente em repouso, em posição supina e em jejum. Após 15 a 30 minutos da canulação de veia periférica, foi coletada amostra de sangue (tempo: - 30) e após outros 30 minutos, coletado sangue nos tempos 0 (basal), $15 \mathrm{~min}, 30 \mathrm{~min}, 45 \mathrm{~min}, 60$ min e 90 min, sendo que no tempo 0, foi infundido por via IV periférica 10 (dez) $\mu \mathrm{g}$ de desmopressina (DDAVP ${ }^{\circledR}$, Ferring Pharmaceuticals, Reino Unido). Foram dosados cortisol e ACTH em todos os tempos do teste. Foi definido como resposta positiva um incremento de $>20 \%$ de cortisol no pico de resposta em relação ao basal e incremento de $>35 \%$ de ACTH (Nieman et al., 1993). 


\subsection{Teste do hCRH}

Teste semelhante ao anterior. No tempo 0, infusão IV periférica de 100 (cem) $\mu \mathrm{g}$ de hCRH (Merck, Darmstadt, Alemanha). O critério de resposta definido por Newell-Price et al. em 2002 é o incremento de cortisol > 14\% e $>105 \%$ com o ACTH. É sabido que o hCRH possui estímulo menos potente e prolongado que o $\mathrm{CRH}$ ovino (oCRH), explicando o menor valor de corte para o cortisol. Em relação ao ACTH, Newell-Price et al. (2002) definiram o valor de corte tão alto para manter especificidade de 100\%, já que em sua casuística, alguns casos de SEA apresentaram respostas em ACTH muito intensas. Em nosso estudo, a resposta foi definida por um critério modificado, $>14 \%$ para o cortisol e $>50 \%$ para o $\mathrm{ACTH}$, principalmente para viabilizar a correlação clínico-molecular.

\subsection{Teste do GHRP-6}

Semelhante aos testes anteriores, com coletas e dosagens iguais, sendo acrescida à dosagem do $\mathrm{GH}$ em todos os tempos. Foi infundido no tempo basal, $1 \mu \mathrm{g}$ por kg/peso de GHRP-6 (Bachem, Torrence, Estados Unidos). O critério de resposta utilizado para o cortisol foi o mesmo da desmopressina, um incremento de $>20 \%$ em relação ao valor basal (Nieman et al. 1993). Para o ACTH, foi definido resposta um incremento de $>50 \%$ em relação ao basal, critério semelhante utilizado por alguns autores para o oCRH (Kaye e Krapo, 1990; Invitti et al., 1999; Giraldi et al., 2001). 


\subsection{Ensaios hormonais}

As dosagens hormonais foram realizadas no Laboratório de Hormônios (LIM-42) do Laboratório Central do HC-FMUSP.

O cortisol sérico foi mensurado por fluoroimunoensaio pelo Sistema AutoDelfia (Wallac Oy, Turku, Finlândia), com coeficientes de variação intra e interensaio de $<10 \%$ e $<12 \%$ respectivamente, com sensibilidade de $1,0 \mu \mathrm{g} / \mathrm{dL}$. O cortisol urinário foi mensurado pelo mesmo sistema usado para a mensuração do cortisol sérico, com coeficientes de variação intra e interensaio $<8 \%$, sendo o método sem extração (cortisol urinário total), com sensibilidade de 1,0 $\mu \mathrm{g} / \mathrm{dL}$.

$\mathrm{O}$ ACTH foi mensurado por método imunoradiométrico (CIS bio International, Gif/Yvette, França), com coeficientes de variação intra e interensaios de $<14 \%$ e $<20 \%$ respectivamente, com sensibilidade de $16,2 \mathrm{pg} / \mathrm{mL}$.

A determinação do $\mathrm{GH}$ foi realizada com método imunofluorométrico, Sistema AutoDelfia (Wallac Oy, Turku, Finlândia), com coeficientes de variação intra e interensaio $<7 \%$, com sensibilidade de $0,1 \mathrm{ng} / \mathrm{mL}$.

Finalmente, o IGF1 foi mensurado por método imunoradiométrico com extração (DSL-5600, Diagnostic Systems Laboratories Inc., Webster, Texas, Estados Unidos), com coeficientes de variação intra e interensaio $<17 \%$, com sensibilidade de $25,0 \mathrm{ng} / \mathrm{mL}$.

\section{Extração de RNA Total}

Uma pequena amostra de tecido (tumoral e normal) foi fragmentado em pulverizador de tecido (Mikro-Dismembrator U - B. Braun, Melsungen, Alemanha). Durante todo processo o tecido foi mantido congelado em nitrogênio líquido, prevenindo a atividade de enzimas que pudessem degradar o RNA. O pulverizado 
foi homogeneizado em 1,0 mL do reagente TRIzol $^{\circledR}$ (Invitrogen, Life Technologies) e incubado durante $5 \mathrm{~min}$ a temperatura ambiente (TA). Foi adicionado $0,2 \mathrm{~mL}$ de clorofórmio a solução e agitado vigorosamente durante $15 \mathrm{~s}$, com repouso de 3 min a TA. Em seguida, a mistura foi submetida à centrifugação durante 15 min a 14.000 rotações por minuto (rpm) a $4{ }^{\circ} \mathrm{C}$ em centrífuga refrigerada Eppendorf 5804R (Eppendorf AG, Hamburg, Alemanha), com a separação de três fases. O RNA total presente na fase superior foi transferido para um outro tubo e submetido à precipitação com $0,5 \mathrm{~mL}$ de álcool isopropílico com $10 \mathrm{~min}$ de incubação em gelo e posterior centrifugação a $14.000 \mathrm{rpm}$ por $10 \mathrm{~min}$ a $4^{\circ} \mathrm{C}$. O botão de RNA resultante foi lavado em $0,5 \mathrm{~mL}$ de etanol $75 \%$ com centrifugação a $10.000 \mathrm{rpm}$ por $5 \mathrm{~min}$ a $4^{\circ} \mathrm{C}$ e foi ressuspenso em $50 \mu \mathrm{L}$ de água milli-Q estéril tratada com dietipirocarbonato $0,01 \%$.

A concentração de RNA total foi determinada por espectrofotometria (GeneQuant II RNA/DNA Calculator - GE Healthcare, Chalfont St. Giles, Reino Unido) no comprimentos de onda $260 \mathrm{~nm}$. Foram utilizadas amostras de RNA com relação 260/280 nm > 1,8. Pequena quantidade desse RNA (500 ng) foi submetido à eletroforese em gel de agarose a 1,2\% para verificar a integridade do material pela presença das bandas de RNA ribossomais $28 \mathrm{~S}$ e $18 \mathrm{~S}$, em brometo de etídio ( $\mathrm{EtBr}$ ) 3,0 $\mu \mathrm{g} / \mathrm{mL}$ e visualizado em transiluminador de luz ultravioleta (UV) (Figura $2 \mathrm{~A}$ ). O RNA ficou armazenado $\mathrm{a}-80^{\circ} \mathrm{C}$ até posterior utilização.

\section{Síntese do cDNA e RT-PCR Semi-quantitativa do Gene BCR}

A síntese de DNA complementar (cDNA) foi realizada a partir de 1,0 $\mu \mathrm{g}$ de RNA total pela utilização da transcripatse reversa (SuperScript ${ }^{T M}$ /I Reverse Transcriptase Invitrogen, Life Technologies) com hexanucleotídeos randômicos (Random Primers - 
Invitrogen, Life Technologies), de acordo com o protocolo do fabricante. O cDNA recém-sintetizado foi diluído em $80 \mu$ de água milli-Q estéril e armazenado $\mathrm{a}-20^{\circ} \mathrm{C}$.

A qualidade dessas amostras foi verificada pela amplificação em reação em cadeia da polimerase pela transcripatse reversa (RT-PCR) semi-quantitativa do gene controle interno BCR (break poin cluster region) que, segundo observações de Watzinger e Lion (1998), esse gene constitutivo é o mais indicado para avaliar a qualidade do cDNA quando comparado com os gene Abelson, beta-2 microglobulina e porfobilinogênio desaminase, pois enquanto esses estavam expressos em cDNAs de baixa qualidade, o sinal de amplificação do gene BCR desaparecia.

A reação de PCR para a amplificação do gene $B C R$, previamente padronizada, foi realizada com 2,0 $\mu \mathrm{L}$ de cDNA, tampão da enzima $1 \times[$ Tris- $\mathrm{HCl} 10$ $\mathrm{mM}(\mathrm{pH} 9,0), \mathrm{KCl} 50 \mathrm{mM}, \mathrm{MgCl}_{2}$ 1,5 mM], 0,2 $\mu \mathrm{M}$ dNTP mix, 0,4 $\mu \mathrm{M}$ iniciador BCR sense e antisense, e 1,0 U Taq DNA polimerase (GE Healthcare Bio-Science). Essa reação foi incubada em termociclador Master Cycler (Eppendorf AG) inicialmente a $95^{\circ} \mathrm{C}$ por $5 \mathrm{~min}$, seguido por 35 ciclos a $95^{\circ} \mathrm{C}$ por $30 \mathrm{~s}, 55^{\circ} \mathrm{C}$ por 1 min e $72{ }^{\circ} \mathrm{C}$ por $1 \mathrm{~min}$ e $30 \mathrm{~s}$, com extensão final a $72^{\circ} \mathrm{C}$ por $10 \mathrm{~min}$. O produto de PCR resultante foi analisado em gel de agarose 2,0\% com EtBr em transiluminador de luz UV para visualização das bandas com o correspondente número de pares de base $(\mathrm{pb})$ (Figura 2 B). Somente as amostras que apresentaram amplificação do gene BCR foram consideradas nesse trabalho.

Os iniciadores do gene BCR foram desenhados com o auxílio do programa Primer3 (frodo.wi.mit.edu/cgi-bin/primer3/primer3_www.cgi - Whitehead Institute for Biomedical Research, Cambridge, Reino Unido): BCR [377 pb] (NM_004327) sense 5'-GAG AAG AGG GCG AAC AAG-3' e antisense 5'-CTC TGC TTA AAT CCA GTG GC-3'. O par de iniciadores foi construído em exons diferentes, a fim de evitar amplificação de possível DNA genômico presente nas amostras de RNA. 
A
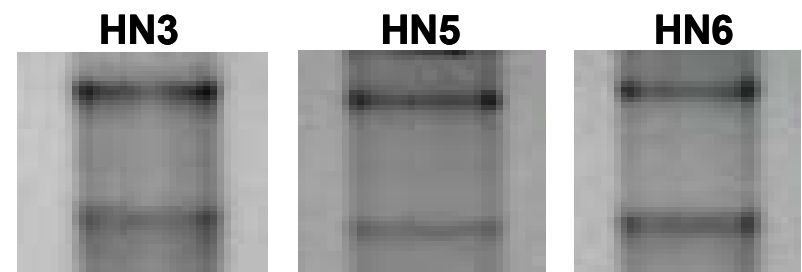

HN7

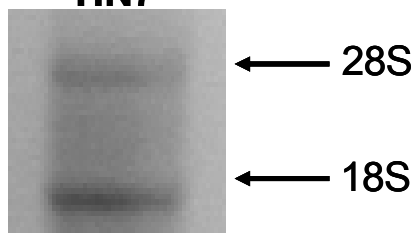

Hipófises normais

ALSJ

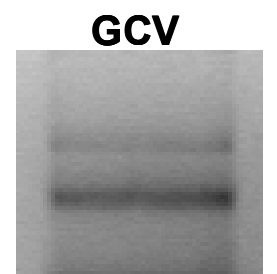

$\operatorname{scc}$
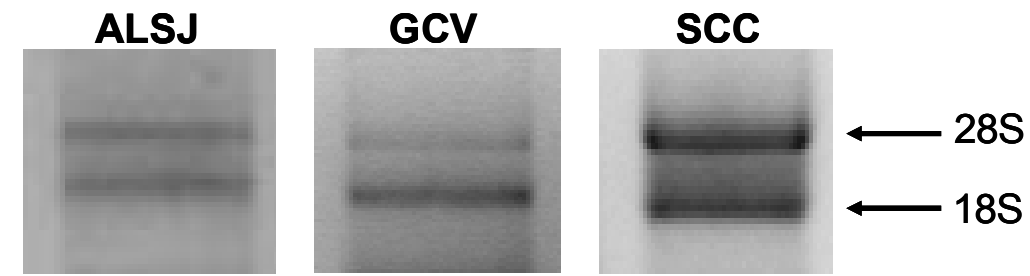

Tumores corticotróficos

B

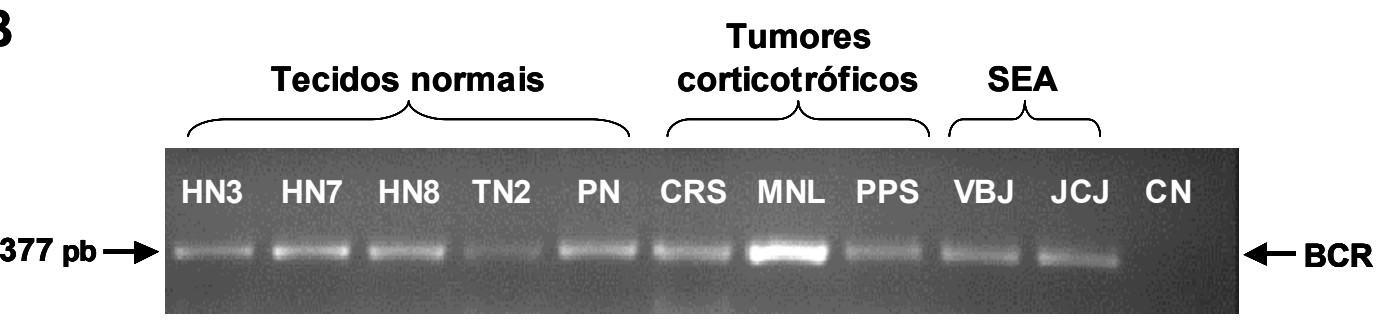

Figura 2. A) Gel ilustrativo da integridade do RNA total de 4 amostras de hipófise normal (HN3, HN5, HN6 e HN7) e 3 amostras de tumor corticotrófico (ALSJ, GCV e SCC), em gel de agarose 1,2\% com EtBr. B) Gel ilustrativo do produto de RT-PCR semi-quantitativa do gene BCR em 5 amostras de tecidos normais (HN3, HN7, HN8, TN2 e PN), 4 tumores corticotróficos (CRS, MNL e PPS) e 2 tumores ectópicos produtores de ACTH (VBJ e JCJ), em gel de agarose 2,0\% com EtBr. Tu, tumor; SEA, Secreção Ectópica de $\mathrm{ACTH}$; HN, hipófise normal; TN, timo normal; PN, pulmão normal; $\mathrm{CN}$, controle negativo; pb, pares de base 


\section{PCR Semi-quantitativa dos Genes PIT1 e BCR}

Com o intuito de afastar possível contaminação de tecido hipofisário normal nos tumores corticotróficos, foi realizada RT-PCR semiquantitativa para a coamplificação do gene PIT1 (Korbonits et al., 2001), gene normalmente expresso no tecido hipofisário normal, e do gene controle BCR em todas as amostras de hipófise normal e tumores corticotróficos.

A reação de co-amplificação foi padronizada quanto à temperatura ideal de annealing, para garantir fragmentos amplificados de alta qualidade e impedir a amplificação de produtos inespecíficos. Foi padronizado também o número ideal de ciclos nessa co-amplificação para que a reação termine na fase exponencial de amplificação, longe do ponto de saturação. O par de iniciadores PIT1 foi constuído em exons diferentes com o programa Primer3: PIT1 [194 pb] (NM_000306) sense 5'-GTG GGA GCA AAT GAA AGG AA-3' e antisense 5'-ACC CGT TTT TCT CTC TGC CT-3'. A reação foi realizada com $3,5 \mu \mathrm{L}$ de cDNA, tampão da enzima $1 \mathrm{X}$ [Tris- $\mathrm{HCl} 20 \mathrm{mM}(\mathrm{pH} 8,4), \mathrm{KCl} 50 \mathrm{mM}$ ], tampão enhancer $1 \mathrm{X}, 2,0 \mathrm{mM} \mathrm{MgCl}$, $0,2 \mu \mathrm{M}$ dNTP mix, 0,4 $\mu \mathrm{M}$ iniciador BCR sense e antisense, 1,2 $\mu \mathrm{M}$ iniciador PIT1 sense e antisense, $4 \mathrm{M}$ betaína e 1,0 U Taq Platinum DNA polimerase (Invitrogen, Life Technologies). A reação ocorreu no termociclador Master Cycler (Eppendorf $A G$ ) a $95^{\circ} \mathrm{C}$ por 5 min, seguido de 35 ciclos a $95^{\circ} \mathrm{C}$ por $30 \mathrm{~s}, 57^{\circ} \mathrm{C}$ por $1 \mathrm{~min}$ e $72^{\circ} \mathrm{C}$ por $1 \mathrm{~min}$ e $30 \mathrm{~s}$, com $10 \mathrm{~min}$ de extensão final a $72^{\circ} \mathrm{C}$. O produto da PCR contendo os fragmentos amplificados dos genes foram fracionados em gel de agarose 2,0\% com EtBr e visualizados em luz UV. A partir dessa reação, foi excluída uma amostra de hipófise "normal" onde não foi observada a amplificação do gene PIT1, bem como, aqueles tumores corticotróficos PIT1 positivos (Figura 3). A Figura 4 apresenta um fluxograma da inclusão final das amostras para o estudo molecular dos genes de interesse (AVPR1B, GHSR-1a e CRHR1). 

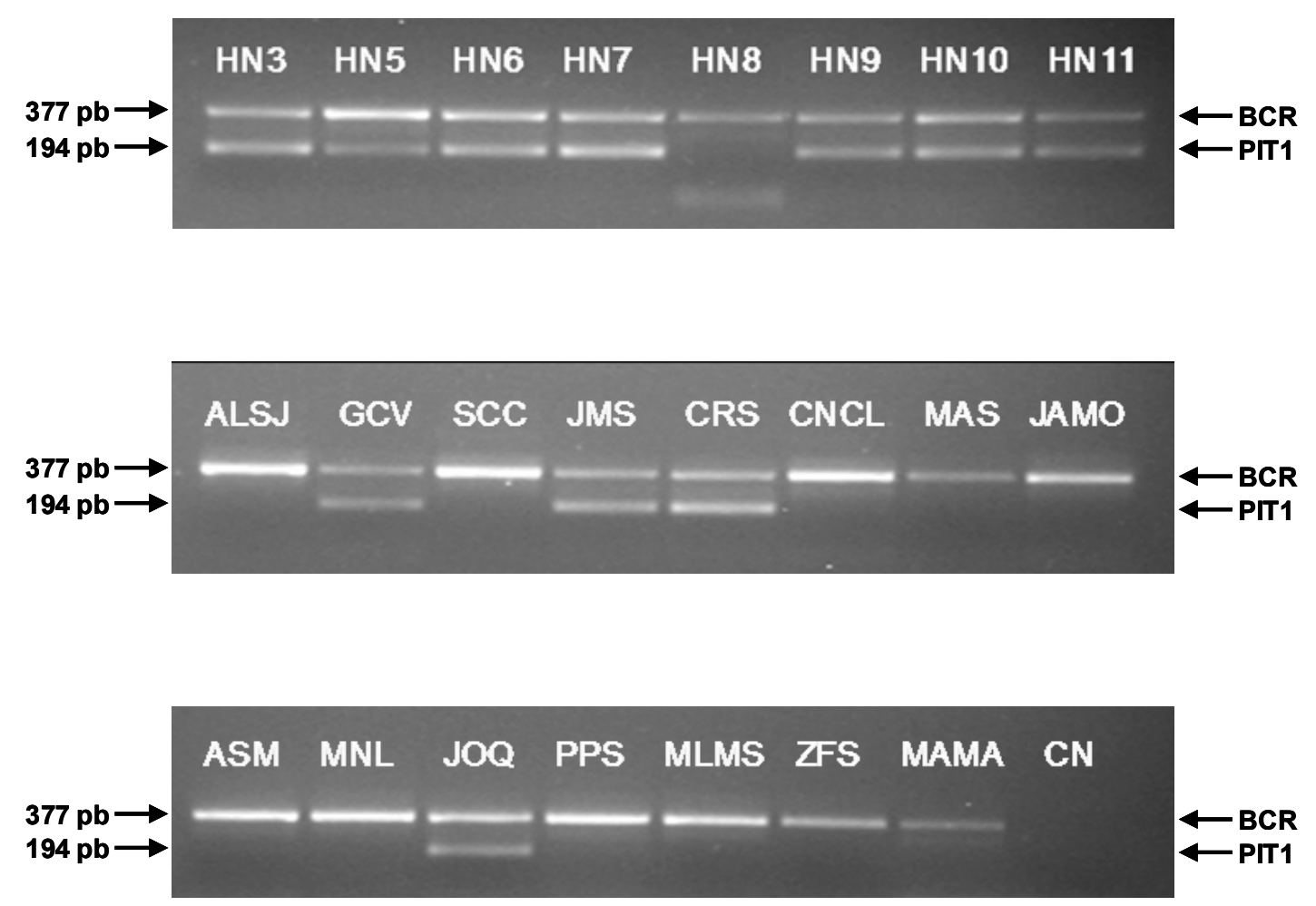

Figura 3. Co-amplifcação dos genes BCR e PIT1 por RT-PCR semi-quantitativa em amostras de hipófise normal e tecidos tumorais corticotróficos, visualizados em gel de agarose 2,0\% com EtBr. HN, hipófise normal; $\mathrm{CN}$, controle negativo; pb, pares de base 


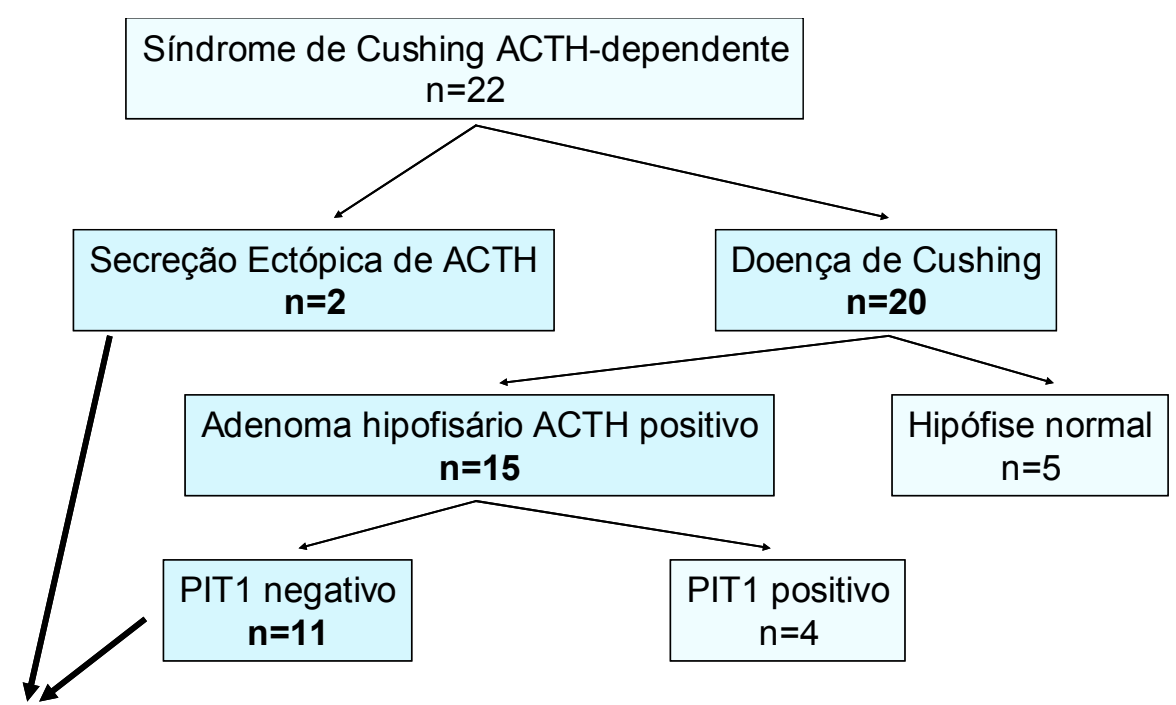

Estudo molecular dos genes de interesse

$\mathbf{n = 1 3}\{$ 11: Doença de Cushing

2: Secreção Ectópica de ACTH

Figura 4. Fluxograma da inclusão final das amostras dos pacientes com síndrome de Cushing ACTH-dependente para o estudo molecular dos genes de interesse (AVPR1B, GHSR-1a e CRHR1) 


\section{PCR Quantitativa em Tempo Real (qPCR) dos Genes em Estudo}

A reação de $P C R$ quantitativa em tempo real (qPCR) é uma técnica rápida e acurada que permite a determinação direta dos produtos amplificados durante a fase exponencial da reação. Esse fragmento amplificado é marcado pelo reagente SYBR Green, que emite fluorescência ao se ligar ao DNA dupla fita recém-sintetizado, e pode ser lido durante a reação por um detector em tempo real.

Neste trabalho, foi utilizado o método de quantificação relativa, uma vez que não é necessário saber o número absoluto de cópias de cada gene e sim a diferença de expressão entre os tipos de tecidos estudados (Giulietti et al., 2001). Esse método envolve a quantificação do gene de interesse em relação a um gene controle, nesse caso o gliceraldeído-3-fostato desidrogenase (GAPDH).

As reações de qPCR foram realizadas no aparelho Rotor-Gene RG-3000 (Corbett Research, Sidney, Austrália) com o conjunto de reagentes Quantitect ${ }^{T M}$ SYBR Green RT-PCR for quantitative, real time, one step RT-PCR (Qiagen GmbH, Hilden, Alemanha) que realiza a transcrição reversa do RNA em cDNA e, em seguida, a reação de amplificação do gene escolhido.

Os iniciadores específicos usados na reação foram cuidadosamente desenhados para evitar a amplificação de produtos inespecíficos e formação de dímeros, uma vez que o SYBR Green se liga a qualquer DNA dupla fita. Para tanto, foi utilizado o programa Primer3 para desenhar os seguintes pares de iniciadores em exons diferentes: GHSR-1a [192 pb] (NM_198407) sense 5'-ACC AGA ACC ACA AGC AAA CC-3' e antisense 5'-TGA TGG CAG CAC TGA GGT AG-3'; AVPR1B [221 pb] (NM_000707) sense 5'-CAG CAG CAT CAA CAC CAT CT-3' e antisense 5'-CCA TGT AGA TCC AGG GGT TG-3'; CRHR1 [182 pb] (NM_004382) 
sense 5'-CTG CCC TGC CTT TTT CTA TG-3' e antisense 5'-AGT GGC CCA GGT AGT TGA TG-3'; GAPDH [226 pb] (NM_002046) sense 5'-GAA GGT GAA GGT CGG AGT-3' e antisense 5'-GAA GAT GGT GAT GGG ATT TC-3'.

Cada reação foi constituída de 100 ng de RNA, QuantiTect Sybr Green Master Mix 1 X (tampão, dNTP mix, SYBR Green I e 2,5 mM $\mathrm{MgCl}_{2}$ ), 0,15 $\mu \mathrm{L}$ HotStarTaq DNA polimerase, 0,2 $\mu \mathrm{M}$ iniciador sense e antisense. Para a síntese de cDNA a reação foi incubada a $50{ }^{\circ} \mathrm{C}$ por $30 \mathrm{~min}$ e a $95{ }^{\circ} \mathrm{C} 15 \mathrm{~min}$. Em seguida, a reação de amplificação ocorreu em 35 ciclos sob as seguintes condições: $94{ }^{\circ} \mathrm{C}$ por $20 \mathrm{~s}, 53^{\circ} \mathrm{C}$ (AVPR1B) ou $58^{\circ} \mathrm{C}$ (GHSR-1a e CRHR1) por $30 \mathrm{~s}$, e $72^{\circ} \mathrm{C}$ por $30 \mathrm{~s}$. Sempre que uma reação para determinado gene alvo era realizada, o mesmo ocorria para o GAPDH nas mesmas condições, em paralelo. Todas as amostras foram analisadas em duplicata, tanto para o gene alvo quanto para o gene controle.

As intensidades de fluorescência foram medidas ao final de cada ciclo de extensão e estes valores foram plotados em uma curva onde é possível vizualizar a amplificação exponencial dos produtos de PCR. Após a síntese do fragmento, o aparelho promove desnaturação lenta e contínua entre $72{ }^{\circ} \mathrm{C}$ e $99{ }^{\circ} \mathrm{C}$ a $0,2{ }^{\circ} \mathrm{C} / \mathrm{s}$, gerando uma curva de dissociação, onde é possível verificar a presença de produtos amplificados inespecíficos e dímeros de iniciadores. A curva de dissociação gera um pico em temperatura específica referente a cada fragmento amplificado: GAPDH $\left[82,3^{\circ} \mathrm{C}\right]$ (Figura $5 \mathrm{~A}$ ), GHSR1a $\left[83,1^{\circ} \mathrm{C}\right]$ (Figura $5 \mathrm{~B}$ ), AVPR1B $\left[84,2^{\circ} \mathrm{C}\right]$ (Figura $5 \mathrm{C}$ ), CRHR1 [84, $\left.8^{\circ} \mathrm{C}\right]$ (Figura 5 D). Outra forma de analisar a identidade das reações é pela eletroforese em gel de agarose para visualizar o produto da qPCR em tamanho apropriado (Figura 6). 
A quantificação relativa foi obtida pelos valores de limiar do ciclo (CT threshold cycle), no qual o aumento no sinal associado à fase exponencial de amplificação do produto da PCR começa a ser detectada (Ginzinger, 2002). O CT é um momento da reação que pode ocorrer em qualquer intervalo entre um ciclo e outro da PCR.

O modelo matemático adotado para calcular a intensidade de expressão relativa depende da eficiência de amplificação dos genes alvo e controle. Assim, foram realizadas reações de qPCR para todos os gene, nas condições padronizadas acima, com RNA de hipófise normal em diluições seriadas: 200 ng, 100 ng, 50 ng, 25 ng, 12,5 ng, 6,3 ng, 3,1 ng e 1,2 ng. Para o cálculo da eficiência de amplificação foi aplicada a fórmula: $E=10^{(-1 / \text { slope) }}$ (Rasmussen, 2001).

A comparação da eficiência entre os genes foi calculada pela subtração entre os valores do CT do gene alvo e GAPDH, e a diferença foi plotada em um gráfico contra o logaritmo da quantidade da RNA inicialmente colocada. Se a inclinação da reta ou slope for menor que 0,1 (positivo ou negativo), a eficiência de amplificação entre os genes é considerada equivalente (Figuras 7 A e B). A análise de eficiência dos genes $\mathrm{CRHRH}$ e AVPR1B foi muito semelhante à do GAPDH, assim, o cálculo comparativo $2^{-\Delta \Delta C T}$ pode ser utilizado (Livak et al., 2001). O método $2^{-\Delta \Delta C T}$ utiliza um RNA referência para comparação com as amostras em estudo, nesse caso o tecido referência escolhido foi uma hipófise normal. Inicialmente, o $\Delta \mathrm{CT}$ de cada amostra foi calculado pela subtração entre o valor de CT do gene alvo e o valor de CT do gene GAPDH. O mesmo cálculo foi realizado para encontrar o $\Delta \mathrm{CT}$ da amostra referência. Em seguida, o $\Delta \Delta \mathrm{CT}$ é obtido pela subtração do $\Delta \mathrm{CT}$ amostra e $\Delta \mathrm{CT}$ referência e, assim, a fórmula $2^{-\Delta \Delta C T}$ é aplicada. 
Para o gene GHSR-1a, onde sua eficiência de amplificação com o GAPDH não foi equivalente (slope $>0,1$ - Figura $7 \mathrm{C}$ ), foi utilizado o modelo matemático para o cálculo da quantificação relativa descrito por Pfaffl (2001), baseado na seguinte fórmula:

$$
R=\frac{\left(E_{\text {alvo }}\right)^{\left.\Delta C P_{\text {avo }} \text { (referência - amostra }\right)}}{\left(E_{\text {GAPDH }}\right)^{\Delta C P_{\text {GAPDH }}(\text { referência - amostra })}}
$$

O valor do ponto de cruzamento (CP - crossing point) nesse modelo matemático é equivalente ao CT, representando a fluorescência do limiar da amostra na fase exponencial de amplificação. Nessa análise também é considerado um RNA referência (hipófise normal). Sendo que, a razão (R) descreve a expressão relativa entre o gene alvo e o gene controle (GAPDH). A eficiência de amplificação (E) da reação, tanto do gene alvo como do GAPDH é dada pela curva com diluições seriadas, conforme descrito anteriormente. $\mathrm{O} \triangle \mathrm{CP}$ do gene alvo e controle é a diferença entre o valor de CP do RNA referência e o CP da amostra, de ambos os genes. Em seguida, é calculada a razão entre o $\triangle \mathrm{CP}$ gene alvo e $\triangle \mathrm{CP}$ GAPDH. 
A

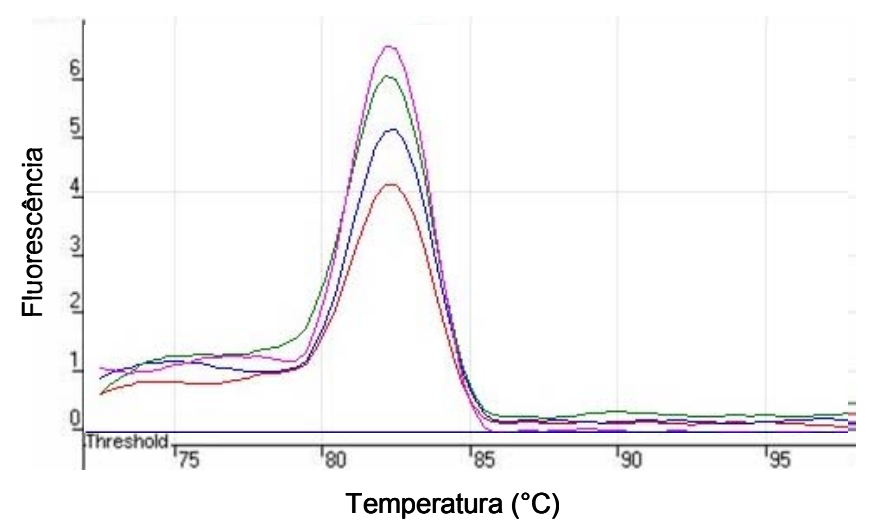

B

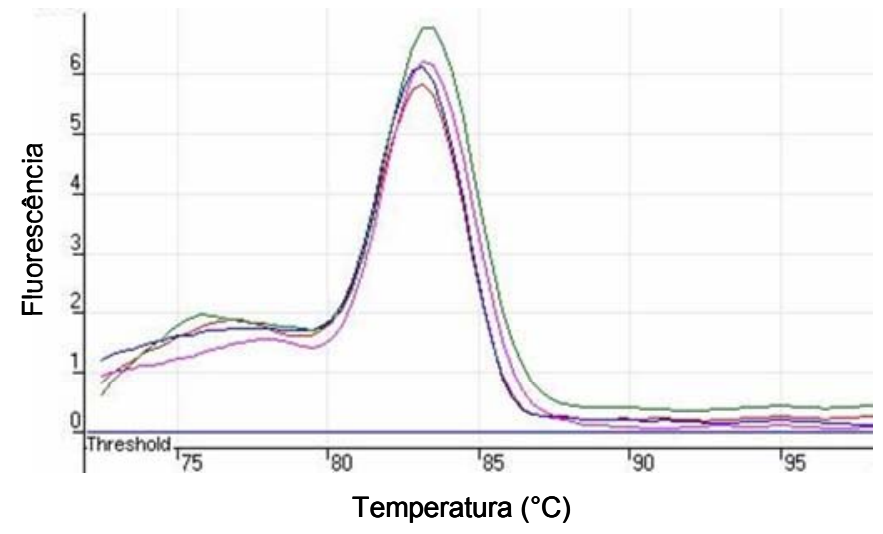

C

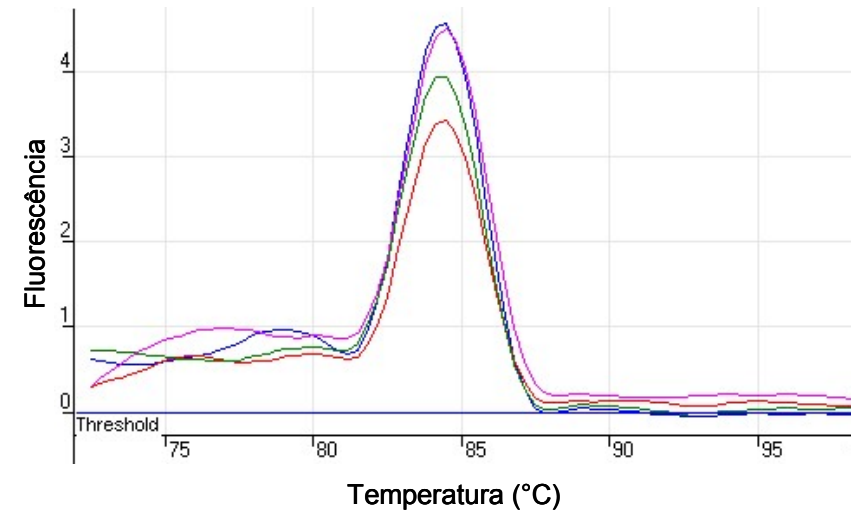

D

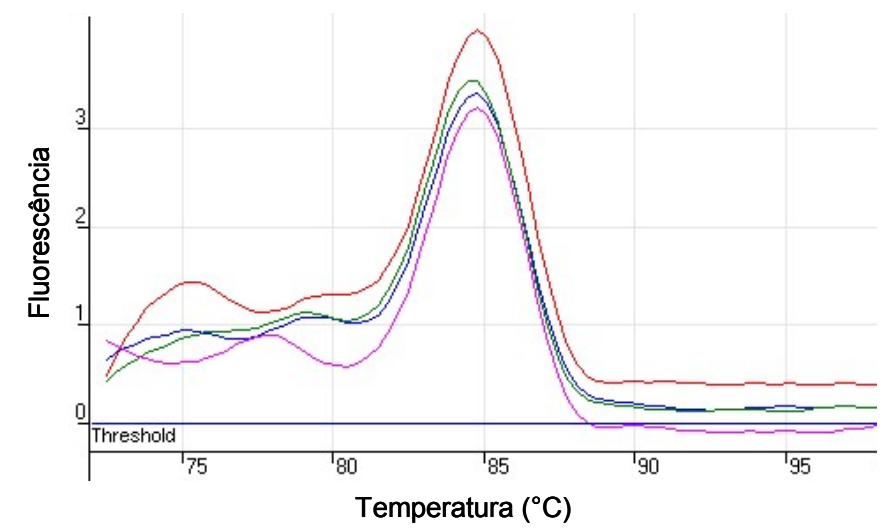

Figura 5. Curvas de dissociação dos genes GAPDH (A), GHSR-1a (B), AVPR1B (C) e CRHR1 (D) 


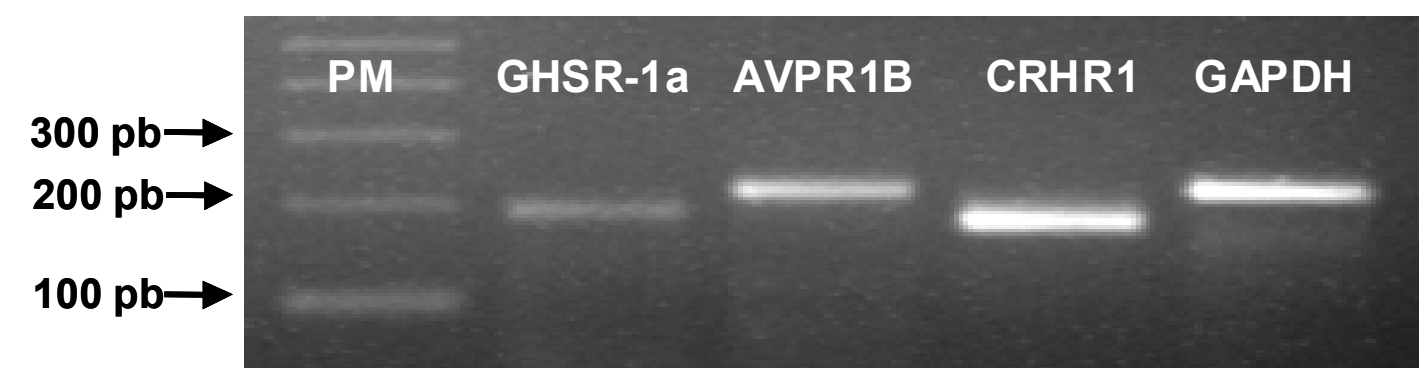

Figura 6. Representação dos genes alvo (GHSR-1a $=192 \mathrm{pb}$, AVPR1B $=221 \mathrm{pb}$ e CRHR1=182 pb) e do gene controle (GAPDH = 226) em gel de agarose $2,0 \%$ com $\mathrm{EtBr}$ para verificar a amplificação de produtos inespecíficos. PM, peso molecular, pb, pares de base 
A

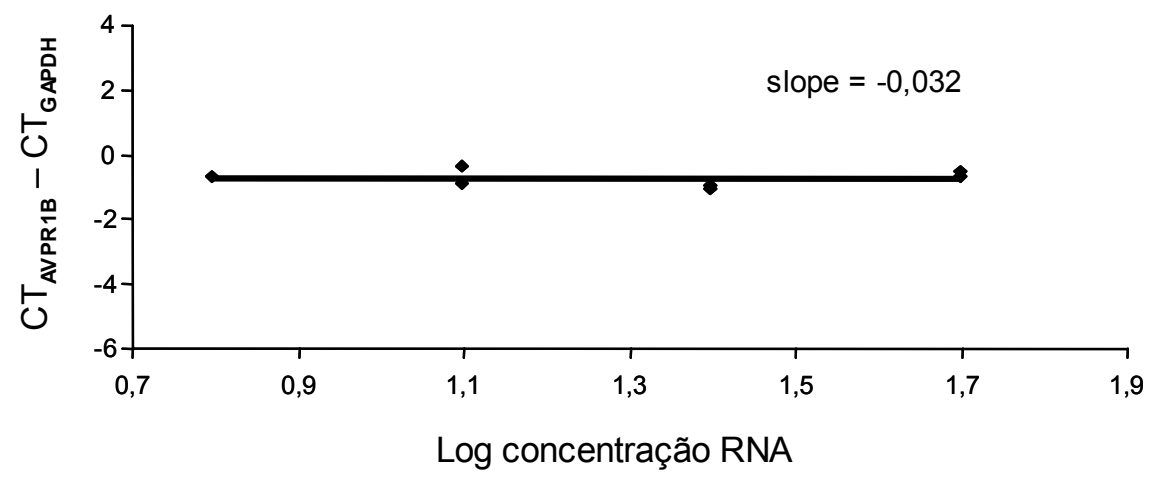

B

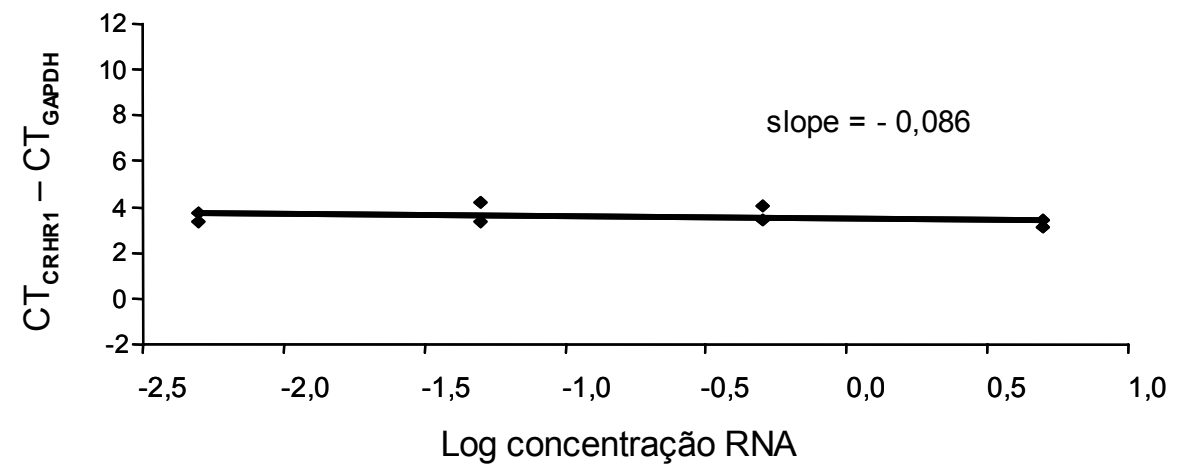

C

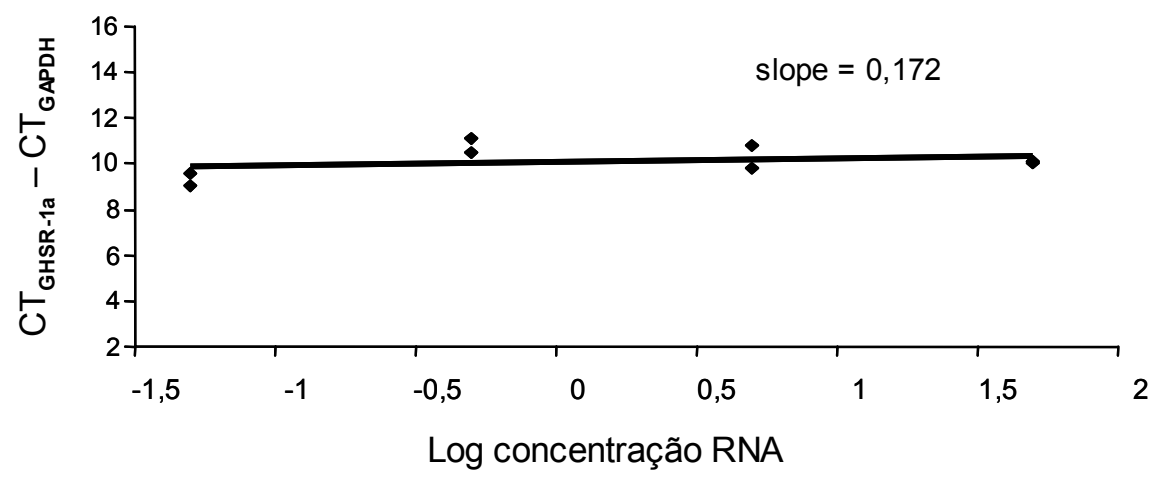

Figura 7. Determinação da eficiência de amplificação (slope) dos genes AVPR1B (A), CRHR1 (B) e GHSR-1a (C), em relação ao gene controle GAPDH 


\section{Análise Estatística}

As análises estatísticas foram realizadas no programa JMP Starter 5.1.1. (SAS Institute Inc., Heidelberg, Alemanha).

$\mathrm{Na}$ comparação dos dados clínicos e laboratoriais das casuísticas dos indivíduos controles e dos pacientes portadores da SC (Tabela 11) foi utilizado o teste de Wilcoxon.

Para as análises dos resultados de estímulo (pico vs. basal) de $\mathrm{ACTH}$, cortisol e GH no teste do GHRP-6 nos indivíduos controles e pacientes portadores da DC, foi utilizado o teste de Wilcoxon, assim como para os testes da desmopressina e hCRH.

Para localizar as diferenças existentes entre os indivíduos controles e pacientes com SC em relação às médias de ACTH, cortisol e GH no teste do GHRP-6, após análise de variância, foi adotado o método de comparações múltiplas de Bonferroni.

Na comparação dos resultados de expressão do RNAm dos genes GHSR1a, AVPR1B e CRHR1 nas amostras tumorais e dos tecidos normais, foram utilizados o teste da mediana. O teste de Kruskal-Wallis foi usado na análise dos resultados de expressão gênica quando comparado mais de 2 grupos. Para visualizar a distribuição das intensidades de expressão, foram utilizados diagramas de caixa (Box-Plot). A linha horizontal no meio da caixa representa a mediana; a parte inferior e superior da caixa indicam os percentis 25 e 75 ; e as barras externas representam os valores mais extremos.

Por último, foi utilizado o teste de Spearman para correlacionar os resultados de expressão dos genes GHSR-1a, AVPR1B e CRHR1 entre si.

Foi definida a significância estatística quando o valor do $p$ foi $<0,05$. Os dados são apresentados em média $\pm \mathrm{DP}$, exceto para idade dos pacientes e dos indivíduos controles, onde os dados são apresentados em mediana e variação. 


\section{RESULTADOS}

\section{Teste do GHRP-6 no Grupo Controle}

Nos 21 indivíduos controles, pareados com os pacientes com DC, observou-se um estímulo (basal vs. pico) significativo do cortisol com o GHRP-6 $(1 \mu \mathrm{g} / \mathrm{kg})(13,1 \pm 6,3$ para $17,7 \pm 5,7 \mu \mathrm{g} / \mathrm{dL}, p=0,003)$, tendo um incremento médio de 50,9 \pm 53,9\% em relação ao valor basal (tempo 0) (Tabela 11).

Com relação ao ACTH, também foi observado estímulo significativo após a infusão do GHRP-6 $(22,6 \pm 19,6$ para $43,3 \pm 29,4 \mathrm{pg} / \mathrm{mL}, p=0,001)$, sendo o incremento médio de $135 \pm 179 \%$ em relação ao tempo 0 .

Conforme esperado pelo poder secretagogo do GHRP-6, houve intenso estímulo da secreção de $\mathrm{GH}(1,4 \pm 1,9$ para $21,7 \pm 15,9 \mathrm{ng} / \mathrm{mL}, p<0,001)$. As concentrações séricas de IGF1 (basal) dos indivíduos controles foram 280,1 \pm $162,5 \mathrm{ng} / \mathrm{mL}$ 
Tabela 11. Comparação dos valores de cortisol, ACTH, GH e IGF1 basais e pós estímulo com GHRP-6 nos indivíduos controles e nos pacientes com doença de Cushing

\begin{tabular}{|c|c|c|c|}
\hline & $\begin{array}{l}\text { CONTROLES } \\
(N=21)\end{array}$ & $\begin{array}{l}\text { DOENÇA DE CUSHING } \\
\qquad(\mathrm{N}=20)\end{array}$ & $p$ \\
\hline $\begin{array}{l}\text { Cortisol basal } \\
\qquad(\mu \mathrm{g} / \mathrm{dL})\end{array}$ & $13,1 \pm 6,3$ & $19,8 \pm 5,1$ & $<0,001$ \\
\hline $\begin{array}{l}\text { Cortisol pico } \\
\qquad(\mu \mathrm{g} / \mathrm{dL})\end{array}$ & $17,7 \pm 5,7$ & $29,8 \pm 9,7$ & $<0,001$ \\
\hline $\begin{array}{c}\text { Incremento } \\
\% \\
\end{array}$ & $50,9 \pm 53,9$ & $58,8 \pm 48,8$ & NS \\
\hline $\begin{array}{c}\text { ACTH basal } \\
(\mathrm{pg} / \mathrm{mL})\end{array}$ & $22,6 \pm 19,6$ & $93,5 \pm 95,1$ & $<0,001$ \\
\hline $\begin{array}{c}\text { ACTH pico } \\
(\mathrm{pg} / \mathrm{mL})\end{array}$ & $43,3 \pm 29,4$ & $273 \pm 232,9$ & $<0,001$ \\
\hline $\begin{array}{c}\text { Incremento } \\
\% \\
\end{array}$ & $135 \pm 179$ & $274,8 \pm 289$ & NS \\
\hline $\begin{array}{c}\text { GH basal } \\
(\mathrm{ng} / \mathrm{mL})\end{array}$ & $1,4 \pm 1,9$ & $0,3 \pm 0,4^{*}$ & 0,026 \\
\hline $\begin{array}{c}\text { GH pico } \\
(\mathrm{ng} / \mathrm{mL}) \\
\end{array}$ & $21,7 \pm 15,9$ & $7,2 \pm 10,9^{*}$ & $<0,001$ \\
\hline $\begin{array}{c}\text { IGF1 } \\
\text { (ng/mL) }\end{array}$ & $280,1 \pm 162,5$ & $319,2 \pm 154,1^{*}$ & NS \\
\hline
\end{tabular}

Valores em média $\pm \mathrm{DP} ; \mathrm{N}$, Número; NS, não significante; *Todos os pacientes com SC ACTH-dependente $(n=22)$ 


\section{Testes nos Pacientes com Síndrome de Cushing}

\subsection{Teste do GHRP-6}

Com relação ao cortisol, nos pacientes com DC, houve aumento significativo dos valores basal vs. pico após a infusão do GHRP-6 (1 $\mu \mathrm{g} / \mathrm{kg})$ $(19,8 \pm 5,1$ para $29,8 \pm 9,7 \mu \mathrm{g} / \mathrm{dL}, p<0,001)$, tendo um incremento médio de $58,8 \pm 48,8 \%$ em relação ao valor basal (Tabela 11). O incremento de cortisol (valores absolutos) foi significativamente maior que nos indivíduos controles ( $p=0,035$ no tempo -30 e $p<0,001$ nos demais tempos) (Figura 8 A), embora percentualmente o incremento tenha sido semelhante.

Analisando individualmente os pacientes com DC, 14/20 (70\%) pacientes responderam ao teste com aumento de cortisol (critério $>20 \%$ ). Nos dois casos de DC portadores de macroadenomas, um respondeu ao teste $(19,9$ para $33,1 \mu \mathrm{g} / \mathrm{dL}$, $66,3 \%$ ) e no outro caso, cujo tumor foi o maior de todos com invasão supra e paraselar, não houve resposta significativa $(25,9$ para $28 \mu \mathrm{g} / \mathrm{dL}, 8,1 \%)$. Nos pacientes com SEA, não houve resposta importante de cortisol $(36,3$ para 38,5 $\mu \mathrm{g} / \mathrm{dL}, 6 \%$; e 61,4 para $68,3 \mu \mathrm{g} / \mathrm{dL}, 11,2 \%$ ), embora nesse último paciente, se utilizado o valor basal como a média dos tempos -30 e $0(55,3 \mu \mathrm{g} / \mathrm{dL})$, ocorreu um estímulo de $23,5 \%$ (Tabela 12).

Em relação ao ACTH, também houve aumento significativo após o GHRP6 nos pacientes com DC $(93,5 \pm 95,1$ para $273 \pm 232,9 \mathrm{pg} / \mathrm{mL}, p<0,001)$, com um incremento médio de $274,8 \pm 289 \%$ em relação ao valor basal (Tabela 11 ). O incremento absoluto de $\mathrm{ACTH}$ foi significativamente maior que nos indivíduos controles ( $p<0,001$ em todos os tempos) (Figura 8 B), embora percentualmente, tenha sido semelhante. 
Individualmente, $14 / 20(70 \%)$ dos pacientes com DC responderam ao teste com aumento de ACTH (critério > 50\%). Nos dois casos de macroadenomas, um deles respondeu ao teste brilhantemente (55 para $399 \mathrm{pg} / \mathrm{mL}, 625 \%$ ) tendo respondido também em cortisol, e no outro caso com volumoso tumor hipofisário, não houve resposta significativa (257 para 330 pg/mL, 28,4\%). Nos pacientes com SEA, houve resposta importante de ACTH em um dos pacientes (883 para 1545 $\mathrm{pg} / \mathrm{mL}, 75 \%$ ), e ausência de resposta no outro caso (433 para $371 \mathrm{pg} / \mathrm{mL}$ ) (Tabela 12). Apesar das respostas significativas de cortisol e ACTH terem ocorrido em $70 \%(14 / 20)$ dos pacientes com DC, somente $13 / 20$ pacientes $(65 \%)$ apresentaram ambas as respostas de cortisol e ACTH positivas.

Não foi possível a determinação de valores de corte para as respostas de cortisol e ACTH nos testes do GHRP-6 capazes de separar totalmente os indivíduos controles daqueles com DC, tanto em incremento percentual de resposta, como em aumento absoluto do hormônio em relação ao valor basal devido à grande superposição de respostas dessas duas situações (Figura 9). Desse modo, o teste do GHRP-6 não serviu para o diagnóstico da SC. O mesmo ocorre com os outros secretagogos, já que os indivíduos normais comumente respondem ao $\mathrm{CRH}$ e até $>50 \%$ desses podem responder à desmopressina (Scott et al., 1999). Assim, ressalta-se que esses testes servem fundamentalmente para o diagnóstico diferencial da SC ACTH-dependente.

Apesar do grande bloqueio da secreção de GH que a SC produz, houve aumento significativo do GH no teste do GHRP-6 nos pacientes (principalmente na DC) $(0,3 \pm 0,4$ para $7,2 \pm 10,9 \mathrm{ng} / \mathrm{mL}, p<0,001)$, porém, de magnitude menor que nos indivíduos controles $(p=0,007$ no tempo $15 ; p<0,001$ nos demais tempos; sendo que no tempo $0, p=0,091$ ) (Figura $8 \mathrm{C}$ ). As concentrações séricas de IGF1 dos pacientes com SC $(\mathrm{n}=22)$ foram $319,2 \pm 154,1 \mathrm{ng} / \mathrm{mL}$, semelhante aos dos indivíduos controles. 

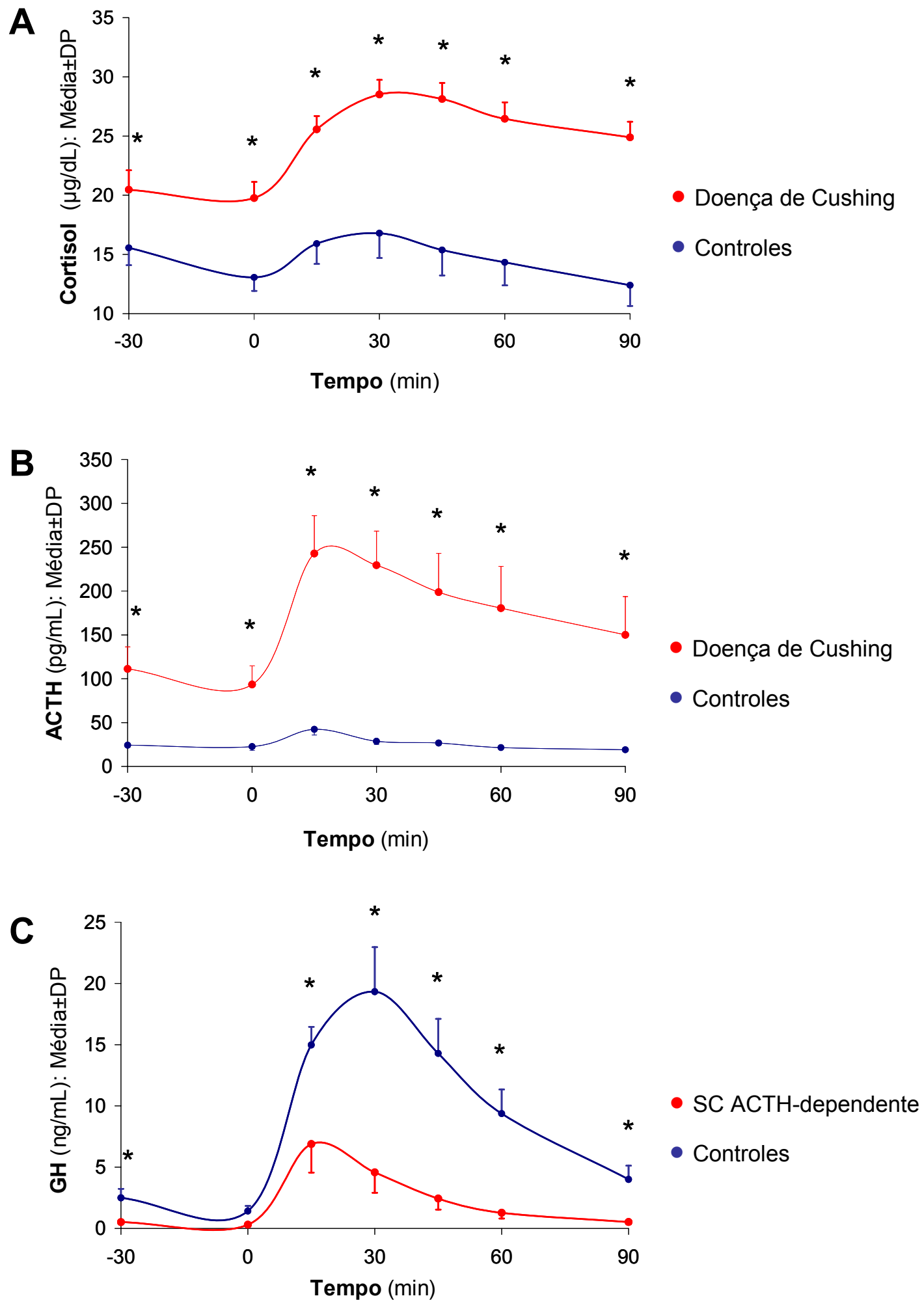

Figura 8. Comparação das respostas de cortisol (A), ACTH (B) e GH (C) no teste do GHRP-6 nos indivíduos controles e nos pacientes com síndrome de Cushing ACTH-dependente. Doença de Cushing: $n=20$; indivíduos controles: $n=21$; síndrome de Cushing ACTH-dependente: $n=22$; SC, síndrome de Cushing; ${ }^{*} p<0,05$ 
Tabela 12. Teste do GHRP-6 nos pacientes com tumores ectópicos produtores de $\mathrm{ACTH}$

VBJ, $\subsetneq, 18$ anos, Tumor carcinóide tímico ACTH +

\begin{tabular}{cccccccccc}
\hline & $-\mathbf{3 0}$ & $\mathbf{0}$ & $\mathbf{1 5}$ & $\mathbf{3 0}$ & $\mathbf{4 5}$ & $\mathbf{6 0}$ & $\mathbf{9 0}$ & Pico & $\begin{array}{c}\text { Incremento } \\
(\%)\end{array}$ \\
\hline $\begin{array}{c}\text { Cortisol } \\
\mu \mathrm{g} / \mathrm{dL}\end{array}$ & 37,1 & 36,3 & 36,6 & 35,8 & 38,5 & 37,3 & 37,2 & 38,5 & 6 \\
$\begin{array}{c}\text { ACTH } \\
\mathrm{pg} / \mathrm{mL}\end{array}$ & 464 & 433 & 371 & 342 & 268 & 219 & 204 & 371 & 0 \\
$\begin{array}{c}\mathbf{G H} \\
\mathrm{ng} / \mathrm{mL}\end{array}$ & $<0,1$ & $<0,1$ & $<0,1$ & $<0,1$ & $<0,1$ & $<0,1$ & $<0,1$ & $<0,1$ & 0 \\
\hline
\end{tabular}

JCJ, $\widehat{~}, 26$ anos, Tumor carcinóide pulmonar ACTH +

\begin{tabular}{cccccccccc}
\hline & $-\mathbf{3 0}$ & $\mathbf{0}$ & $\mathbf{1 5}$ & $\mathbf{3 0}$ & $\mathbf{4 5}$ & $\mathbf{6 0}$ & $\mathbf{9 0}$ & Pico & $\begin{array}{c}\text { Incremento } \\
(\%)\end{array}$ \\
\hline $\begin{array}{c}\text { Cortisol } \\
\mu \mathrm{g} / \mathrm{dL}\end{array}$ & 49,3 & 61,4 & 66,5 & 66,6 & 68 & 68,3 & 65,3 & 68,3 & $11,2^{*}$ \\
$\begin{array}{c}\text { ACTH } \\
\mathrm{pg} / \mathrm{mL}\end{array}$ & 803 & 883 & 1468 & 1545 & 1351 & 1122 & 896 & 1545 & $\mathbf{7 5}$ \\
$\begin{array}{c}\mathbf{G H} \\
\mathrm{ng} / \mathrm{mL}\end{array}$ & $<0,1$ & $<0,1$ & $<0,1$ & $<0,1$ & $<0,1$ & $<0,1$ & $<0,1$ & $<0,1$ & 0 \\
\hline
\end{tabular}

$\bar{*}$ Incremento de 23,5\% se for utilizado como valor basal a média dos tempos - 30 e 0 (55,3 $\mu \mathrm{g} / \mathrm{dL})$ 

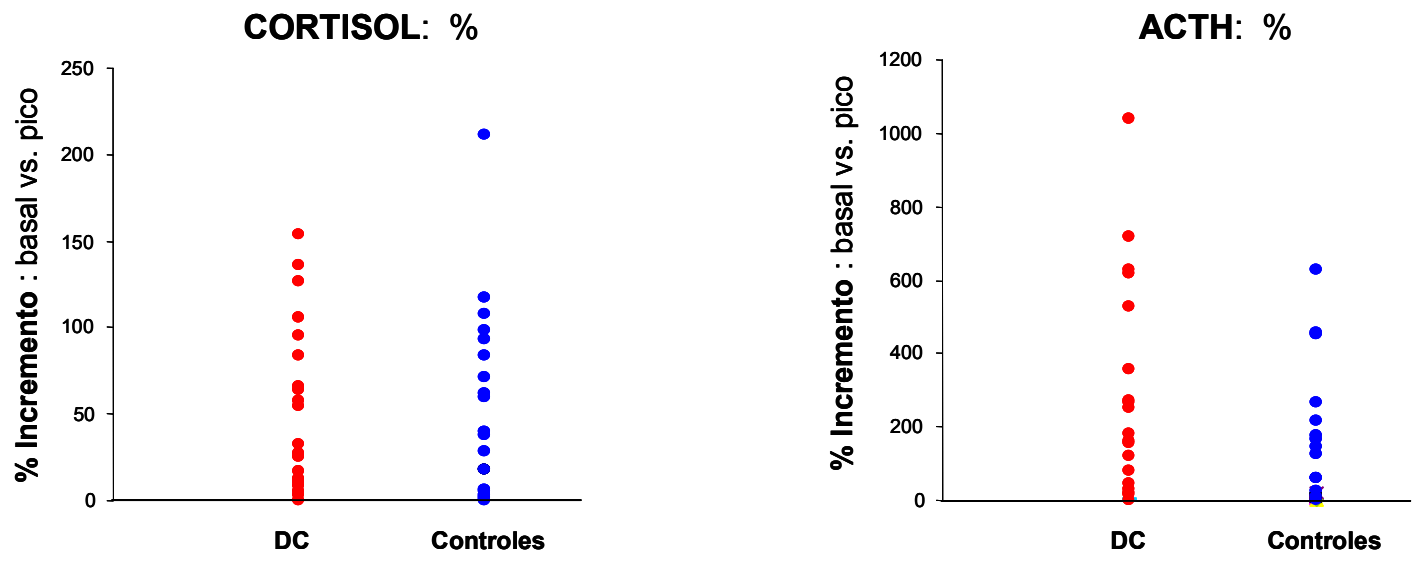

CORTISOL: Valor Absoluto
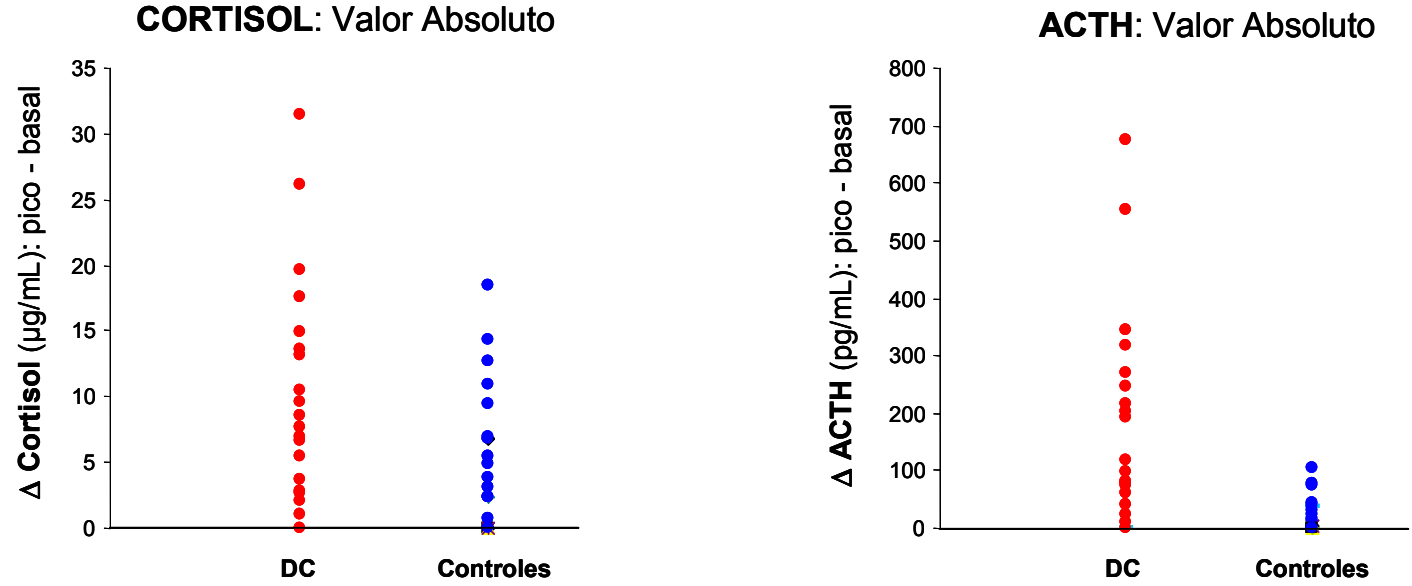

Figura 9. Respostas individuais ao teste do GHRP-6 dos pacientes com síndrome de Cushing ACTH-dependente e dos indivíduos controles. DC, doença de Cushing; $\Delta$, diferença entre o valor absoluto do hormônio no pico menos o valor absoluto no basal (tempo 0) 


\subsection{Teste da Desmopressina}

Nos pacientes com DC, observou-se aumento significativo do cortisol (basal vs. pico) após a infusão da desmopressina $(10 \mu \mathrm{g})(21,5 \pm 7,3$ para $32,1 \pm$ $10,2 \mu \mathrm{g} / \mathrm{dL}, p<0,001)$, com um incremento médio de $59,4 \pm 60,2 \%$ em relação ao valor basal.

Individualmente, $15 / 20(75 \%)$ dos pacientes com DC responderam ao teste com aumento de cortisol (critério > 20\%). Nos pacientes com SEA, não houve resposta de cortisol em nenhum dos dois casos (40,2 para $47,8 \mu \mathrm{g} / \mathrm{dL}, 18,9 \%$; e $68,6$ para $70,3 \mu \mathrm{g} / \mathrm{dL}, 2,4 \%$ ) (Figura 10$)$.

Em relação ao $\mathrm{ACTH}$, também houve aumento importante após a desmopressina nos pacientes com DC $(83,4 \pm 71,3$ para $259,4 \pm 294,3 \mathrm{pg} / \mathrm{mL}$, $p<0,001$ ), tendo um incremento médio de $219,3 \pm 183,8 \%$ em relação ao valor basal. Individualmente, todos os 20 pacientes com DC responderam ao teste com aumento de ACTH (critério > 35\%). Nos pacientes com SEA, houve resposta importante de ACTH em um caso (360 para $1326 \mathrm{pg} / \mathrm{mL}, 268 \%$ ), e pouco importante no outro caso (510 para 611 pg/mL, 19,8\%) (Figura 10). Assim, apesar das respostas significativas de ACTH em todos os pacientes, somente 15/20 (75\%) dos pacientes com DC apresentaram ambas as respostas de cortisol e ACTH positivas.

\subsection{Teste do hCRH}

O teste foi realizado em somente 15 pacientes com SC ACTHdependente (13 com DC e nos 2 com tumores ectópicos produtores de ACTH).

Não houve aumento significativo do cortisol após infusão do hCRH (basal vs pico) nos pacientes com DC $(20,4 \pm 5,5$ para $24,6 \pm 6,1 \mu \mathrm{g} / \mathrm{dL})$, tendo um 
incremento médio de $26,4 \pm 29,9 \%$ em relação ao valor basal. Individualmente, apenas $7 / 13(54 \%)$ responderam ao teste com cortisol (critério > 14\%).

Em relação ao ACTH, também não foi observado estímulo significativo (basal vs. pico) nos pacientes com DC $(93,1 \pm 62,4$ para 196,5 $\pm 216,1 \mathrm{pg} / \mathrm{mL})$, tendo um incremento médio de $84,6 \pm 120 \%$ em relação ao valor basal. Ao ser utilizado o critério de resposta de ACTH > 50\% em relação ao basal, somente 6/13 pacientes (46\%) tiveram resposta positiva ao hCRH. Além do mais, apenas $46 \%$ (6/13) dos pacientes com DC tiveram ambas as respostas significativas.

Nenhum dos 2 pacientes com SEA respondeu ao teste, tanto para cortisol quanto para ACTH (Figura 10).

$\mathrm{Na}$ tabela 13 , estão resumidos os resultados dos três testes de estímulo nos pacientes com SC ACTH-dependente. Para efeito comparativo com o estudo de expressão dos respectivos receptores, foi definido como resposta positiva a um secretagogo quando ambos os estímulos de cortisol e ACTH foram significantes, exceção para os casos de SEA onde cada um dos pacientes apresentou ampla secreção de ACTH em um dos testes (Tabela 12).

$\mathrm{Na}$ tabela 14, estão resumidos os resultados dos testes somente nos pacientes que foram submetidos ao estudo molecular dos genes de interesse. 

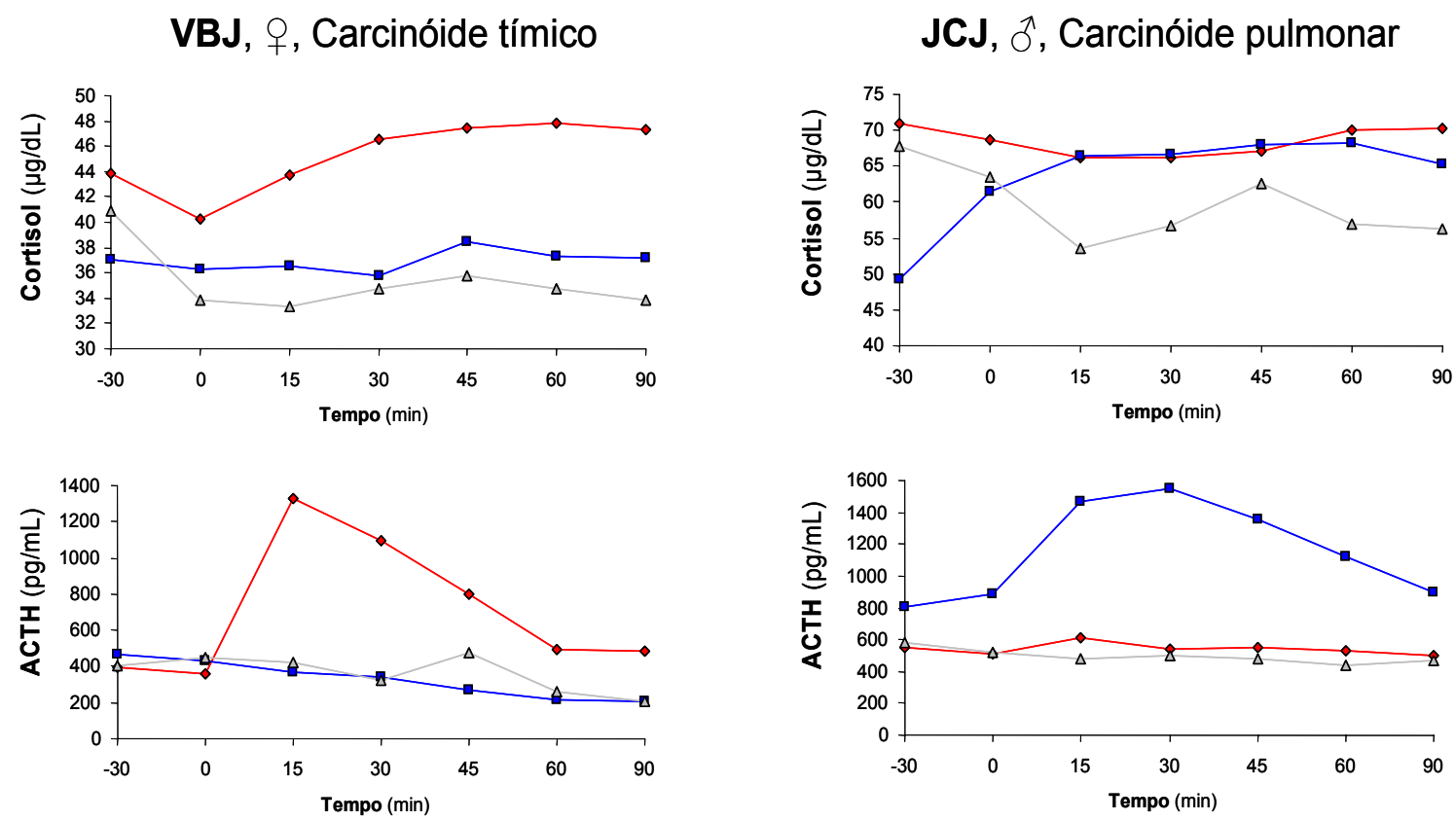

- Demopressina

- GHRP-6

$\triangle \mathrm{hCRH}$

Figura 10. Respostas individuais aos testes nos pacientes com Secreção Ectópica de ACTH 
Tabela 13. Resumo dos testes de estímulo nos pacientes com síndrome de Cushing ACTH-dependente

\begin{tabular}{|c|c|c|c|c|c|}
\hline \multirow[b]{2}{*}{$\mathbf{N}^{\circ}$} & \multirow[b]{2}{*}{ Paciente } & \multirow[b]{2}{*}{ Diagnóstico } & \multicolumn{3}{|c|}{ RESPOSTA } \\
\hline & & & $\begin{array}{c}\text { Desmopressina } \\
(\mathrm{F}>20 \% \mathrm{e} \\
\mathrm{ACTH}>35 \%) \\
\end{array}$ & $\begin{array}{c}\text { GHRP-6 } \\
(\mathrm{F}>20 \% \text { e } \\
\text { ACTH }>50 \%) \\
\end{array}$ & $\begin{array}{c}\text { hCRH } \\
(\mathrm{F}>14 \% \text { e } \\
\text { ACTH }>50 \%) \\
\end{array}$ \\
\hline 1 & ALSJ & Doença de Cushing & - & + & + \\
\hline $2^{*}$ & GCV & Doença de Cushing & + & + & - \\
\hline 3 & SCC & Doença de Cushing & + & + & - \\
\hline $4^{*}$ & JMS & Doença de Cushing & + & + & NR \\
\hline $5^{*}$ & NMSS & Doença de Cushing & + & - & NR \\
\hline $6^{*}$ & CRS & Doença de Cushing & + & + & NR \\
\hline 7 & CNCL & Doença de Cushing & + & + & NR \\
\hline $8^{*}$ & ITS & Doença de Cushing & + & + & NR \\
\hline 9 & MAS & Doença de Cushing & + & + & NR \\
\hline 10 & JAMO & Doença de Cushing & + & + & NR \\
\hline $11^{*}$ & ECM & Doença de Cushing & - & - & + \\
\hline 12 & ASM & Doença de Cushing & + & - & - \\
\hline 13 & MNL & Doença de Cushing & - & - & + \\
\hline $14^{*}$ & JOQ & Doença de Cushing & - & - & + \\
\hline 15 & PPS & Doença de Cushing & + & + & - \\
\hline 16 & MLMS & Doença de Cushing & - & - & - \\
\hline $17^{¥}$ & RSRR & Doença de Cushing & + & + & + \\
\hline $18^{*}$ & RMS & Doença de Cushing & + & + & - \\
\hline 19 & ZFS & Doença de Cushing & + & - & - \\
\hline 20 & MAMA & Doença de Cushing & + & + & + \\
\hline 21 & VBJ & SEA/Carcin. timo & $+\S$ & - & - \\
\hline 22 & $\mathrm{JCJ}$ & SEA/Carcin. pulmão & - & $+\S$ & - \\
\hline
\end{tabular}

$\mathrm{N}^{\circ}$, Número do paciente; *Amostras excluídas do estudo molecular dos genes de interesse por expressão positiva de PIT1; ${ }^{\sharp}$ Amostras excluídas do estudo molecular por anátomopatológico com hipófise normal; ${ }^{\S}$ Resposta de ACTH; NR, não realizado; +, positiva; -, negativa; F, cortisol; SEA, Secreção Ectópica de ACTH; Carcin., Tumor carcinóide 
Tabela 14. Resumo dos testes de estímulo nos pacientes com síndrome de Cushing ACTH-dependente que foram submetidos ao estudo molecular dos genes de interesse

\begin{tabular}{cccccc}
\hline & & & \multicolumn{4}{c}{ RESPOSTA } \\
\cline { 3 - 6 } No $^{*}$ & Paciente & Diagnóstico & $\begin{array}{c}\text { Desmopressina } \\
(\mathrm{F}>20 \% \mathrm{e} \\
\text { ACTH }>35 \%)\end{array}$ & $\begin{array}{c}\text { GHRP-6 } \\
(\mathrm{F}>20 \% \mathrm{e} \\
\text { ACTH }>50 \%)\end{array}$ & $\begin{array}{c}\text { hCRH } \\
(\mathrm{F}>14 \% \mathrm{e} \\
\text { ACTH }>50 \%)\end{array}$ \\
\hline 1 & ALSJ & Doença de Cushing & - & + & + \\
3 & SCC & Doença de Cushing & + & + & - \\
7 & $\mathrm{CNCL}$ & Doença de Cushing & + & + & NR \\
9 & MAS & Doença de Cushing & + & + & NR \\
10 & JAMO & Doença de Cushing & + & + & NR \\
12 & ASM & Doença de Cushing & + & - & - \\
13 & MNL & Doença de Cushing & - & - & + \\
15 & PPS & Doença de Cushing & + & + & - \\
16 & MLMS & Doença de Cushing & - & - & - \\
19 & ZFS & Doença de Cushing & + & - & - \\
20 & MAMA & Doença de Cushing & + & + & + \\
\hline 21 & VBJ & SEA/ Carcin. timo & $+^{*}$ & - & - \\
22 & JCJ & SEA/ Carcin. pulmão & - & $+^{*}$ & - \\
\hline
\end{tabular}

${ }^{*}$ Resposta de ACTH; NR, não realizado; +, positiva; -, negativa; F, cortisol; SEA, Secreção Ectópica de ACTH; Carcin., Tumor carcinóide 


\section{Expressão dos Genes em Estudo}

\subsection{Expressão do RNAm do GHSR-1a}

Houve expressão do RNAm do GHSR-1a nas amostras das hipófises normais e nas amostras dos pacientes com tumores corticotróficos, além de expressão importante em um dos casos de secreção ectópica de ACTH (tumor carcinóide de pulmão ACTH positivo) (Figura 11).

Quando analisadas as intensidades de expressão, houve maior magnitude nas hipófises normais do que nas amostras dos outros tecidos controles (timo e pulmão), sendo que a expressão nesses últimos foi muito pequena (Figura 12).

Houve tendência de maior expressão do GHSR-1a nas amostras dos tumores corticotróficos quando comparado às hipófises normais, porém, sem significância estatística (Figura 13).

\subsection{Expressão do RNAm do AVPR1B}

Assim como no resultado do GHSR-1a, houve expressão nas amostras das hipófises normais e nas amostras dos pacientes com tumores corticotróficos, além da expressão nos dois casos de SEA (Figura 14).

A expressão do RNAm do AVPR1B foi de maior magnitude nas hipófises normais do que nas amostras dos outros tecidos controles (timo e pulmão), sendo praticamente inexistente nesses últimos (Figura 15).

Houve maior expressão do AVPR1B nas amostras dos tumores corticotróficos em relação às hipófises normais $(p=0,019)$ (Figura 16). 


\subsection{Expressão do RNAm do CRHR1}

Houve expressão do RNAm do CRHR1 nas amostras das hipófises normais e na maioria das amostras dos pacientes com tumores corticotróficos. Nas outras amostras de tecidos normais (timo e pulmão) e nos casos de secreção ectópica de ACTH, a expressão foi praticamente inexistente (Figuras 17 e 18).

A expressão do CRHR1 nas amostras dos tumores corticotróficos foi semelhante quando comparado às hipófises normais, embora tenha um tendência de ser maior nos tumores corticotróficos (Figura 19).

\section{Correlações Clínico-moleculares}

Quando separados os pacientes com tumores corticotróficos em relação à resposta ao teste do GHRP-6 (responsivos vs. não responsivos), houve maior expressão do RNAm do GHSR-1a nos pacientes responsivos $(p=0,023)$ (Figura 20), estabelecendo-se uma associação do resultado in vivo ao teste com a magnitude de expressão do GHSR-1a.

Embora a expressão do GHSR-1a nos tumores corticotróficos tenha sido semelhante às hipófises normais, ao ser analisado somente o subgrupo dos pacientes responsivos ao teste do GHRP-6, foi verificado maior expressão do GHSR-1a em relação às hipófises normais $(p=0,018)$ (Figura 20).

Também foi observada associação da resposta in vivo ao GHRP-6 com a magnitude de expressão do RNAm do GHSR-1a nos pacientes com tumores ectópicos produtores de ACTH. O paciente com tumor carcinóide pulmonar que teve resposta importante ao teste do GHRP-6, mostrou intensa expressão do RNAm do GHSR-1a quando comparado às amostras do pulmão normal e do outro paciente com SEA não responsivo ao GHRP-6. O resultado dessa expressão ainda 
foi comparável aos tumores corticotróficos e superior às hipófises normais (Figura $21 \mathrm{~A})$.

Ao ser analisada a correlação entre o resultados dos testes da desmopressina e a expressão do RNAm do AVPR1B, não houve diferença entre os pacientes com DC respondedores vs. não respondedores (Figura 22).

Por outro lado, houve nítida relação entre as respostas in vivo à desmopressina e a análise molecular do AVPR1B nos pacientes com tumores ectópicos produtores de ACTH. O paciente com tumor carcinóide tímico produtor de ACTH que teve resposta importante à desmopressina, mostrou expressão do RNAm do AVPR1B muito superior à encontrada nas amostras de timo normal, e cerca de $5 \mathrm{X}$ maior que no outro paciente com SEA que não respondeu ao teste (Figura $21 \mathrm{~B}$ ).

Não houve associação da expressão do RNAm do CRHR1 com a resposta in vivo ao teste do $\mathrm{hCRH}$ nos pacientes com $\mathrm{DC}$ quando divididos em respondedores e não respondedores (Figura 23). Entretanto, ressalta-se aqui, que essa análise foi prejudicada pelo menor número de pacientes que foram submetidos ao teste do hCRH. Apesar disso, nos pacientes com tumores ectópicos produtores de $\mathrm{ACTH}$, que não responderam ao teste do $\mathrm{hCRH}$, não apresentaram expressão do $\mathrm{CRH} 1$, o que explicaria essa ausência de respostas (Figura $21 \mathrm{C}$ ).

Foram encontradas fortes correlações na expressão do RNAm dos três genes entre si nas amostras dos tumores corticotróficos (Figuras 24, 25 e 26), sendo inexistentes as correlações nas amostras de hipófises normais.

Na tabela 15, estão sintetizados os resultados de expressão de todos os receptores em todas as amostras estudadas, normais e tumorais, além dos resultados dos testes de estímulo nos pacientes portadores de tumores corticotróficos e de tumores ectópicos produtores de ACTH. 


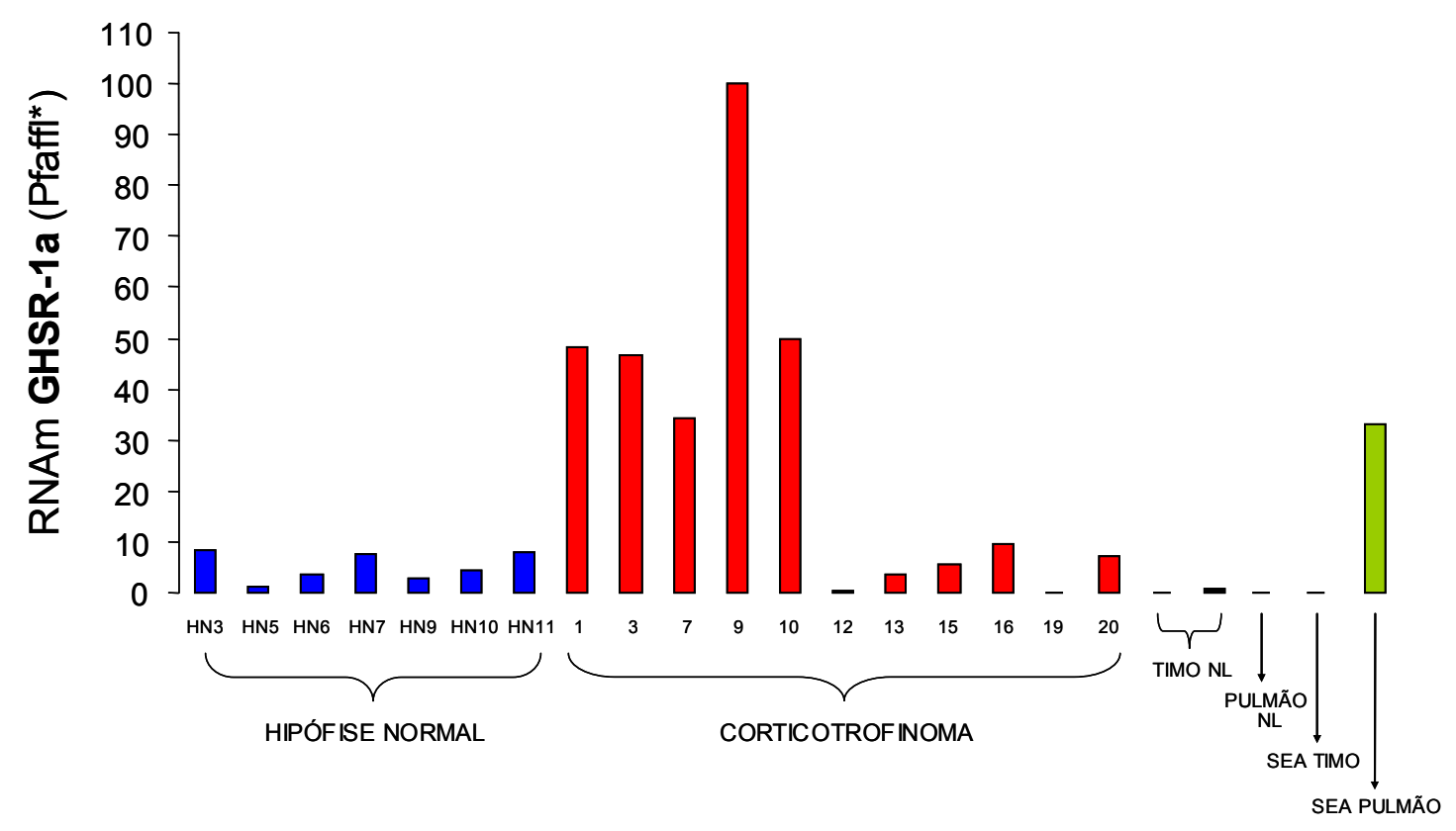

Figura 11. Valores individuais de expressão do RNAm do GHSR-1a das amostras dos tecidos normais (hipófises, timos e pulmão) e dos pacientes com síndrome de Cushing ACTH-dependente (Corticotrofinomas e Secreção Ectópica de ACTH); " modelo matemático de Pfaffl (2001); NL, Normal; SEA, Secreção Ectópica de ACTH 


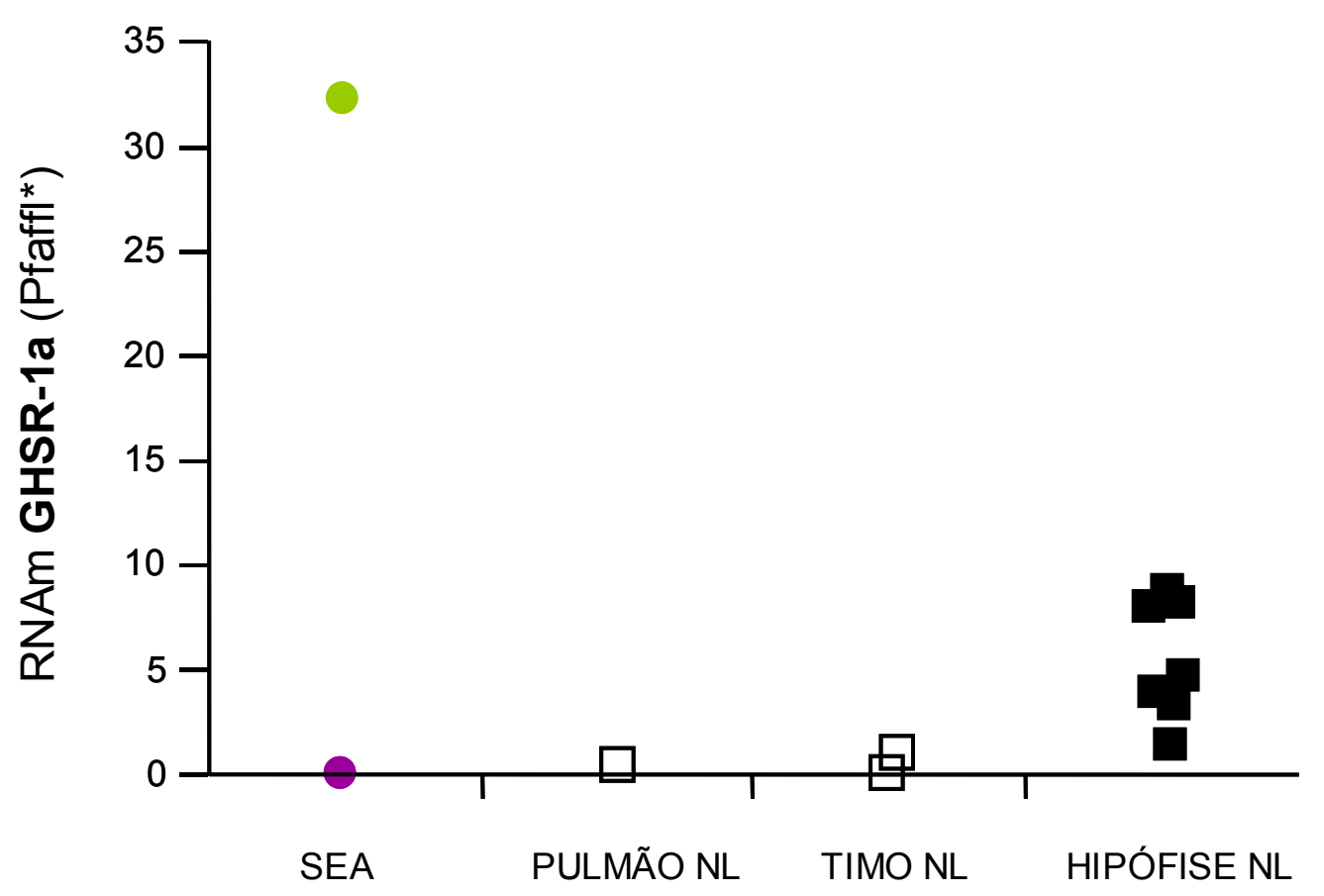

Tumor carcinóide pulmonar

- Tumor carcinóide tímico

Figura 12. Valores individuais de expressão do RNAm do GHSR-1a das amostras de tecidos normais (hipófises, timos e pulmão) e dos pacientes com Secreção Ectópica de ACTH; SEA, Secreção Ectópica de ACTH; NL, Normal; *modelo matemático de Pfaffl (2001) 


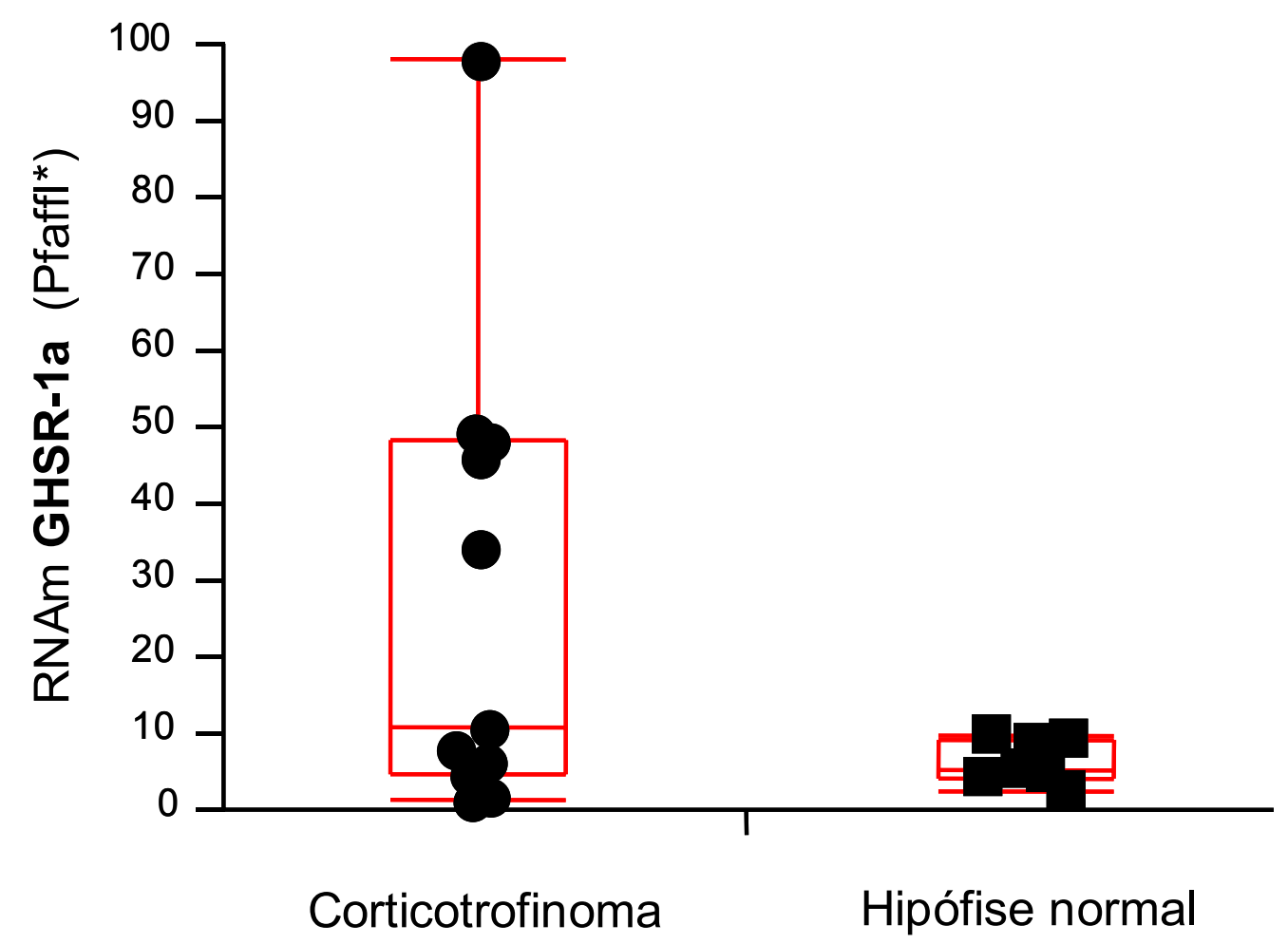

Figura 13. Expressão do RNAm do GHSR-1a nas amostras dos tumores corticotróficos e hipófises normais; *modelo matemático de Pfaffl (2001) 


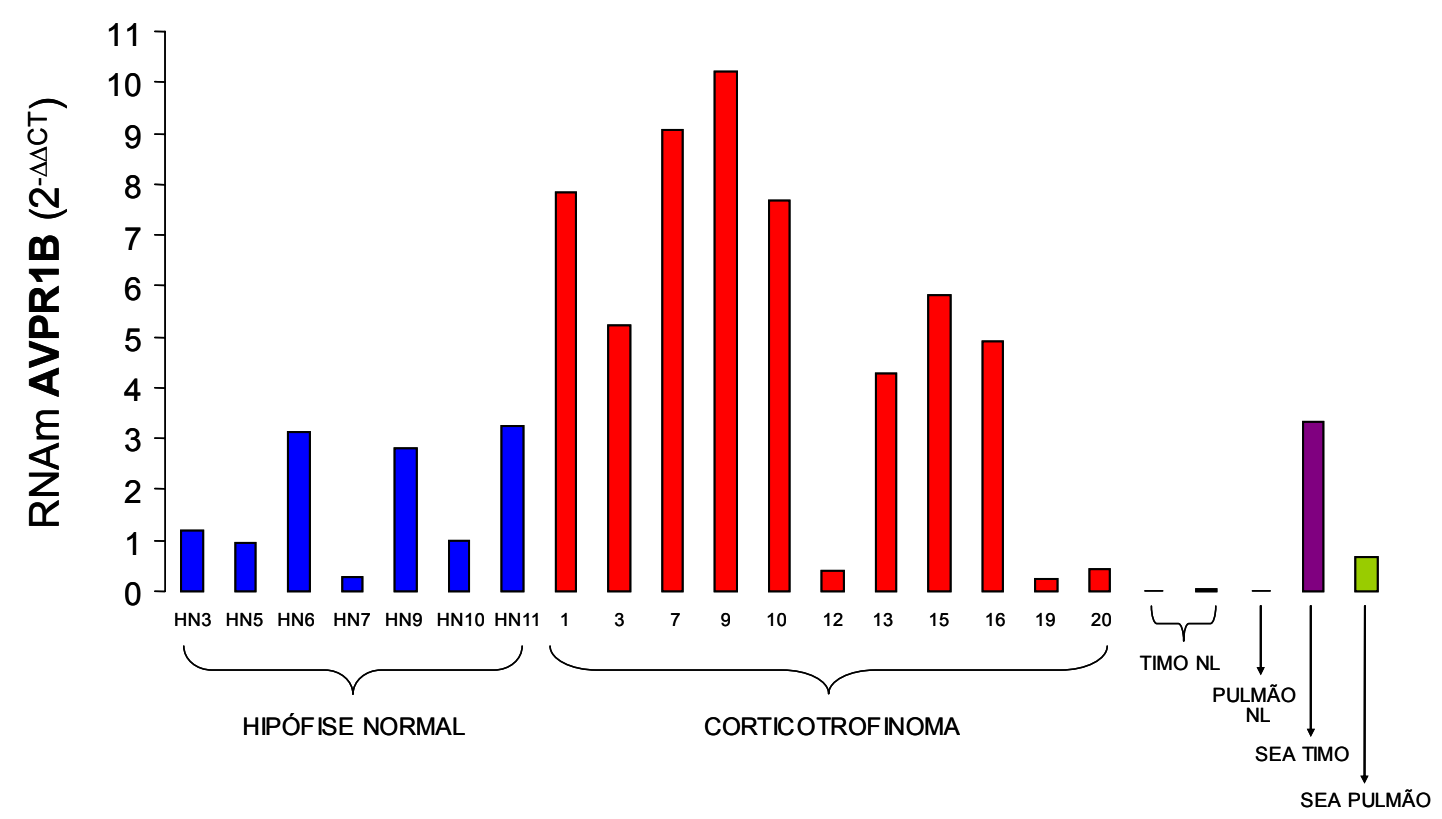

Figura 14. Valores individuais de expressão do RNAm do AVPR1B das amostras dos tecidos normais (hipófises, timos e pulmão) e dos pacientes com síndrome de Cushing ACTH-dependente (Corticotrofinomas e Secreção Ectópica de ACTH); NL, Normal; SEA, Secreção Ectópica de ACTH 


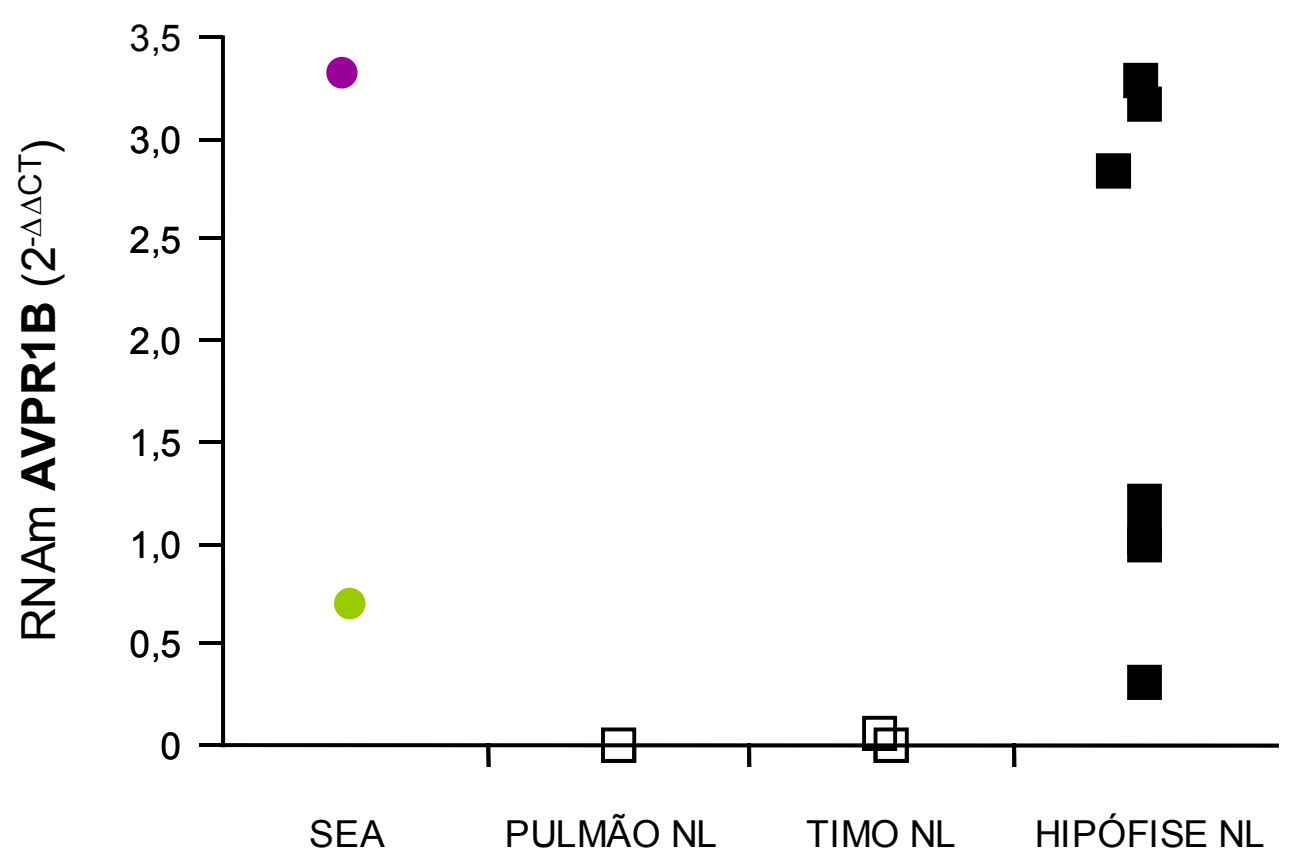

Tumor carcinóide pulmonar

- Tumor carcinóide tímico

Figura 15. Valores individuais de expressão do RNAm do AVPR1B das amostras de tecidos normais (hipófises, timos e pulmão) e dos pacientes com SEA; SEA, Secreção Ectópica de ACTH; NL, Normal 


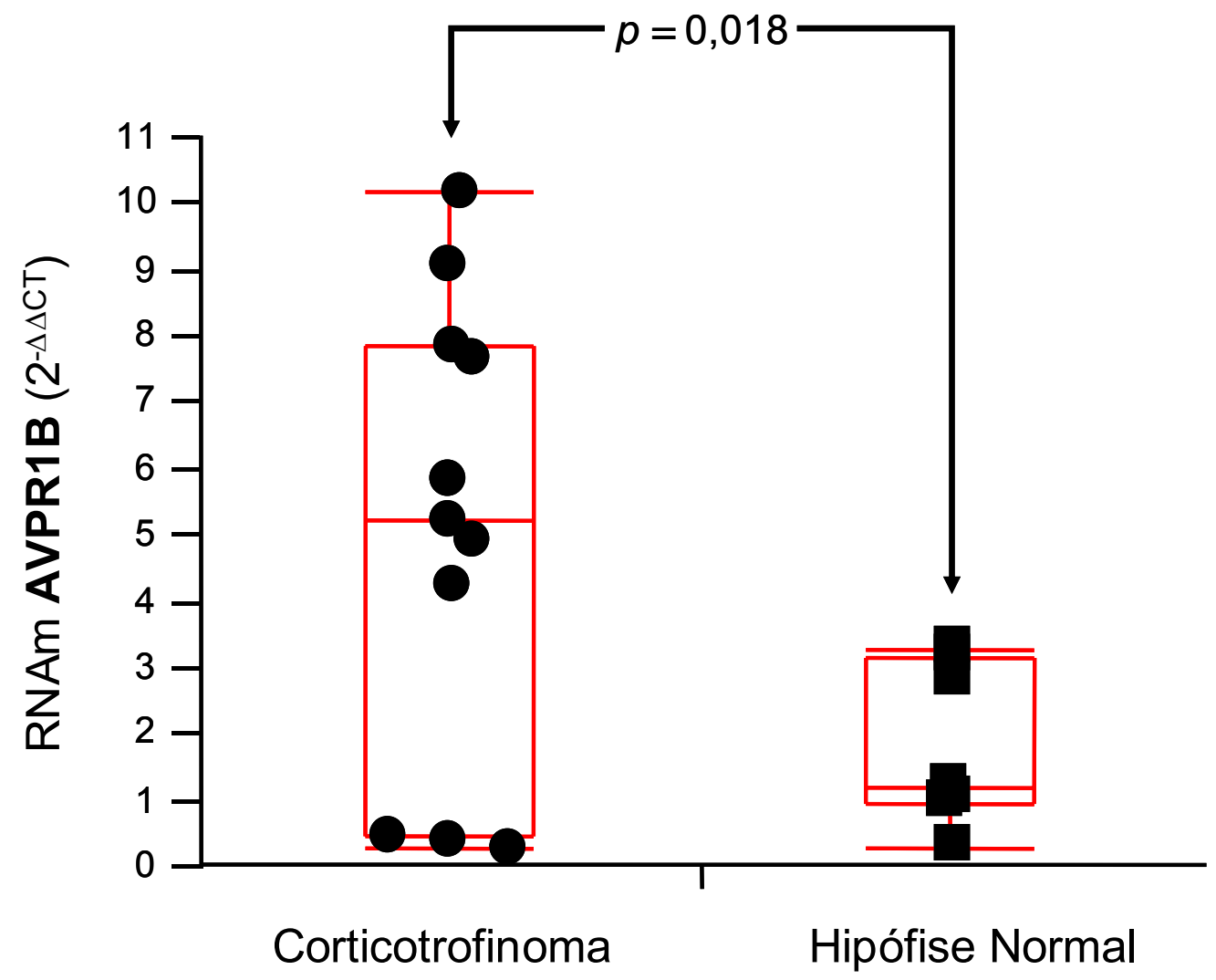

Figura 16. Expressão do RNAm do AVPR1B nas amostras dos tumores corticotróficos e hipófises normais 


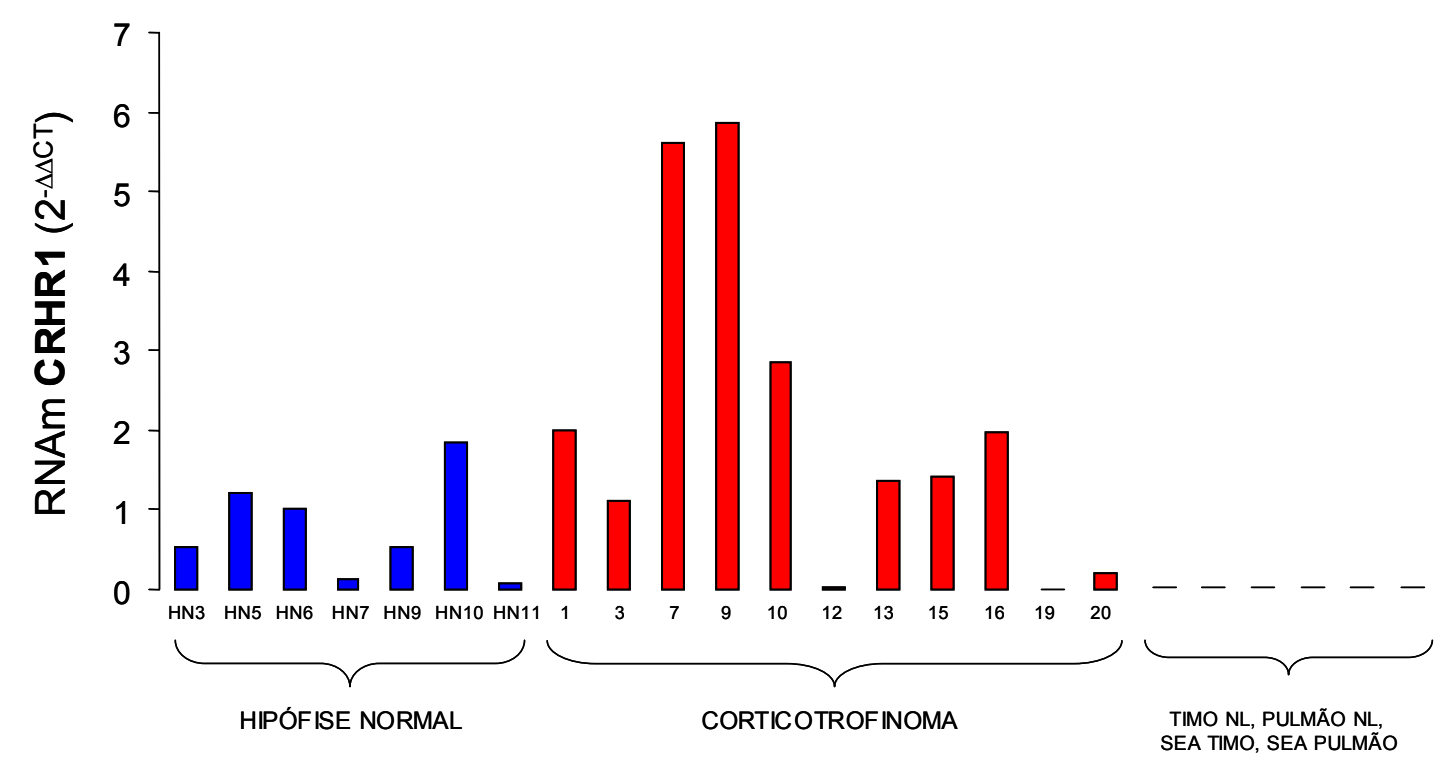

Figura 17. Valores individuais de expressão do RNAm do CRHR1 das amostras dos tecidos normais (hipófises, timos e pulmão) e dos pacientes com síndrome de Cushing ACTH-dependente (Corticotrofinomas e Secreção Ectópica de ACTH); NL, Normal; SEA, Secreção Ectópica de ACTH 


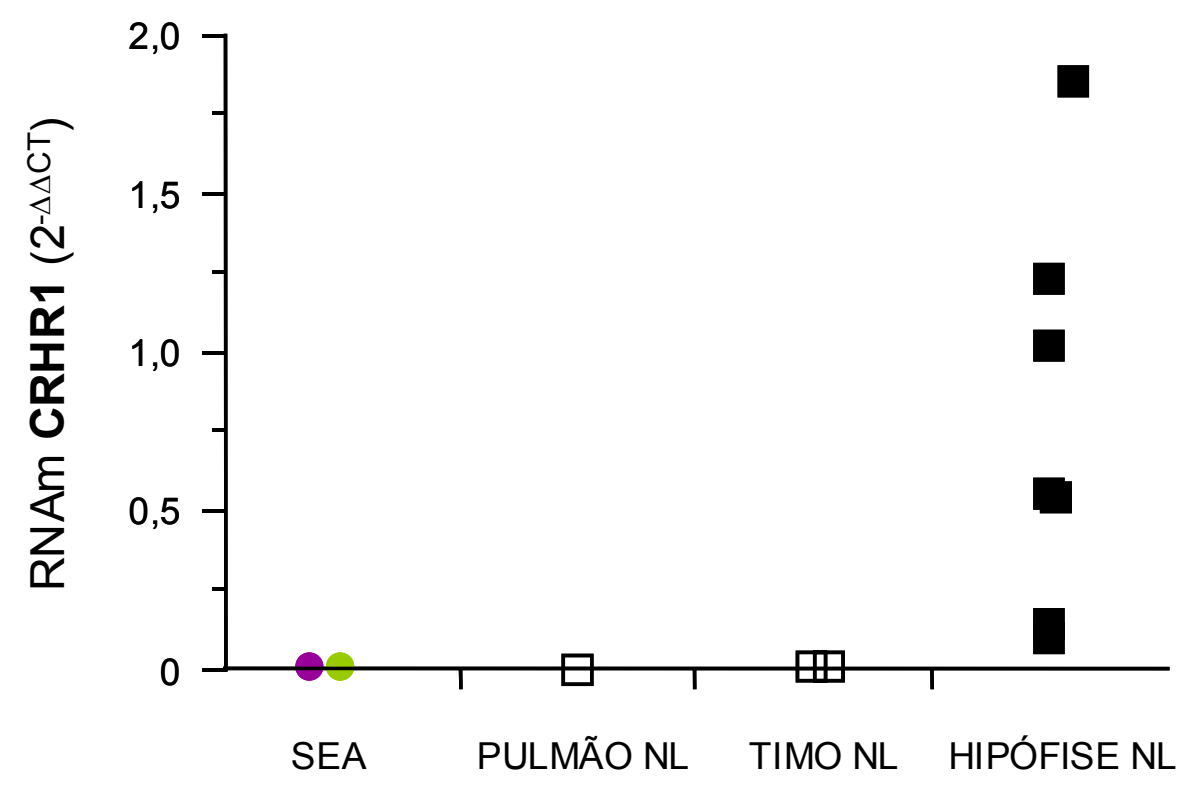

Tumor carcinóide pulmonar

Tumor carcinóide tímico

Figura 18. Valores individuais de expressão do RNAm do CRHR1 das amostras de tecidos normais (hipófises, timos e pulmão) e dos pacientes com Secreção Ectópica de ACTH; SEA, Secreção Ectópica de ACTH; NL, Normal 


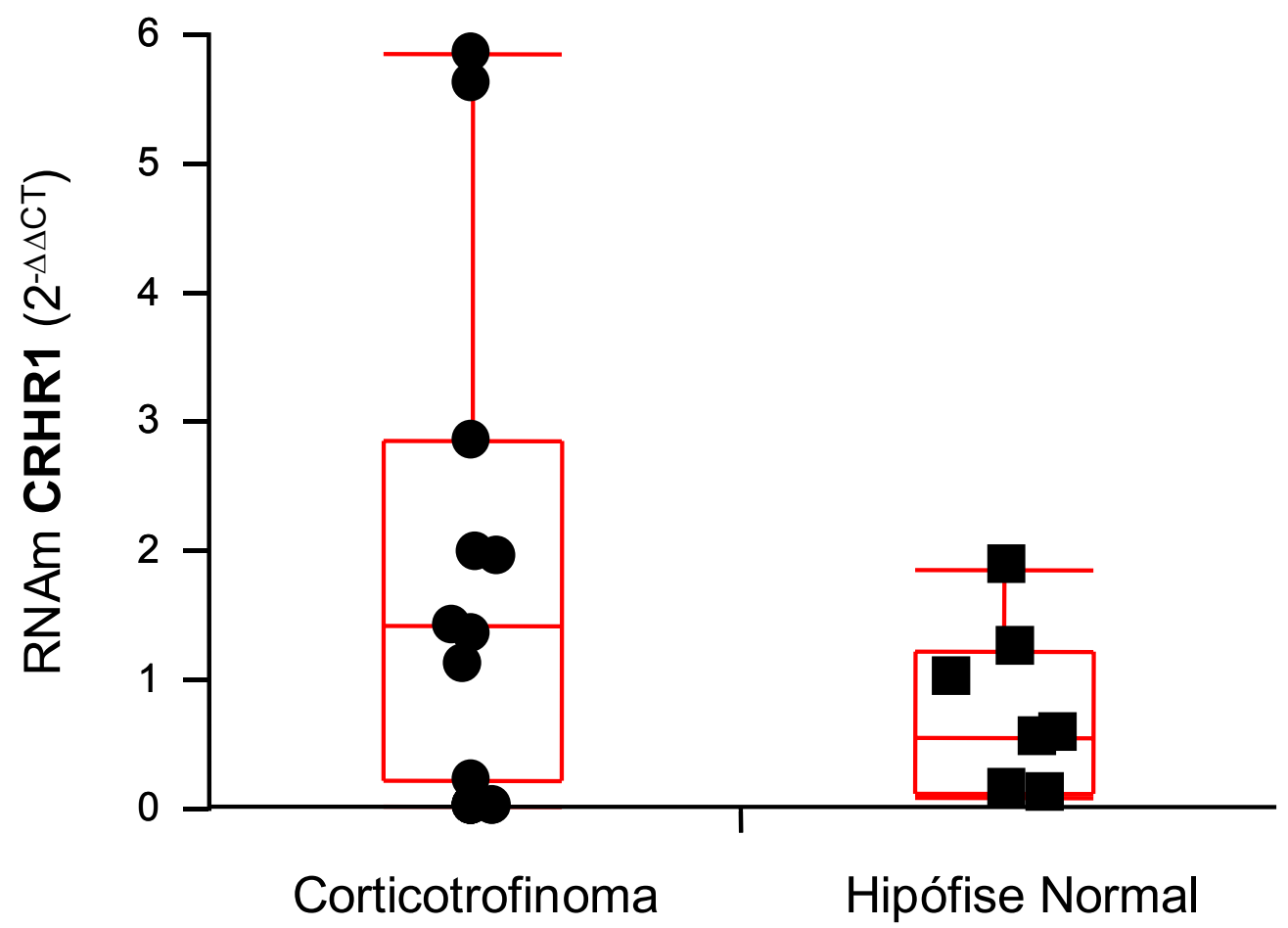

Figura 19. Expressão do RNAm do CRHR1 nas amostras dos tumores corticotróficos e hipófises normais 


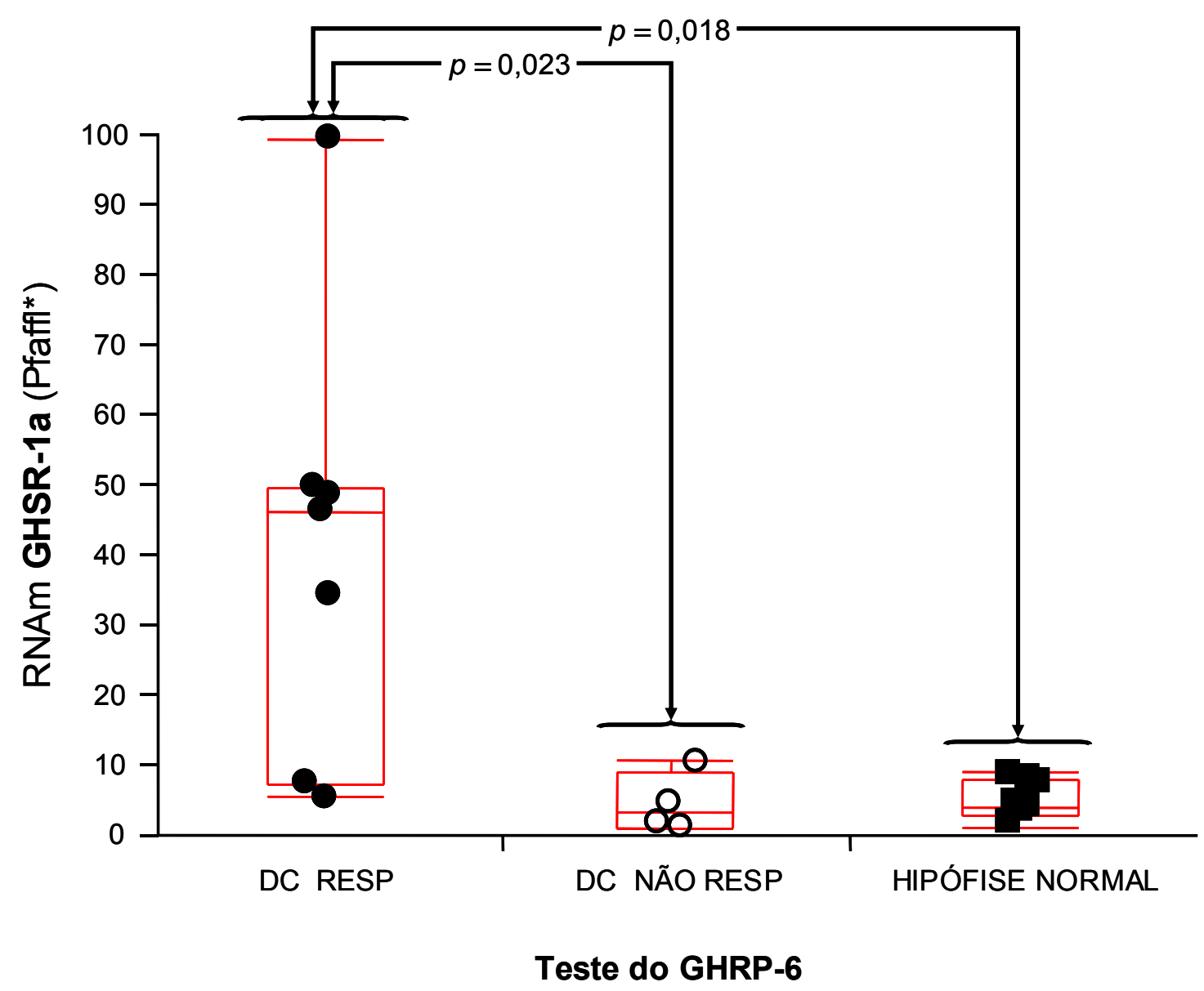

Figura 20. Expressão do RNAm do GHSR-1a nos pacientes com doença de Cushing responsivos e não responsivos ao teste do GHRP-6 e nas hipófises normais; DC, doença de Cushing, *modelo matemático de Pfaffl (2001) 
A

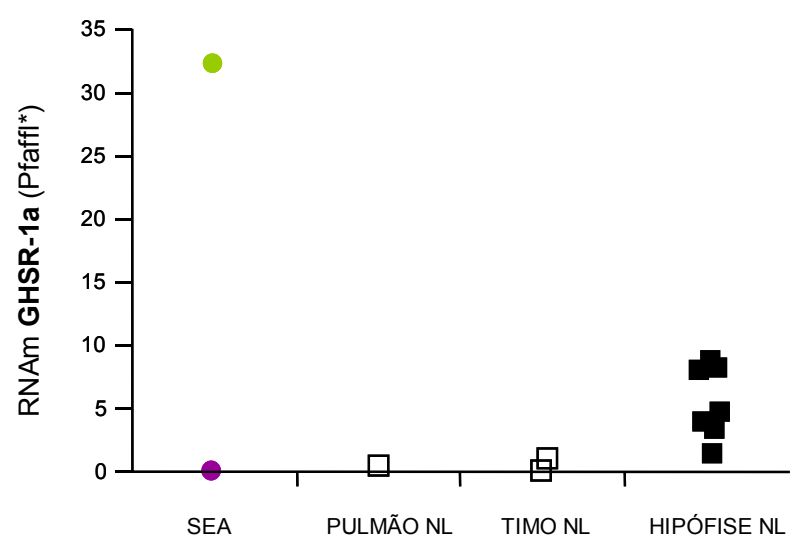

B

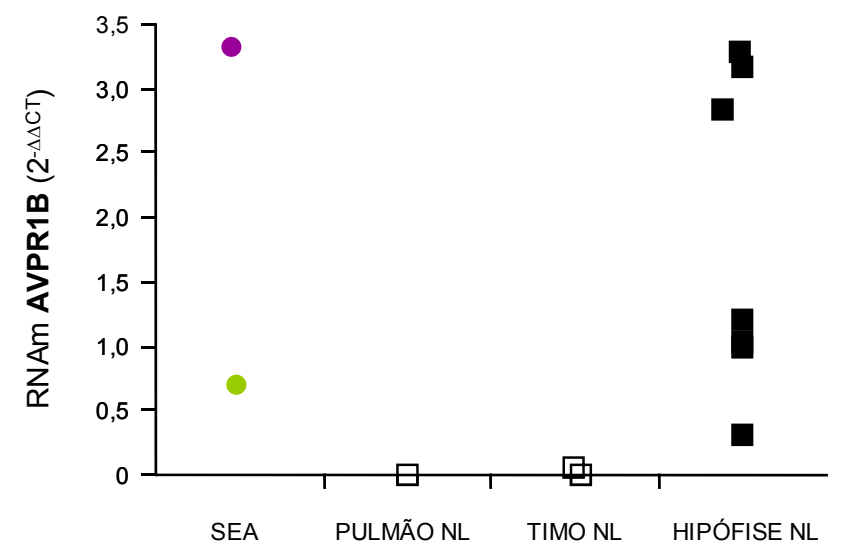

C

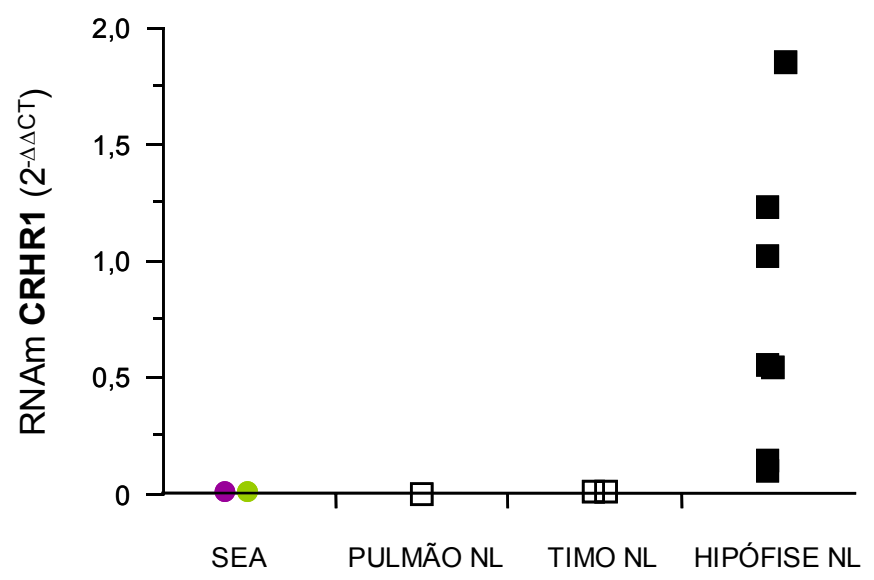

- Tumor carcinóide pulmonar, ACTH +:

$\{\rightarrow$ Resposta positiva ao GHRP-6

$\{\rightarrow$ Resposta negativa à desmopressina

$\rightarrow$ Resposta negativa ao hCRH
- Tumor carcinóide tímico, ACTH +:

$\rightarrow$ Resposta negativa ao GHRP-6 $\{\rightarrow$ Resposta positiva à desmopressina $\rightarrow$ Resposta negativa ao hCRH

Figura 21. Resultados dos testes de estímulo com GHRP-6, desmopressina e hCRH nos pacientes com Secreção Ectópica de ACTH, e expressão do RNAm dos receptores GHSR-1a (A), AVPR1B (B), e CRHR1 (C) nos respectivos pacientes e nas amostras de tecidos normais (hipófises, timos e pulmão); SEA, Secreção Ectópica de ACTH; NL, Normal, *modelo matemático de Pfaffl (2001) 


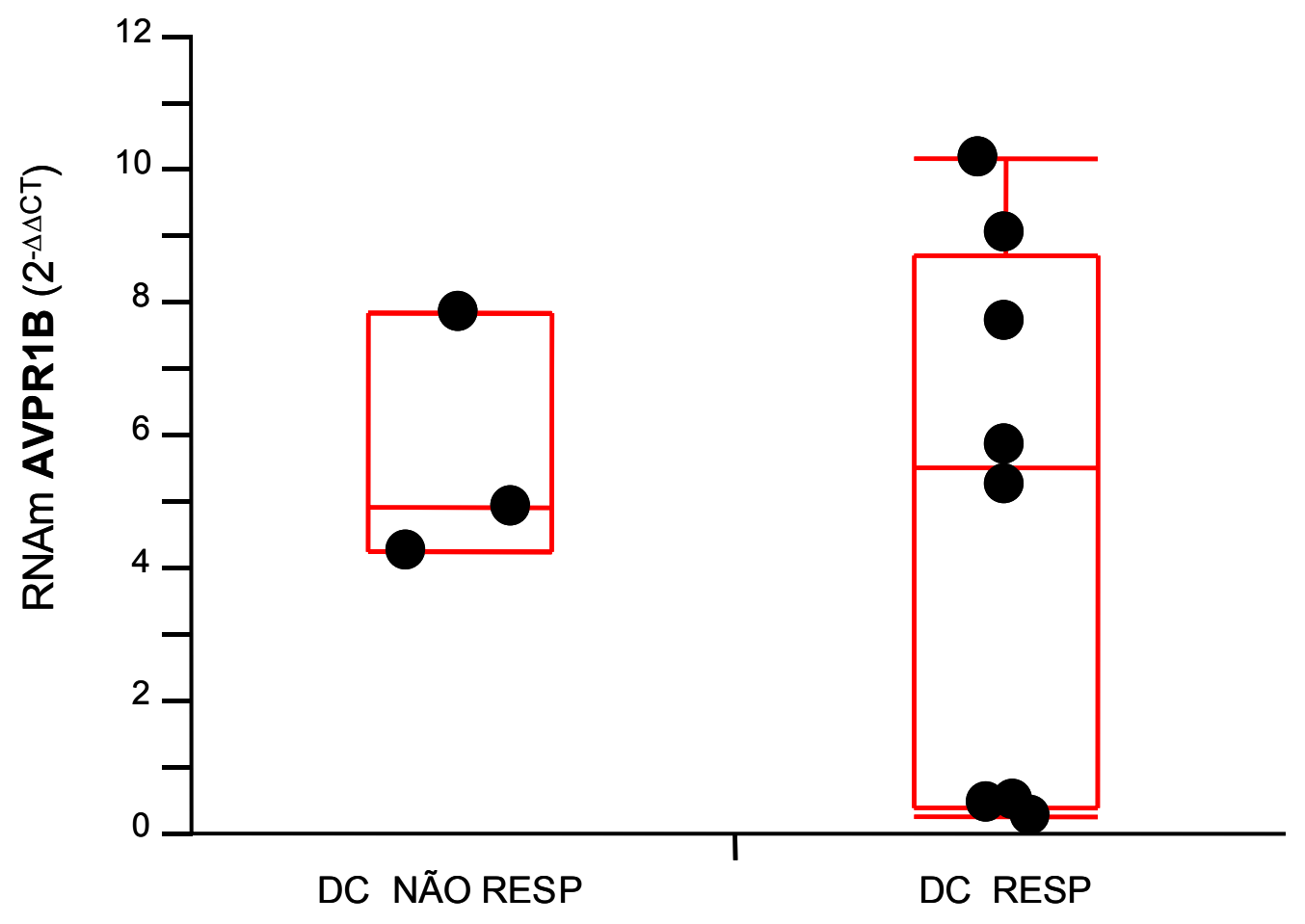

Teste da desmopressina

Figura 22. Expressão do RNAm do AVPR1B nos pacientes com doença de Cushing responsivos e não responsivos ao teste da desmopressina; DC, doença de Cushing 


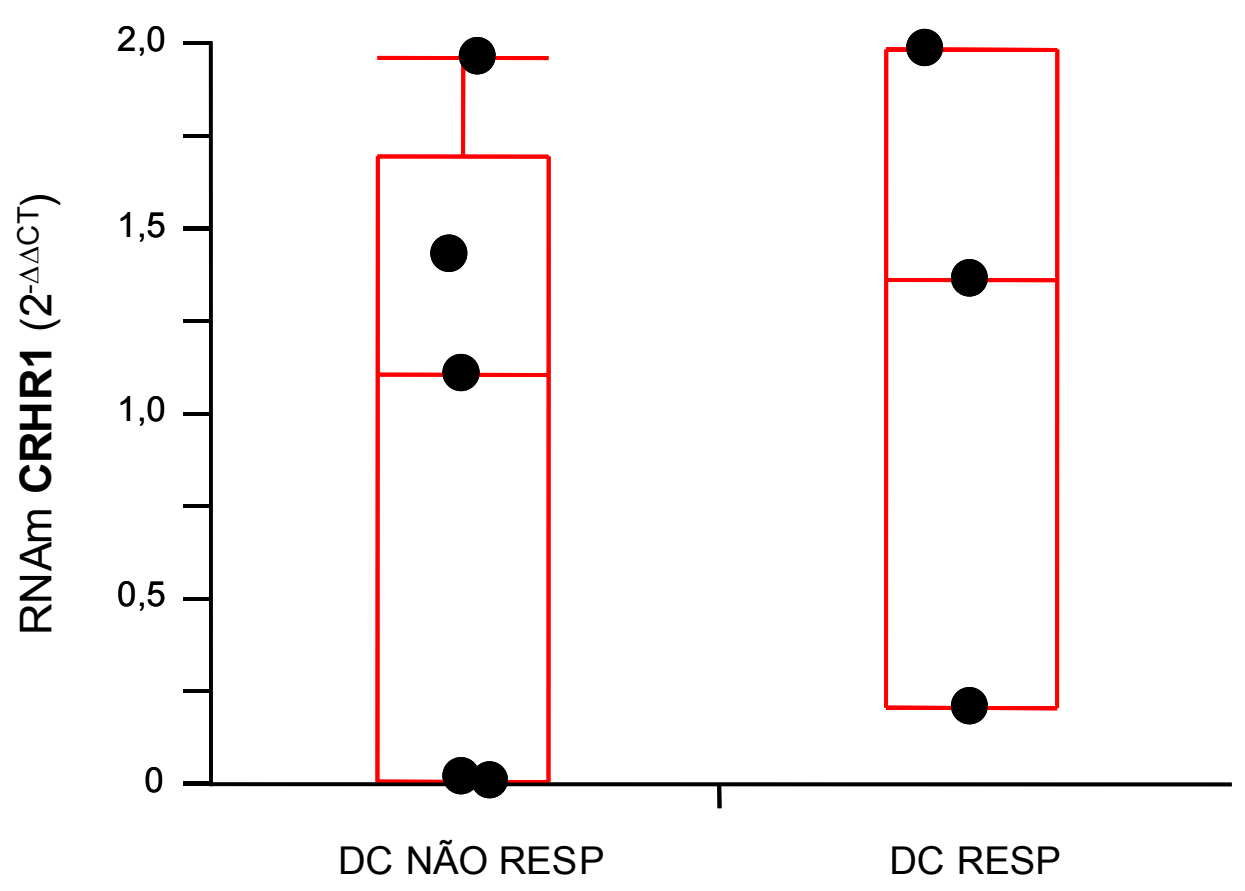

Teste do hCRH

Figura 23. Expressão do RNAm do CRHR1 nos pacientes com doença de Cushing responsivos e não responsivos ao teste do hCRH; DC, doença de Cushing 


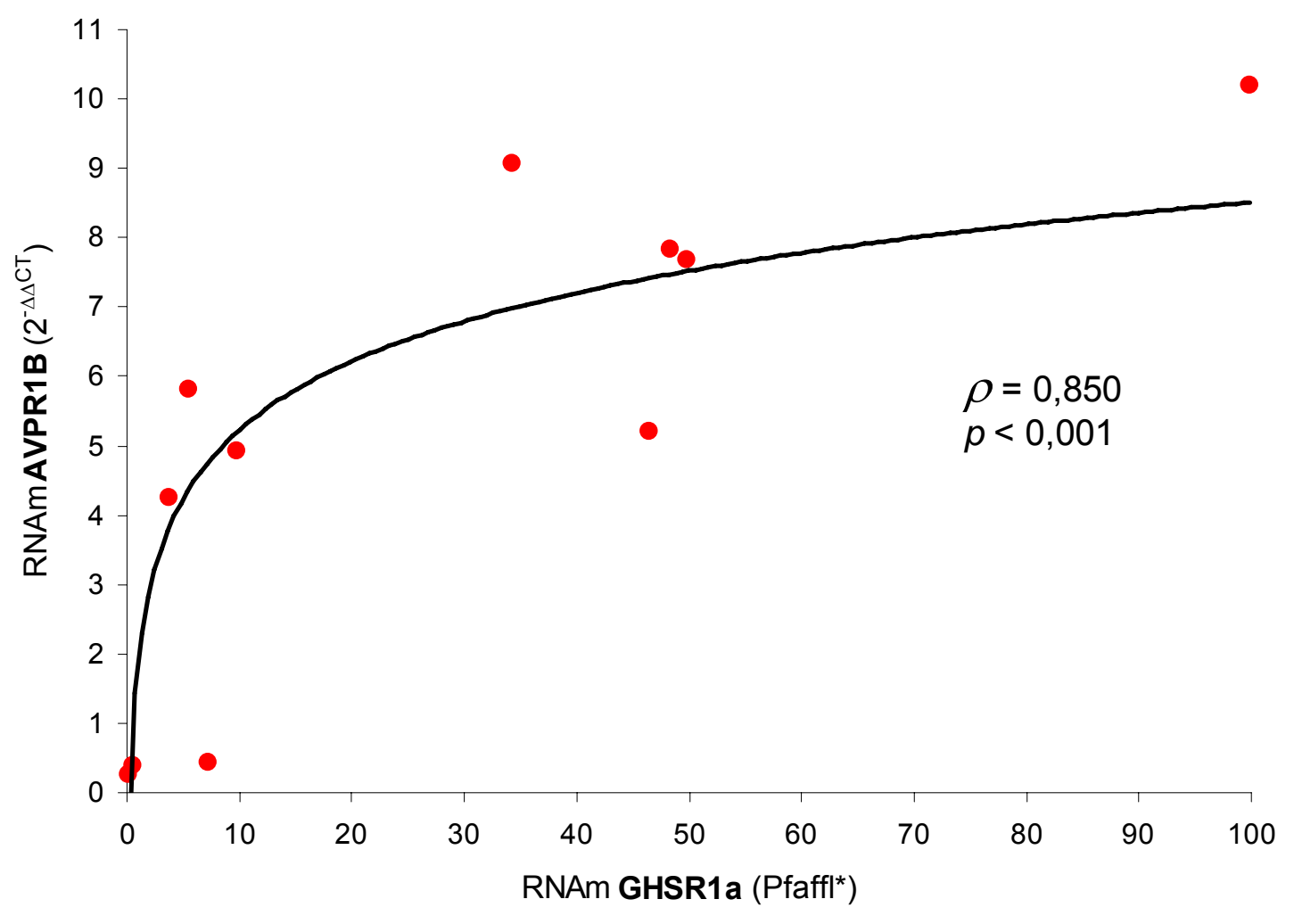

Figura 24. Correlação entre a expressão do RNAm dos receptores GHSR-1a e AVPR1B nas amostras de tumores corticotróficos; *modelo matemático de Pfaffl (2001) 


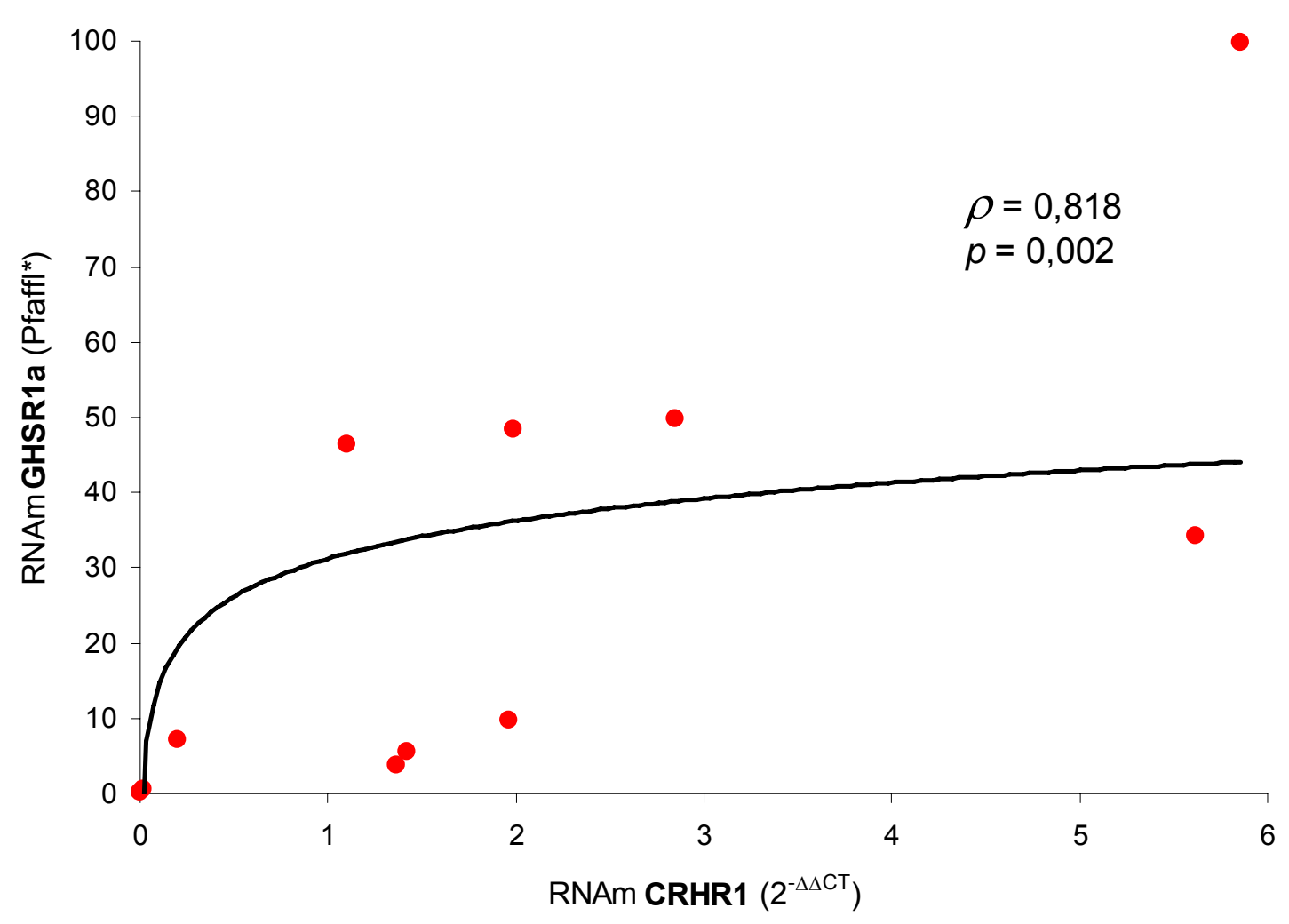

Figura 25. Correlação entre a expressão do RNAm dos receptores CRHR1 e GHSR-1a nas amostras de tumores corticotróficos; *modelo matemático de Pfaffl (2001) 


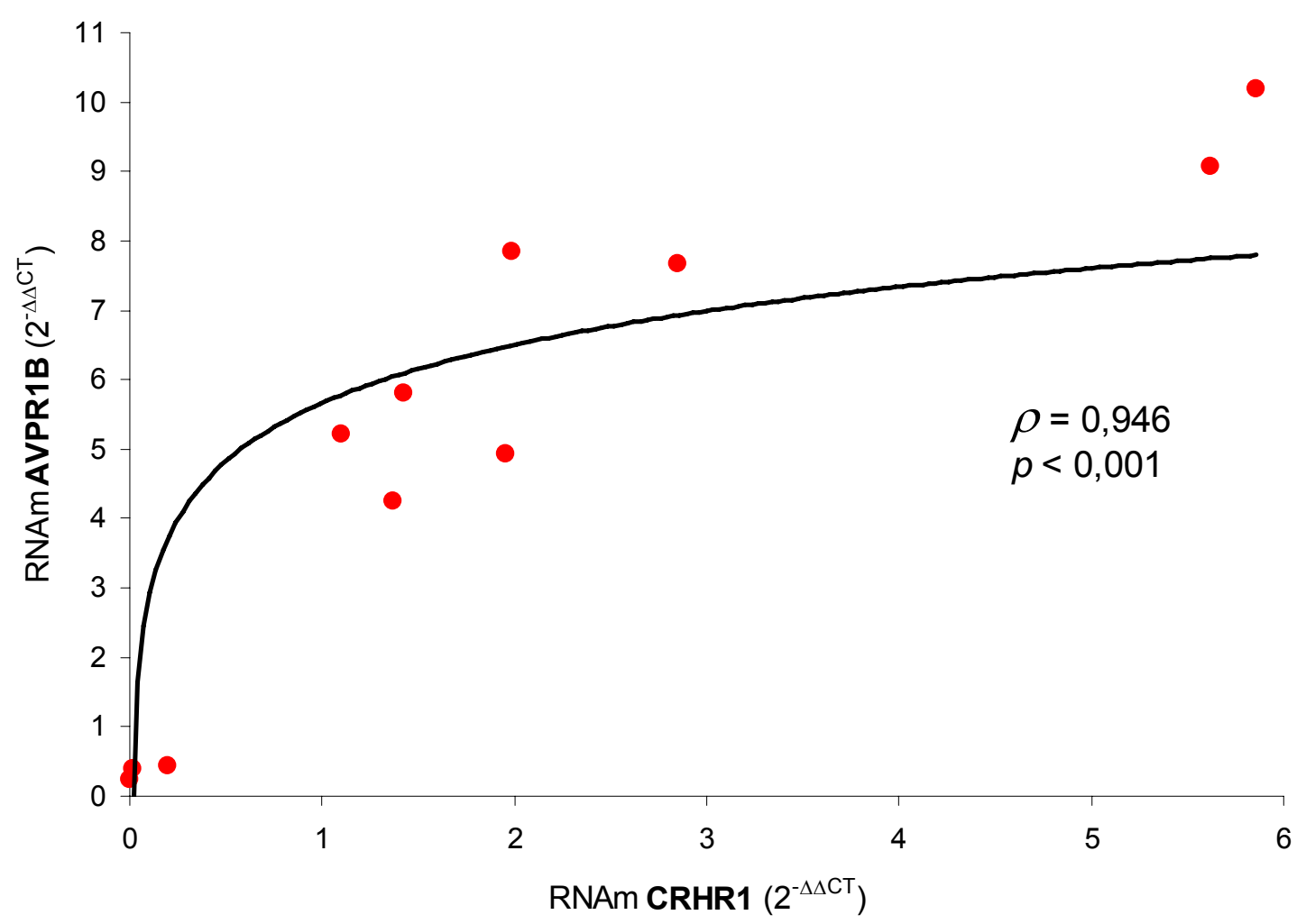

Figura 26. Correlação entre a expressão do RNAm dos receptores CRHR1 e AVPR1B nas amostras de tumores corticotróficos 
Tabela 15. Resultados dos testes de estímulo e resumo da expressão dos re ceptores nas amostras estudadas

\begin{tabular}{|c|c|c|c|c|c|c|c|c|c|c|c|}
\hline \multirow{2}{*}{$\mathbf{N}^{\circ}$} & \multirow{2}{*}{ Nome } & \multirow{2}{*}{$A P+I H$} & \multirow{2}{*}{ Diagnóstico } & \multirow{2}{*}{ Tumor } & \multicolumn{3}{|c|}{ RESPOSTA } & \multirow{2}{*}{$\begin{array}{c}\text { RT-PCR } \\
\text { PIT1 }\end{array}$} & \multicolumn{3}{|c|}{ qPCR } \\
\hline & & & & & GHRP-6 & Desmopressina & hCRH & & GHSR-1a* & AVPR1B $^{\mp}$ & CRHR1 $^{*}$ \\
\hline 1 & ALSJ & Adenoma hipofisário, ACTH + & Doença de Cushing & Microadenoma & + & - & + & - & 48,344 & 7,835 & 1,986 \\
\hline 3 & SCC & Adenoma hipofisário, ACTH + & Doença de Cushing & Microadenoma & + & + & - & - & 46,454 & 5,205 & 1,102 \\
\hline 7 & $\mathrm{CNCL}$ & Adenoma hipofisário, ACTH + & Doença de Cushing & Microadenoma & + & + & NR & - & 34,279 & 9,063 & 5,618 \\
\hline 9 & MAS & Adenoma hipofisário, ACTH + & Doença de Cushing & Microadenoma & + & + & NR & - & 99,857 & 10,196 & 5,856 \\
\hline 10 & JAMO & Adenoma hipofisário, ACTH + & Doença de Cushing & Microadenoma & + & + & NR & - & 49,770 & 7,674 & 2,848 \\
\hline 12 & ASM & Adenoma hipofisário, ACTH + & Doença de Cushing & Microadenoma & - & + & - & - & 0,556 & 0,384 & 0,019 \\
\hline 13 & MNL & Adenoma hipofisário, ACTH + & Doença de Cushing & Microadenoma & - & - & + & - & 3,718 & 4,257 & 1,366 \\
\hline 15 & PPS & Adenoma hipofisário, ACTH + & Doença de Cushing & Microadenoma & + & + & - & - & 5,491 & 5,816 & 1,424 \\
\hline 16 & MLMS & Adenoma hipofisário, ACTH + & Doença de Cushing & Microadenoma & - & - & - & - & 9,706 & 4,925 & 1,959 \\
\hline 19 & ZFS & Adenoma hipofisário, ACTH + & Doença de Cushing & MACROADENOMA & - & + & - & - & 0,116 & 0,252 & 0,002 \\
\hline 20 & MAMA & Adenoma hipofisário, ACTH + & Doença de Cushing & MACROADENOMA & + & + & + & - & 7,228 & 0,435 & 0,202 \\
\hline 21 & VBJ & Carcinóide tímico, ACTH + & SEA & Tímico & - & + & - & NR & 0,140 & 3,317 & 0,011 \\
\hline \multirow[t]{11}{*}{22} & JCJ & Carcinóide pulmonar, ACTH + & SEA & Pulmonar & + & - & - & NR & 33,176 & 0,688 & 0,002 \\
\hline & HN3 & $\mathrm{NR}$ & Hipófise normal & NR & NR & NR & NR & + & 8,464 & 1,181 & 0,540 \\
\hline & HN5 & NR & Hipófise normal & NR & NR & NR & NR & + & 1,000 & 0,959 & 1,214 \\
\hline & HN6 & NR & Hipófise normal & $N R$ & NR & NR & NR & + & 3,461 & 3,138 & 1,000 \\
\hline & HN7 & NR & Hipófise normal & NR & NR & $N R$ & NR & + & 7,766 & 0,287 & 0,126 \\
\hline & HN9 & NR & Hipófise normal & NR & NR & NR & $N R$ & + & 2,968 & 2,809 & 0,529 \\
\hline & HN10 & NR & Hipófise normal & NR & NR & NR & NR & + & 4,214 & 1,000 & 1,840 \\
\hline & HN11 & $N R$ & Hipófise normal & NR & $N R$ & $N R$ & NR & + & 7,960 & 3,249 & 0,088 \\
\hline & $\mathrm{TN} 1$ & $N R$ & Timo normal & $N R$ & $N R$ & $N R$ & NR & $N R$ & 0,035 & 0,049 & 0,001 \\
\hline & TN2 & NR & Timo normal & NR & NR & NR & $N R$ & NR & 0,608 & 0,000 & 0,001 \\
\hline & $\mathrm{PN}$ & NR & Pulmão normal & NR & NR & NR & NR & NR & 0,174 & 0,000 & 0,000 \\
\hline
\end{tabular}

$\mathrm{N}^{\circ}$ Número do paciente; AP + IH, Anátomo-patolológico e imunohistoquímica; NR, Não realizado; SEA, Secrecão Ectópica de ACTH; +, positivo; - negativo; RT-PCR, reação em cadeia da polimerase pela transcripatse reversa; qPCR, reação de PCR quantitativa; ${ }^{*}$ modelo matemático de Pfaffl (2001); ${ }^{*}$ cálculo do $2^{-\Delta \Lambda C T}$ (Livak e Schmittgen, 2001) 


\section{DISCUSSÃO}

O diagnóstico diferencial da síndrome de Cushing ACTH-dependente é um dos maiores desafios da clínica endocrinológica. Isso decorre entre outros fatores, da baixa sensibilidade da RM que evidencia apenas $50 \%$ dos tumores corticotróficos, pela limitação da especificidade dos testes dinâmicos e principalmente pelo comportamento clínico e laboratorial semelhante de alguns tumores carcinóides com a doença de Cushing. Esse diagnóstico diferencial é por vezes tão difícil que $12,5 \%$ dos pacientes em um centro de referência permaneceram com etiologia indefinida mesmo após anos de inúmeros procedimentos diagnósticos e terapêuticos (Isidori et al., 2006).

O cateterismo bilateral e simultâneo de seios petrosos inferiores é o teste padrão ouro nesse diagnóstico diferencial. Apesar da maior casuística de pacientes que foram submetidos a este procedimento ter mostrado acurácia de 100\% (Oldfield et al., 1991), outras casuísticas importantes mostraram acurácia em torno de 94\% (87 a 98\%) (Newell-Price et al., 1998; Invitti et al., 1999; Kaltsas et al., 1999; Colao et al., 2001; Lefournier et al., 2003; Lindsay e Nieman, 2005). Entretanto, o CBSSPI é um teste invasivo e não isento de complicações potencialmente letais, embora muito pouco freqüentes (Lefournier et al., 1999). Outra desvantagem é a necessidade de realização do procedimento em centros de referência com experiência no método. 
Assim, há muitos anos, tem-se usado testes dinâmicos de secreção hormonal com o objetivo de identificar respostas que sejam preditivas e específicas para esse diagnóstico diferencial, utilizando-se os testes do $\mathrm{CRH}$, da desmopressina, e mais recentemente, com os GHS (Ghigo et al., 1997b). Por outro lado, sabe-se que alguns pacientes com doença de Cushing não respondem a um ou outro secretagogo (Newell-Price et al., 1998), sendo então importante o conhecimento e disponibilidade de vários estimulantes para serem usados nos testes dinâmicos e durante o CBSSPI.

O padrão de respostas exageradas de $\mathrm{ACTH}$ e cortisol com $\mathrm{CRH}$ e com a desmopressina nos pacientes com síndrome de Cushing ACTH-dependente tem sido atribuído à "superexpressão" dos respectivos receptores CRHR1 e AVPR2/AVPR1B nesses tumores, sendo que diferenças de expressão poderiam explicar as diferentes respostas apresentadas nos pacientes. Entretanto, poucos estudos foram feitos com o objetivo de comprovar tal associação.

Em relação aos GHS, existe ainda mais dúvida acerca do mecanismo pelo qual ocorrem as respostas de ACTH e cortisol nos pacientes com doença de Cushing. Os estudos de expressão do receptor GHSR-1a nos tumores corticotróficos são discordantes no que se referem à comparação com o tecido hipofisário normal (de Keyzer et al., 1997, Korbonits et al., 2001). Em trabalho recente aventou-se a hipótese de a resposta ser mediada pelo AVP, observando-se estímulo de ACTH e cortisol semelhante da desmopressina e do GHRP-6, além de forte correlação do pico de cortisol com os dois secretagogos, sugerindo um efeito mediado por vias semelhantes (Oliveira et al., 2003). Esse mecanismo secretório dos GHS é o mais provável em indivíduos normais (Korbonits et al., 2004), porém, menos provável na doença de Cushing. Além disso, o mecanismo central (sistema nervoso central) da ação sobre o eixo hipotálamo-hipófise-adrenal dos GHS nos 
indivíduos normais, provavelmente inclui ações mediadas pelo $\mathrm{CRH}$, neuropeptídeo Y e GABA (Korbonits et al., 2004; Giordano et al., 2004).

Além da avaliação das respostas à desmopressina e ao hCRH e correlação com a expressão do RNAm dos respectivos receptores AVPR1B e CRHR1, o trabalho em apreço teve como objetivos mais importantes: correlacionar os padrões de resposta de ACTH e cortisol in vivo com o GHRP-6 com a expressão do RNAm do receptor GHSR-1a; avaliar o uso do GHRP-6 no diagnóstico diferencial da síndrome de Cushing ACTH-dependente; e comparar as respostas de ACTH e cortisol dos pacientes com doença de Cushing com indivíduos controles pareados em sexo e idade. Para tanto, foi avaliada uma das maiores casuísticas individuais de pacientes com síndrome de Cushing ACTH-dependente que foi submetida ao estímulo com um GHS, contendo dois tumores ectópicos produtores de ACTH.

Em semelhança ao que ocorre com a desmopressina e principalmente com o $\mathrm{CRH}$, onde os indivíduos normais respondem a esses secretagogos, o GHRP-6 não foi capaz de discernir os pacientes com a doença de Cushing dos indivíduos controles, tanto pela análise do incremento percentual de resposta quanto pelo aumento absoluto do ACTH e cortisol (Figura 9). Por isso, postula-se que somente testes de estímulo após supressão com dexametasona, principalmente com o $\mathrm{oCRH}$, seriam úteis no diagnóstico diferencial entre hipercortisolismo endógeno e quadros de pseudo-Cushing (Yanovski et al., 1993).

Pelo valor de corte de cortisol tradicionalmente utilizado nos testes de estímulo com oCRH e desmopressina (Nieman et al., 1993) e pelos resultados nos pacientes com SEA deste trabalho, definimos como resposta positiva de cortisol ao GHRP-6 um aumento de > 20\% em relação ao basal. Com relação ao $\mathrm{ACTH}$, é sabido que sua especificidade é menor que o cortisol para o diagnóstico diferencial entre a doença de Cushing e a SEA (Newell-Price et al., 1998 e 2002), fato comprovado nos casos deste trabalho. Assim, semelhante ao critério utilizado 
na literatura para o ACTH no teste de estímulo com oCRH (Kaye \& Crapo, 1990; Invitti et al., 1999; Giraldi et al., 2001), pelo valor de corte usado para vários tipos de respostas hormonais (exemplo: respostas anômalas de cortisol em AIMAH; Lacroix et al., 2001), e pela limitação da casuística do trabalho, foi definido como resposta positiva de $\mathrm{ACTH}$ ao GHRP-6 um incremento de $>50 \%$ em relação ao valor basal. A utilização desse critério foi mais arbitrária do que com o cortisol, pois não diferenciou os pacientes com doença de Cushing do paciente com SEA, sendo mais importante na correlação da resposta in vivo ao GHRP-6 com o estudo molecular do GHSR-1a.

Utilizando-se então esses critérios, foi observada resposta positiva de ACTH e cortisol ao GHRP-6 na maioria dos pacientes com DC concordando com os dados da literatura com GHS na síndrome de Cushing (Ghigo et al., 1997b; Arvat et al., 1998; Grottoli et al., 1999; Arvat et al., 1999; Coiro et al., 2000; Leal-Cerro et al., 2002; Oliveira et al., 2003; Silva et al., 2006), sendo essas respostas mais intensas do que nos indivíduos controles (Figura 8). Individualmente, 65\% (13/20) dos pacientes com doença de Cushing responderam ao teste do GHRP-6, embora, analisando em separado as respostas, $70 \%$ (14/20) tiveram respostas positivas ao cortisol e $70 \%$ $(14 / 20)$ com o ACTH.

Idealmente, seria necessário maior número de pacientes submetidos ao teste do GHRP-6, especialmente mais casos de SEA, para se estabelecer valores de corte suficientes para uma especificidade de $100 \%$ no diagnóstico diferencial da SC ACTH-dependente. Além disso, este trabalho não teve como objetivo primário definir um critério de resposta para o teste do GHRP-6. Assim, as dosagens hormonais foram realizadas com ensaios disponíveis na rotina de avaliação dos pacientes da instituição, estando sob influência das limitações próprias de cada laboratório, especialmente em relação à sensibilidade do ensaio do ACTH. 
De qualquer modo, é inequívoco o fato de um dos pacientes com SEA deste estudo ter respondido fortemente ao GHRP-6 (ACTH: 883 para $1545 \mathrm{pg} / \mathrm{mL}, 75 \%$ ), sendo o segundo caso de SEA a ser documentado na literatura responsivo ao GHS. O primeiro caso descrito foi um tumor carcinóide brônquico que respondeu à hexarelina (Arnaldi et al., 2003b). Nesse último caso, foi demonstrada a expressão do RNAm do GHSR-1a no tumor por RT-PCR. Apesar do pequeno número de pacientes da literatura que foram submetidos a testes com os GHS na SC, essas duas respostas em pacientes com SEA, limitam o uso desse teste no diagnóstico diferencial na SC ACTH-dependente.

Com relação ao $\mathrm{GH}$, houve um aumento significativo do hormônio após o estímulo do GHRP-6 nos indivíduos controles, maior que nos pacientes portadores da SC (Figura 8). Nesses últimos pacientes, como esperado e relatado em outros trabalhos (Leal-Cerro et al., 1994; Borges et al., 1997; Ghigo et al., 1997; Leal-Cerro et al., 2002; Correa-Silva et al., 2004 ${ }^{1}$ ), houve uma resposta atenuada na secreção de $\mathrm{GH}$, especialmente na $\mathrm{DC}$. Em relação às concentrações de IGF1, não houve diferença entre os pacientes com SC e os indivíduos controles (Tabela 11), concordando com dados da literatura (Lebrethon et al., 2000).

Classicamente, o hipercortisolismo crônico, como na SC, está associado com respostas bloqueadas de $\mathrm{GH}$ a vários tipos de estímulos (Casanueva et al., 1992). Os mecanismos pelos quais ocorrem esses bloqueios não estão totalmente esclarecidos, mas podem ser em parte atribuídos ao aumento do tônus somatostaninérgico, diminuição da liberação do GHRH e ação inibitória direta do cortisol na hipófise (Leal-Cerro et al., 1994; Borges et al., 1997). Por outro lado, um

\footnotetext{
${ }^{1}$ Correa-Silva SRC, Nascif SO, Silva MR, Senger MH, Miranda WL, Machado AF, Lengyel AMJ. (Divisão de Endocrinologia, Universidade Federal de São Paulo, UNIFESP/EPM, São Paulo, SP). Decreased $\mathrm{GH}$ secretion and enhanced ACTH and cortisol release after ghrelin administration in Cushing's disease: comparison with GHRP-6. (Presented at 12h International Congress of Endocrinology (ICE), 2004 August 31-September 4; Lisbon, Portugal. Abstracts p913-917).
} 
estudo mostrou que o hipercortisolismo exógeno (2 a 6 meses de prednisona 20-60 mg) não alterou a resposta ao GHRP-6 (Borges et al., 1997), refletindo provavelmente a magnitude do bloqueio do hipercortisolismo, dependente da intensidade e duração do quadro. Assim, pode ocorrer resposta de GH aos GHS num quadro de SC leve ou não haver nenhuma resposta em casos graves como nos pacientes com SEA deste estudo.

O estudo molecular do receptor GHSR-1a através de PCR quantitativa mostrou uma tendência de maior expressão do RNAm desse receptor nas amostras dos pacientes com DC quando comparado às hipófises normais, porém, sem significância estatística (Figura 13). Trabalhos anteriores dessa expressão nos tumores corticotróficos mostraram resultados conflitantes, possivelmente devido a limitações, como: uso de iniciadores que não distinguiam qual o receptor do GHS estudado (“GHSR”), pequeno número de amostras ou, também, metodologias menos precisas (RT-PCR semiquantitativa). De Keyzer et al. (1997) relataram expressão aumentada do GHSR-1a nos pacientes com DC ( $n=18)$, utilizando RT-PCR semiquantitativa. Em estudo recente e o único até então com PCR quantitativo, Korbonits et al. (2001) mostraram expressão semelhante desse receptor nas amostras de pacientes com DC $(n=12)$ e em hipófises normais, resultados portanto semelhantes aos encontrados em nosso trabalho.

Apesar dos estudos de expressão do RNAm do GHSR-1a serem conflitantes, há evidências in vitro que sugerem um efeito direto dos GHS nos tumores corticotróficos. Um estudo em culturas de tumores corticotróficos, demonstrou secreção de ACTH dose-dependente após estimulação direta com o MK-0677 (Barlier et al., 1999). No entanto, outros autores não observaram essa ação direta também em culturas de adenomas corticotróficos, utilizando metodologia de mensuração do fluxo de cálcio intracelular (Lania et al., 1998). 
Entretanto, em nosso estudo, analisando a expressão do RNAm do GHSR1a com a resposta in vivo ao GHS nos pacientes com síndrome de Cushing ACTHdependente, foi demonstrado maior expressão do GHSR-1a nas amostras dos pacientes com DC responsivos ao GHRP-6 quando comparado aos não responsivos (Figura 20). Embora a expressão do GHSR-1a tenha sido semelhante nas hipófises normais e nos tumores corticotróficos como um todo (Figura 13), quando analisados somente os casos responsivos, houve maior expressão do que nas hipófises normais (Figura 20). Além disso, nos casos de SEA, houve forte associação entre a resposta in vivo e a expressão do RNAm do GHSR-1a (Figura $21 \mathrm{~A}$ ).

Embora não se possa excluir a influência de outros fatores mediando essas respostas, tais como interação entre os receptores (Figuras 24 e 25), os achados deste trabalho sugerem fortemente o efeito direto dos GHS nos tumores, e que a "superexpressão" do RNAm do GHSR-1a seja responsável pela resposta exagerada de ACTH e cortisol com os GHS nos pacientes com SC ACTH-dependente.

Contudo, um aspecto ainda não esclarecido sobre a fisiopatologia da expressão do receptor GHSR-1a nos pacientes com SC, é se a expressão aumentada desse receptor seria primária nos tumores ou induzida pelo hipercortisolismo. Estudo em animais, mostrou que a adrenalectomia reduzia significativamente a expressão do RNAm do GHSR na hipófise e que a terapia substitutiva com dexametasona restabelecia essa expressão (Tamura et al., 2000).

Entretanto, um trabalho estudou a região promotora do gene GHSR-1a humano responsiva a glicocorticóide, demonstrando regulação negativa na transcrição desse gene com infusão de hidrocortisona (Petersenn et al., 2001). Não existem estudos com modelos de animais transgênicos para o GHSR-1a na tumorigênese hipofisária, como também não existe estudo que pesquisou mutações 
nesse receptor que é acoplado à proteína $G$ (subfamília $G_{q}$ ), em pacientes portadores da SC ACTH-dependente.

Apesar de não ter sido objeto de estudo, é necessário fazer algumas considerações sobre a relação da ghrelina com os tumores corticotróficos. Recentemente, um trabalho mostrou co-localização da ghrelina e do ACTH em grânulos secretórios de dois corticotrofinomas densamente granulados, através de imunohistoquímica por microscopia eletrônica. Com isso, foi aventada a hipótese de ação autócrina/parácrina da ghrelina na secreção de ACTH nos tumores corticotróficos (Martínez-Fuentes et al., 2006). Outro ponto discutido no trabalho foi o papel da ghrelina na proliferação celular desses tumores hipofisários. Sabe-se que a ghrelina possui ação na proliferação de linhagens celulares de neoplasias (próstata, fígado, adrenal, pâncreas, entre outras) (Korbonits et al., 2004) e em uma linhagem de somatotrofinomas de ratos (Nanzer et al., 2004). São necessários outros estudos para entender o papel da ghrelina na regulação celular dos tumores hipofisários, especialmente nos produtores de GH e ACTH.

Finalmente, em relação à ghrelina, há evidências de que suas concentrações plasmáticas estão alteradas em pacientes portadores da síndrome de Cushing quando comparadas às dos indivíduos normais. Porém, os resultados dos trabalhos são contraditórios. Assim, mais estudos são necessários para elucidar a possível contribuição dos níveis circulantes de ghrelina nas respostas exageradas de ACTH e cortisol nos pacientes com DC (Martínez-Fuentes et al., 2006).

Conforme esperado e assim como no teste do GHRP-6, a maioria dos pacientes com DC respondeu ao estímulo com a desmopressina, utilizando o critério tradicionalmente aceito na literatura ( $>20 \%$ para o cortisol e $>35 \%$ para o ACTH) (Nieman et al., 1993). Individualmente, a resposta ocorreu em $75 \%$ (15/20) dos pacientes com DC, sendo que os cinco pacientes que não tiveram resposta positiva em cortisol responderam em ACTH. Entretanto, um paciente portador de 
SEA (tumor carcinóide de timo) respondeu brilhantemente em ACTH (360 para $1326 \mathrm{pg} / \mathrm{mL}, 268 \%$ ). Newell-Price et al. (1998) relataram resposta à desmopressina em tumores ectópicos produtores de ACTH em $28,5 \%$ dos casos. Por outro lado, raramente os pacientes com SEA respondem ao $\mathrm{CRH}$. Assim, o teste da desmopressina possui menor especificidade que o estímulo com $\mathrm{CRH}$.

Existem relatados na literatura de SEA que responderam in vivo à desmopressina e demonstraram expressão do RNAm dos receptores AVPR1B (de Keyzer et al., 1996, dois casos; Arlt et al., 1997, um caso; e Tsagarakis et al., 2002, dois casos) e AVPR2 (Arlt et al., 1997, um caso; Tsagarakis et al., 2002, três casos). Entretanto, essa correlação não é perfeita. Nos estudos supracitados, alguns casos não tiveram concordância entre a resposta in vivo e a expressão dos receptores.

$\mathrm{Na}$ DC, estudos que analisaram essa correlação clínico-molecular são ainda mais escassos. No trabalho de Dahia et al. (1996), nos 11 casos de DC que tiveram significante expressão do AVPR1B, somente um paciente foi submetido ao teste da desmopressina, sendo responsivo. Um estudo recente, correlacionou as respostas in vivo e in vitro da desmopressina em pacientes com tumores corticotróficos e em culturas de células desses tumores. Não foi encontrada correlação entre as respostas, ou seja, a resposta in vivo não foi reproduzida quando foi feito o estímulo direto in vitro. $O$ autor sugeriu que o efeito estimulatório de ACTH da desmopressina seja mediado por fatores extrahipofisários (Pecori Giraldi et al., 2003).

Outro fator importante e pouco relatado nos estudos, mas verificado na prática clínica, é a limitada reprodutibilidade dos testes principalmente com a desmopressina. Com os GHS, sabe-se que existe boa reprodutibilidade nas respostas, principalmente com relação ao GH (Ghigo et al., 1997a). Em nosso estudo, alguns pacientes que não responderam ao teste do GHRP-6 foram retestados, comprovando o resultado prévio. 
Neste trabalho, houve maior expressão do RNAm do receptor AVPR1B nas amostras dos pacientes com DC, quando comparado às hipófises normais (Figura 16). Esse resultado está de acordo com os dados já relatados na literatura (de Keyzer et al., 1996; Dahia et al., 1996; de Keyzer et al., 1998). Entretanto, não houve diferença na expressão do AVPR1B nos pacientes com DC quando divididos entre responsivos e não responsivos ao teste da desmopressina, talvez pelo pequeno número de pacientes estudados que não responderam. Embora a relação direta entre a resposta in vivo e a expressão do receptor não tenha sido demonstrada, a maioria dos pacientes respondeu à desmopressina e também apresentou maior expressão do AVPR1B.

Além disso, houve nítida associação entre a expressão do RNAm do AVPR1B e resposta à desmopressina nos pacientes com SEA. A paciente portadora do tumor carcinóide tímico que respondeu ao teste da desmopressina, apresentou maior expressão do que os timos normais, e $5 \mathrm{X}$ maior expressão do que no tumor carcinóide pulmonar onde não se observou resposta in vivo (Figura $21 \mathrm{~B}$ ).

Assim, os resultados sugerem uma associação da expressão do receptor AVPR1B com a resposta de ACTH e cortisol com a desmopressina nos pacientes portadores da SC ACTH-dependente, principalmente na SEA. Da mesma forma que a correlação clínico-molecular do gene GHSR-1a, também não pode ser excluído o papel de outros fatores como a influência dos outros receptores, dada a significativa relação de expressão entre eles (Figuras 24 e 26).

Semelhante ao que ocorre com o receptor GHSR-1a, existe na literatura algum questionamento sobre influência do hipercortisolismo sobre a expressão do receptor AVPR1B. Estudo em animais mostrou que administração de corticóides regulava positivamente o AVPR1B (Rabadan-Diehl et al., 1997). Entretanto, os dados de expressão do receptor AVPR1B em casos de DC e de SEA, são 
sugestivos de que a expressão seja primária e não induzida pelo hipercortisolismo. Outro ponto importante, é que mutações ativadoras no AVPR1B não parecem fazer parte da patogênese da $D C$, já que não foram encontradas mutações em amostras de tumores corticotróficos (Dahia et al., 1996).

Em relação ao teste do $\mathrm{CRH}$ deste trabalho, algumas limitações importantes prejudicaram a correta análise da associação da resposta in vivo com a expressão do RNAm do CRHR1. Um terço dos pacientes não realizaram o teste por indisponibilidade desse peptídeo no momento da avaliação diagnóstica.

Apesar da menor e menos prolongada resposta do $\mathrm{hCRH}$ quando comparada ao oCRH descrita na literatura (Kaye e Crapo, 1990), as respostas obtidas em nossos pacientes foram bem menores que as esperadas. Individualmente, $46 \%$ dos pacientes com DC responderam ao teste, mesmo utilizando um critério mais adequado de resposta ( $>14 \%$ para o cortisol e $>50 \%$ para o $\mathrm{ACTH})$.

A avaliação quantitativa da expressão do RNAm do CRHR1 mostrou resultado semelhante nas amostras dos pacientes com DC e nas hipófises normais (Figura 19). Esse resultado não corrobora aqueles já descritos na literatura (de Keyzer et al., 1996; de Keyzer et al., 1998; Dieterich et al., 1998). Entretanto, os estudos anteriores não utilizaram metodologias quantitativas, sendo este trabalho o primeiro a fazê-lo na SC ACTH-dependente.

Vale ressaltar a associação da expressão do RNAm do CRHR1 com a resposta ao hCRH nos pacientes com SEA, uma vez que não apresentaram resposta e nem expressão do receptor (Figura $21 \mathrm{C}$ ).

Um estudo mostrou expressão do RNAm do CRHR1 em amostras de pacientes com tumores carcinóides brônquicos, mas não correlacionou com respostas in vivo ao $\mathrm{CRH}$ (de Keyzer et al., 1996). 
Assim como o receptor AVPR1B, mutações ativadoras no CRHR1 também não parecem fazer parte da patogênese da $D C$, uma vez que não foram reportadas mutações em tumores corticotróficos (Dieterich et al., 1998). 


\section{CONCLUSÕES}

1. Houve maior expressão do RNAm do receptor GHSR-1a em pacientes com síndrome de Cushing ACTH-dependente que responderam ao GHRP-6, estabelecendo uma relação direta entre a expressão do receptor e a resposta in vivo ao secretagogo, tanto em pacientes com doença de Cushing quanto nos pacientes portadores de tumores ectópicos produtores de ACTH.

2. Não foi observada relação direta entre a expressão do RNAm do receptor AVPR1B com a resposta in vivo à desmopressina nos pacientes com doença de Cushing. Nos pacientes portadores de Secreção Ectópica de ACTH, houve relação entre a resposta in vivo à desmopressina e a expressão do AVPR1B.

3. A magnitude de expressão do RNAm do receptor CRHR1 foi semelhante entre as amostras dos tumores corticotróficos e hipófises normais, não havendo também, associação da resposta in vivo ao hCRH com a expressão do receptor CRHR1 nos pacientes com doença de Cushing. Entretanto, nos pacientes com Secreção Ectópica de ACTH, foi demonstrada a associação da resposta com a expressão. 
4. Um dos pacientes com Secreção Ectópica de ACTH respondeu significativamente ao GHRP-6, limitando o uso do secretagogo no diagnóstico diferencial da síndrome de Cushing ACTH-dependente.

5. Com relação ao teste do GHRP-6, não foram observadas linhas de corte para ACTH e cortisol, capazes de diferenciar os indivíduos controles dos pacientes com doença de Cushing, embora a magnitude de resposta dos hormônios tenha sido maior nos pacientes portadores de tumores corticotróficos. 
ANEXO A
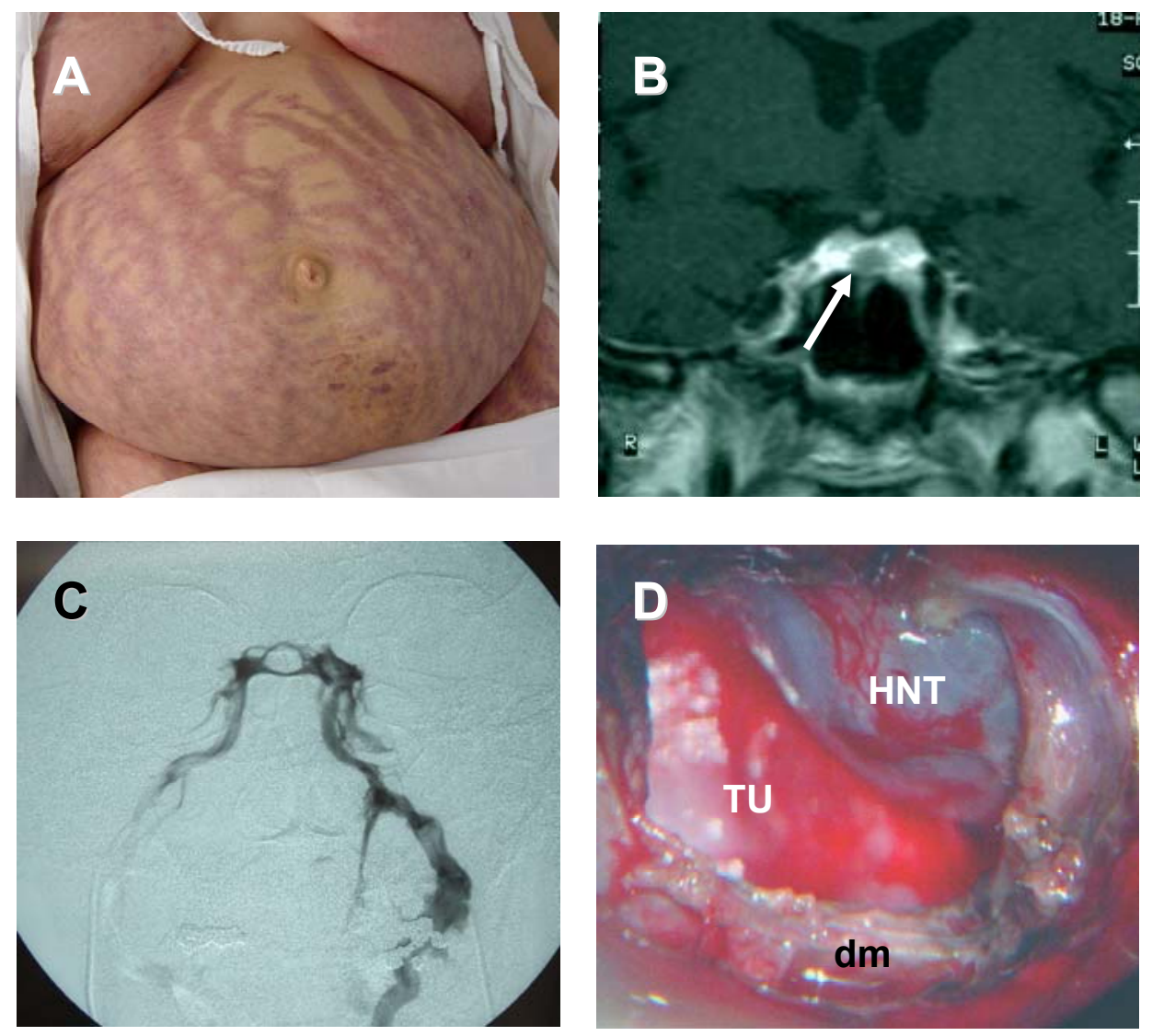

Figura Capa. A) Foto de paciente com síndrome de Cushing (SC) com múltiplas estrias violáceas largas em abdome e coxas; B) Imagem de RM, T1, corte coronal pós gadolíneo, em paciente com SC devido a tumor carcinóide pulmonar, mostrando imagem hipocaptante (seta) na porção mediana da hipófise (incidentaloma); C) Imagem em subtração de cateterismo bilateral de seios petrosos inferiores, mostrando cateteres posicionados nos seios petrosos inferiores e infusão de contraste à esquerda com refluxo para o lado contralateral; D) Visão cirúrgica de acesso transesfenoidal em paciente com macroadenoma hipofisário produtor de ACTH, mostrando abertura da duramáter $(\mathrm{dm})$, lesão amarelada tumoral (TU) e tecido acinzentado à esquerda (tecido hipofisário não tumoral, HNT) 
ANEXO B

\section{HOSPITAL DAS CLÍNICAS}

DA

FACULDADE DE MEDICINA DA UNIVERSIDADE DE SÃO PAULO

\section{TERMO DE CONSENTIMENTO LIVRE E ESCLARECIDO}

(Instruções para preenchimento no verso)

\section{I - DADOS DE IDENTIFICAÇÃO DO SUJEITO DA PESQUISA OU RESPONSÁVEL LEGAL}

1. NOME DO PACIENTE .

DOCUMENTO DE IDENTIDADE $\mathrm{N}^{\circ}$ :

SEXO : $\quad M$

M F

DATA NASCIMENTO: .$/$. $1 / \ldots$

$\mathrm{N}^{0}$

APTO:

BAIRRO:

CIDADE

CEP:

TELEFONE: DDD

..)

2. RESPONSÁVEL LEGAL

NATUREZA (grau de parentesco, tutor, curador etc.)

DOCUMENTO DE IDENTIDADE .

DATA NASCIMENTO .: .......................................

ENDEREÇO:

SEXO : $\quad M$

$\mathrm{F}$

BAIRRO:

CEP:

CIDADE:

$\mathrm{N}^{\circ}$

APTO:

TELEFONE: DDD (

\section{II - DADOS SOBRE A PESQUISA CIENTÍFICA}

1. TÍTULO DO PROTOCOLO DE PESQUISA: Estudo da expressão dos receptores da vasopressina (V2R e V3R), do receptor do GHS (GHSR-1a) e do receptor do CRH (CRHR-

1) em pacientes com tumores corticotróficos: Correlação clínico-molecular

2. PESQUISADOR: Márcio Carlos Machado

CARGO/FUNÇÃO: Médico INSCRIÇÃO CONSELHO REGIONAL No 98291

UNIDADE DO HCFMUSP: Unidade de Neuroendocrinologia, Disciplina de Endocrinologia e Metabologia

3. AVALIAÇÃO DO RISCO DA PESQUISA:

$\begin{array}{lll}\text { SEM RISCO } & \text { RISCO MÍNIMO X } & \text { RISCO MÉDIO } \\ \text { RISCO BAIXO } & \text { RISCO MAIOR } & \end{array}$

(probabilidade de que o indivíduo sofra algum dano como consequência imediata ou tardia do estudo)

4. DURAÇÃO DA PESQUISA : 4 anos 


\title{
III - REGISTRO DAS EXPLICAÇÕES DO PESQUISADOR AO PACIENTE OU SEU REPRESENTANTE LEGAL SOBRE A PESQUISA, CONSIGNADO:
}

\section{SOMENTE PARA OS PACIENTES COM A SÍNDROME DE CUSHING:}

\begin{abstract}
Algumas vezes é difícil diagnosticar a síndrome de Cushing. Por isso, vários medicamentos são usados em exames de sangue para tentar facilitar esse diagnóstico. O nosso trabalho pretende estudar pacientes com a síndrome de Cushing e realizar alguns exames para tentar melhorar o diagnóstico dessa doença.
\end{abstract}

Será necessária a realização de alguns exames (testes):

1. Teste da desmopressina: Será feito pela manhã, em jejum, começando em torno das $7 \mathrm{~h} 30$, com o paciente deitado numa cama ou leito de hospital. Coloca-se uma agulha na veia do braço do paciente. Ao colocar essa agulha o paciente vai sentir uma picada. Retira-se um pouco de sangue (mais ou menos 1 colher de chá). Coloca-se um soro ligado à veia. Espera-se 15 a 30 minutos, retira-se mais um pouco de sangue, mas agora, não é mais picado o paciente. O sangue é retirado direto do equipo do soro, não tendo mais nenhuma dor. Aguardam-se mais 30 minutos. Em seguida, é colhido sangue novamente e é aplicada a medicação na veia (Desmopressina). Colhe-se sangue mais 5 vezes (15, 30, 45, 60 e 90 minutos após a medicação). Normalmente, o paciente não tem nenhum sintoma, mas pode sentir gosto de metal na boca, enjôo leve e sensação do calor no rosto no início do exame, mas sempre terá uma equipe de enfermagem e um médico junto do exame para tratarem os sintomas. Após a última retirada do sangue, será tirado o soro, colocado um curativo no local da picada e se o paciente estiver se sentindo bem volta para onde estava (maior parte das vezes, para a enfermaria da Endocrinologia).

2. Teste do $\mathrm{CRH}$ : O exame é exatamente igual ao anterior, no horário, na posição, nas coletas de sangue, nos sintomas, sendo diferente somente a medicação que será injetada (hCRH - Hormônio liberador de ACTH).

3. Teste do GHRP-6: Também igual aos dois exames anteriores, sendo diferente só a medicação que será injetada na veia (GHRP-6: Peptídeo liberador do hormônio do crescimento).

Os exames serão feitos em dias diferentes, com intervalo de pelo menos 2 dias. Exemplo: segunda, quarta e sexta-feira.

Para tratar essa síndrome de Cushing, precisa fazer uma cirurgia. Na maioria das vezes, a cirurgia é feita pelo nariz para poder chegar até o tumor que está causando a doença. Esse tumor será retirado e mandado para o laudo. Eu também participo dessa cirurgia (expectador) e pego um pequeno pedaço do tumor para estudo no laboratório, sem prejudicar o maior pedaço que vai para laudo.

Após a cirurgia, o paciente continuará o seu tratamento normal na Unidade da Endocrinologia que estava acompanhando, seguindo a rotina normal do atendimento. 
III - REGISTRO DAS EXPLICAÇÕES DO PESQUISADOR AO PACIENTE OU SEU REPRESENTANTE LEGAL SOBRE A PESQUISA, CONSIGNADO:

\section{SOMENTE PARA AS PESSOAS NORMAIS (VOLUNTÁRIAS) QUE PARTICIPÃO DO ESTUDO:}

Algumas vezes é difícil diagnosticar a síndrome de Cushing. Por isso, vários medicamentos são usados em exames de sangue para tentar facilitar esse diagnóstico. O nosso trabalho pretende estudar pacientes com a síndrome de Cushing e realizar alguns exames para tentar melhorar o diagnóstico dessa doença.

Será necessário fazer um exame de sangue (teste) para comparar com os pacientes com a síndrome de Cushing:

1. Teste do GHRP-6: Será feito pela manhã, em jejum, começando em torno das $7 \mathrm{~h} 30$, com o paciente deitado numa cama ou leito de hospital. Coloca-se uma agulha na veia do braço do paciente. Ao colocar essa agulha o paciente vai sentir uma picada. Retira-se um pouco de sangue (mais ou menos 1 colher de chá). Coloca-se um soro ligado à veia. Espera-se 15 a 30 minutos, retira-se mais um pouco de sangue, mas agora, não é mais picado o paciente. O sangue é retirado direto do equipo do soro, não tendo mais nenhuma dor. Aguardam-se mais 30 minutos. Em seguida, é colhido sangue novamente e é aplicada a medicação na veia (GHRP-6: Peptídeo liberador do hormônio do crescimento). Colhe-se sangue mais 5 vezes (15, 30, 45, 60 e 90 minutos após a medicação). Normalmente, o paciente não tem nenhum sintoma, mas pode sentir gosto de metal na boca, enjôo leve e sensação do calor no rosto no início do exame, mas sempre terá uma equipe de enfermagem e um médico junto do exame para tratarem os sintomas. Após a última retirada do sangue, será tirado o soro, colocado um curativo no local da punção e se o paciente estiver se sentindo bem volta para sua casa. 
IV - ESCLARECIMENTOS DADOS PELO PESQUISADOR SOBRE GARANTIAS DO SUJEITO DA PESQUISA;

1. Acesso a qualquer tempo, às informações sobre procedimentos, riscos e benefícios relacionados à pesquisa, inclusive para dirimir eventuais dúvidas.

2. Liberdade de retirar seu consentimento a qualquer momento e de deixar de participar de estudo, sem que isto traga prejuízo à continuidade da assistência.

3. Salvaguarda da confidencialidade, sigilo e privacidade.

4. Disponibilidade de assistência no HCFMUSP, por eventuais danos à saúde decorrentes da pesquisa.

5. Viabilidade de indenização por eventuais danos à saúde decorrentes da pesquisa.

V. INFORMAÇÕES DE NOMES, ENDEREÇOS E TELEFONES DOS RESPONSÁVEIS
PELO ACOMPANHAMENTO DA PESQUISA, PARA CONTATO EM CASO DE
INTERCORRÊNCIAS CLÍNICAS E REAÇÕES ADVERSAS.

Márcio Carlos Machado

Rua Cristiano Viana, n 116 - Ap. 63 - Cerqueira César

São Paulo - SP - Fone (011) 3064-9105

VI. OBSERVAÇÕES COMPLEMENTARES:

VII. CONSENTIMENTO PÓS-ESCLARECIMENTO

Declaro que, após ter sido convenientemente esclarecido pelo pesquisador, e ter entendimento o que me foi explicado consinto em participar do presente Protocolo de Pesquisa.

São Paulo, 
Anexos 107

ANEXO C 
Anexos 108

ANEXO D 
ANEXO E. Tabela com valores hormonais basais e pós estím ulo com GHRP-6 nos indivíduos controles

\begin{tabular}{|c|c|c|c|c|c|c|c|c|c|c|c|c|c|c|}
\hline \multirow[b]{2}{*}{$\mathbf{N}^{\circ}$} & \multirow[b]{2}{*}{ Registro HC } & \multirow[b]{2}{*}{ Sexo } & \multirow[b]{2}{*}{ Idade } & \multicolumn{11}{|c|}{$\begin{array}{l}\text { Teste do GHRP-6 } \\
\end{array}$} \\
\hline & & & & F basal & F pico & $\%$ & $\Delta$ & ACTH basal & ACTH pico & $\%$ & $\Delta$ & GH basal & GH pico & IGF1 \\
\hline 1 & $136461117 \mathrm{I}$ & $\mathrm{F}$ & 28 & 15,4 & 14,1 & 0 & 0 & 16,5 & 16,5 & 0 & 0 & 4,3 & 16,9 & 395 \\
\hline 2 & 13630712D & $\mathrm{F}$ & 22 & 33,3 & 32,1 & 0 & 0 & 18,0 & 17,0 & 0 & 0 & 4,8 & 17,4 & 470 \\
\hline 3 & 13633598K & $\mathrm{F}$ & 29 & 14,6 & 14,6 & 0 & 0 & 16,2 & 16,2 & 0 & 0 & 7,3 & 22,4 & 278 \\
\hline 4 & 136461120B & $M$ & 25 & 14,0 & 14,0 & 0 & 0 & 16,5 & 20,0 & 21,2 & 3,5 & 1,0 & 27,5 & 375 \\
\hline 5 & 2795466C & $\mathrm{F}$ & 33 & 9,3 & 20,2 & 117,2 & 10,9 & 16,5 & 60,0 & 263,6 & 43,5 & 0,1 & 6,0 & 68 \\
\hline 6 & $13644922 \mathrm{~K}$ & $\mathrm{~F}$ & 47 & 13,0 & 15,3 & 17,7 & 2,3 & 19,0 & 43,0 & 126,3 & 24,0 & 0,1 & 15,7 & 242 \\
\hline 8 & 13638520D & $F$ & 23 & 13,1 & 18,0 & 37,4 & 4,9 & 22,0 & 59,0 & 168,2 & 37,0 & 1,8 & 23,6 & 250 \\
\hline 9 & $13645192 \mathrm{~F}$ & $\mathrm{~F}$ & 44 & 6,0 & 18,7 & 211,0 & 12,7 & 16,5 & 91,0 & 451,5 & 74,5 & 0,2 & 11,5 & 162 \\
\hline 10 & $13638521 \mathrm{C}$ & $\mathrm{F}$ & 26 & 6,9 & 13,7 & 98,5 & 6,8 & 16,2 & 19,0 & 17,3 & 2,8 & 0,1 & 30,9 & 390 \\
\hline 11 & $5072812 C$ & $M$ & 38 & 12,6 & 14,9 & 18,2 & 2,3 & 25,0 & 40,0 & 60,0 & 15,0 & 0,2 & 18,5 & 232 \\
\hline 12 & 13644923J & $\mathrm{F}$ & 25 & 15,3 & 29,6 & 93,4 & 14,3 & 16,5 & 120,0 & 627,2 & 103,5 & 1,4 & 27,0 & 421 \\
\hline 13 & 2908411D & $\mathrm{F}$ & 42 & 21,7 & 20,9 & 0 & 0 & 28,0 & 45,1 & 61,0 & 17,1 & 2,2 & 19,1 & 125 \\
\hline 14 & $2739745 C$ & $\mathrm{~F}$ & 54 & 9,2 & 14,7 & 59,8 & 5,5 & 16,5 & 21,0 & 27,3 & 4,5 & 0,2 & 10,0 & 297 \\
\hline 15 & 13609517B & $\mathrm{F}$ & 23 & 20,8 & 24,6 & 18,2 & 3,8 & 16,2 & 45,0 & 177,8 & 28,8 & 1,7 & 81,1 & 115 \\
\hline 17 & 3333981D & $M$ & 39 & 11,4 & 20,9 & 83,3 & 9,5 & 18,0 & 57,0 & 216,0 & 39,0 & 0,1 & 24,0 & 245 \\
\hline 18 & 3389067B & $\mathrm{F}$ & 26 & 11,4 & 12,1 & 6,1 & 0,7 & 107,0 & 36,0 & 0 & 0 & 0,3 & 16,9 & 181 \\
\hline 19 & 13630712D & $F$ & 16 & 6,1 & 8,5 & 39,3 & 2,4 & 16,2 & 17,0 & 4,9 & 0,8 & 0,2 & 5,5 & 740 \\
\hline 20 & $13641220 A$ & $\mathrm{~F}$ & 37 & 6,5 & 13,5 & 107,7 & 7,0 & 16,5 & 18,0 & 9,0 & 1,5 & 1,9 & 26,8 & 423 \\
\hline 21 & $2804100 \mathrm{C}$ & $\mathrm{F}$ & 40 & 10,8 & 13,9 & 28,7 & 3,1 & 16,5 & 16,5 & 0 & 0 & 0,1 & 13,4 & 89 \\
\hline
\end{tabular}

Idade, anos; F, cortisol sérico $800 \mathrm{~h}$ em $\mu \mathrm{g} / \mathrm{dL}$ (VN: 5-25 $\mu \mathrm{g} / \mathrm{dL}) ; \%$, porcentagem de incremento do valor de pico em relação ao valor basal (0); $\Delta$, valor absoluto de incremento (basal - pico); ACTH, ACTH plasmático em pg/mL (VN: <60 pg/mL); GH, GH sérico em ng/mL; IGF1, em ng/mL 
ANEXO F. Tabela com valores hormonais basais e pós estímulo com desmopressina nos pacientes com síndrome de Cushing ACTH-dependente

\begin{tabular}{|c|c|c|c|c|c|c|c|c|c|c|c|c|}
\hline \multirow[b]{2}{*}{$\mathbf{N}^{\circ}$} & \multirow[b]{2}{*}{ Paciente } & \multirow[b]{2}{*}{ Registro HC } & \multirow[b]{2}{*}{ Sexo } & \multirow[b]{2}{*}{ Idade } & \multirow[b]{2}{*}{ Diagnóstico } & \multicolumn{7}{|c|}{ Teste da desmopressina } \\
\hline & & & & & & F basal & F pico & $\%$ & ACTH basal & ACTH pico & $\%$ & RESPOSTA* $^{*}$ \\
\hline 1 & ALSJ & $77063780 \mathrm{~F}$ & $\mathrm{~F}$ & 33 & Doença de Cushing & 34.3 & 37.7 & 9.9 & 147 & 227 & 54.4 & - \\
\hline 2 & GCV & $13470027 \mathrm{C}$ & $\mathrm{F}$ & 33 & Doença de Cushing & 21.2 & 27.5 & 29.7 & 69 & 134 & 94.2 & + \\
\hline 3 & SCC & $3372846 G$ & $\mathrm{~F}$ & 26 & Doença de Cushing & 21.6 & 32.9 & 52.3 & 90 & 166 & 84.4 & + \\
\hline 4 & JMS & $13471132 G$ & $\mathrm{~F}$ & 30 & Doença de Cushing & 20.1 & 29.8 & 48.2 & 111 & 249 & 124.0 & + \\
\hline 5 & NMSS & 3387096D & $\mathrm{F}$ & 53 & Doença de Cushing & 17.0 & 24.2 & 42.3 & 29 & 44 & 51.7 & + \\
\hline 6 & CRS & $13569682 \mathrm{H}$ & $M$ & 30 & Doença de Cushing & 7.0 & 17.2 & 145.7 & 46 & 97 & 110.8 & + \\
\hline 7 & CNCL & 13585880J & $\mathrm{F}$ & 34 & Doença de Cushing & 31.0 & 51.2 & 65.0 & 83 & 600 & 622.0 & + \\
\hline 8 & ITS & 77066954J & $\mathrm{F}$ & 47 & Doença de Cushing & 15.3 & 22.9 & 49.7 & 44 & 80 & 81.9 & + \\
\hline 9 & MAS & $1359030 \mathrm{~F}$ & $\mathrm{~F}$ & 35 & Doença de Cushing & 16.0 & 24.7 & 54.3 & 37 & 149 & 302.0 & + \\
\hline 10 & JAMO & $13591449 \mathrm{~J}$ & $\mathrm{~F}$ & 16 & Doença de Cushing & 14.9 & 21.8 & 46.3 & 18 & 94 & 422.0 & + \\
\hline 11 & ECM & 13608704E & $\mathrm{F}$ & 30 & Doença de Cushing & 19.0 & 20.1 & 5.8 & 126 & 204 & 62.0 & - \\
\hline 12 & ASM & $13614617 \mathrm{~F}$ & $F$ & 34 & Doença de Cushing & 28.3 & 43.1 & 52.3 & 53 & 235 & 343.4 & + \\
\hline 13 & MNL & 13579367D & $\mathrm{F}$ & 38 & Doença de Cushing & 21.4 & 25.4 & 18.7 & 60 & 114 & 90.0 & - \\
\hline 14 & JOQ & 13624608B & M & 32 & Doença de Cushing & 28.7 & 34.0 & 18.5 & 330 & 1293 & 292.0 & - \\
\hline 15 & PPS & $13619831 \mathrm{~F}$ & $F$ & 32 & Doença de Cushing & 16.4 & 58.0 & 253.6 & 47 & 203 & 331.9 & + \\
\hline 16 & MLMS & $13624633 \mid$ & $\mathrm{F}$ & 46 & Doença de Cushing & 35.7 & 37.7 & 5.6 & 52 & 81 & 55.7 & - \\
\hline 17 & RSRR & $3125771 \mathrm{C}$ & $\mathrm{F}$ & 19 & Doença de Cushing & 14.0 & 34.0 & 142.8 & 23 & 68 & 195.6 & + \\
\hline 18 & RMS & $55379444 G$ & $\mathrm{~F}$ & 24 & Doença de Cushing & 24.5 & 29.9 & 22.0 & 32 & 235 & 634.3 & + \\
\hline 19 & ZFS & 13569560I & $\mathrm{F}$ & 48 & Doença de Cushing & 25.1 & 33.0 & 31.4 & 110 & 217 & 97.2 & + \\
\hline 20 & MAMA & $13630788 \mathrm{~J}$ & $\mathrm{M}$ & 15 & Doença de Cushing & 18.6 & 36.1 & 94.1 & 160 & 698 & 336.2 & + \\
\hline 21 & VBJ & $13576967 \mathrm{~F}$ & $\mathrm{~F}$ & 18 & SEA & 40.2 & 47.8 & 18.9 & 360 & 1326 & 268.0 & + \\
\hline 22 & $\mathrm{JCJ}$ & $13620365 \mathrm{H}$ & $\mathrm{M}$ & 26 & SEA & 68.6 & 70.3 & 2.4 & 510 & 611 & 19.8 & - \\
\hline
\end{tabular}

$\mathrm{N}^{\circ}$, número do paciente; Idade, anos; SEA, Secreção Ectópica de ACTH; F, cortisol sérico $800 \mathrm{~h}$ em $\mu \mathrm{g} / \mathrm{dL}(\mathrm{VN}: 5-25 \mu \mathrm{g} / \mathrm{dL}) ; \%$, porcentagem de incremento do valor de pico em relação ao valor basal (0); ACTH, ACTH plasmático em pg/mL $(\mathrm{VN}$ : < 60 pg/mL); +, positivo; - , negativo; *Resposta + (pico vs. basal): Cortis ol > 20\% e ACTH > 35\% (Nieman et al., 1993) 
ANEXO G. Tabela com valores hormonais basais e pós estímulo com GHRP-6 nos pacientes com síndrome de Cushing ACTHdependente

\begin{tabular}{|c|c|c|c|c|c|c|c|c|c|c|c|c|c|c|c|c|c|}
\hline \multirow[b]{2}{*}{$\mathbf{N}^{\circ}$} & \multirow[b]{2}{*}{ Paciente } & \multirow[b]{2}{*}{ Registro HC } & \multirow[b]{2}{*}{ Sexo } & \multirow[b]{2}{*}{ Idade } & \multirow[b]{2}{*}{ Diagnóstico } & \multicolumn{12}{|c|}{ Teste do GHRP-6 } \\
\hline & & & & & & Fbas & F pico & $\%$ & $\Delta$ & ACTH bas & АCTH pico & $\%$ & $\Delta$ & RESPOSTA* & GH bas & GH pico & IGF1 \\
\hline 1 & ALSJ & $77063780 \mathrm{~F}$ & $\mathrm{~F}$ & 33 & $\mathrm{DC}$ & 19.9 & 25.3 & 27.1 & 5.4 & 350 & 903 & 158.0 & 553.0 & + & 0.1 & 0.1 & 134 \\
\hline 2 & GCV & $13470027 \mathrm{C}$ & $\mathrm{F}$ & 33 & DC & 16.3 & 29.9 & 83.4 & 13.6 & 37 & 136 & 267.0 & 99.0 & + & 0.3 & 6.2 & NR \\
\hline 3 & SCC & $3372846 G$ & $\mathrm{~F}$ & 26 & DC & 18.6 & 30.4 & 63.4 & 11.8 & 86 & 303 & 252.0 & 217.0 & + & 0.7 & 5.4 & 201 \\
\hline 4 & JMS & $13471132 \mathrm{G}$ & $\mathrm{F}$ & 30 & DC & 18.6 & 38.3 & 105.9 & 19.7 & 60 & 377 & 528.0 & 317.0 & + & 0.3 & 4 & 485 \\
\hline 5 & NMSS & $3387096 \mathrm{D}$ & $\mathrm{F}$ & 53 & DC & 18.1 & 19.0 & 5.0 & 0.9 & 48 & 44 & 0 & 0 & - & 0.2 & 4.8 & 257 \\
\hline 6 & CRS & $13569682 \mathrm{H}$ & $M$ & 30 & DC & 12.3 & 19.0 & 54.4 & 6.7 & 63 & 140 & 122.2 & 77.0 & + & 0.1 & 10.5 & 376 \\
\hline 7 & CNCL & $13585880 \mathrm{~J}$ & $\mathrm{~F}$ & 34 & $\mathrm{DC}$ & 24.9 & 56.3 & 126.1 & 31.4 & 65 & 740 & 1038.0 & 675.0 & + & 0.1 & 1.3 & NR \\
\hline 8 & ITS & 77066954J & $\mathrm{F}$ & 47 & $\mathrm{DC}$ & 16.7 & 26.3 & 57.4 & 9.6 & 39 & 101 & 159.0 & 62.0 & + & 0.4 & 4.4 & 366 \\
\hline 9 & MAS & $1359030 \mathrm{~F}$ & $\mathrm{~F}$ & 35 & DC & 14.0 & 23.6 & 95.7 & 9.6 & 43 & 312 & 625.6 & 269.0 & + & 0.5 & 28 & 396 \\
\hline 10 & JAMO & $13591449 \mathrm{~J}$ & $\mathrm{~F}$ & 16 & DC & 12.9 & 30.5 & 136.4 & 17.6 & 57 & 259 & 354.0 & 202.0 & + & 0.1 & 3.5 & 472 \\
\hline 11 & $\mathrm{ECM}$ & 13608704E & $\mathrm{F}$ & 30 & DC & 28.2 & 29.2 & 3.5 & 1.0 & 122 & 145 & 18.9 & 23.0 & - & 0.3 & 6.4 & 150 \\
\hline 12 & ASM & $13614617 \mathrm{~F}$ & $\mathrm{~F}$ & 34 & DC & 19.5 & 17.1 & 0 & 0 & 32 & 32 & 0 & 0 & - & 0.3 & 3.5 & 466 \\
\hline 13 & MNL & 13579367D & $\mathrm{F}$ & 38 & DC & 21.7 & 24.5 & 12.9 & 2.8 & 85 & 124 & 45.8 & 39.0 & - & 0.1 & 0.3 & 379 \\
\hline 14 & JOQ & 13624608B & $M$ & 32 & DC & 24.0 & 26.6 & 10.8 & 2.6 & 308 & 555 & 80.2 & 247.0 & - & 0.1 & 0.2 & 169 \\
\hline 15 & PPS & $13619831 \mathrm{~F}$ & $\mathrm{~F}$ & 32 & DC & 24.6 & 50.8 & 106.5 & 26.2 & 28 & 104 & 271.4 & 76.0 & + & 0.2 & 0.9 & 477 \\
\hline 16 & MLMS & 13624633I & $\mathrm{F}$ & 46 & DC & 24.1 & 31.8 & 32.0 & 7.7 & 44 & 53 & 20.5 & 9.0 & - & 0.4 & 13.3 & 189 \\
\hline 17 & RSRR & $3125771 \mathrm{C}$ & $\mathrm{F}$ & 19 & DC & 9.7 & 24.6 & 153.6 & 14.9 & 27 & 221 & 718.5 & 194.0 & + & 1.9 & 46.4 & 366 \\
\hline 18 & RMS & $55379444 G$ & $\mathrm{~F}$ & 24 & DC & 25.4 & 32.3 & 27.2 & 6.9 & 64 & 181 & 182.8 & 117.0 & + & 0.1 & 3.9 & 362 \\
\hline 19 & ZFS & $13569560 \mathrm{I}$ & $\mathrm{F}$ & 48 & DC & 25.9 & 28.0 & 8.1 & 2.1 & 257 & 330 & 28.4 & 73.0 & - & 0.1 & 0.2 & 170 \\
\hline 20 & MAMA & $13630788 \mathrm{~J}$ & $M$ & 15 & DC & 19.9 & 33.1 & 66.3 & 13.2 & 55 & 399 & 625.5 & 344.0 & + & 0.2 & 14.6 & 676 \\
\hline 21 & VBJ & $13576967 \mathrm{~F}$ & $\mathrm{~F}$ & 18 & SEA & 36.3 & 38.5 & 6.0 & 2.2 & 433 & 371 & 0 & 0 & - & 0.1 & 0.1 & 197 \\
\hline 22 & $\mathrm{JCJ}$ & $13620365 \mathrm{H}$ & M & 26 & SEA & 61.4 & 68.3 & 11.2 & 6.9 & 883 & 1545 & 75.0 & 662.0 & + & 0.1 & 0.1 & 95 \\
\hline
\end{tabular}

$\mathrm{N}^{\circ}$, número do paciente; Idade, anos; SEA, Secreção Ectópica de ACTH; DC, doença de Cushing; bas, basal; $\mathrm{F}$, cortisol sérico $800 \mathrm{~h}$ em $\mu \mathrm{g} / \mathrm{dL}$ (VN: $5-25$ $\mu \mathrm{g} / \mathrm{dL}$ ); \%, porcentagem de incremento do valor de pico em relação ao valor basal (0); $\Delta$, valor absoluto de incremento (basal - pico); ACTH, ACTH plasmático em pg/mL (VN: < $60 \mathrm{pg} / \mathrm{mL})$; +, positivo; -, negativo; $\mathrm{GH}, \mathrm{GH}$ sérico em ng/mL; IGF1, em ng/mL; NR, não realizado; *Resposta + (pico vs. basal): Cortisol > 20\% e ACTH > 50\% (Nieman et al., 1993; Kaye \& Krapo, 1990; Invitti et al., 1999; Giraldi et al., 2001) 
ANEXO H. Tabela com valores hormonais basais e pós estímulo com hCRH nos pacientes com síndrome de Cushing ACTHdependente

\begin{tabular}{|c|c|c|c|c|c|c|c|c|c|c|c|c|}
\hline \multirow[b]{2}{*}{$\mathbf{N}^{0}$} & \multirow[b]{2}{*}{ Paciente } & \multirow[b]{2}{*}{ Registro HC } & \multirow[b]{2}{*}{ Sexo } & \multirow[b]{2}{*}{ Idade } & \multirow[b]{2}{*}{ Diagnóstico } & \multicolumn{7}{|c|}{ Teste do hCRH } \\
\hline & & & & & & F basal & F pico & $\%$ & ACTH basal & ACTH pico & $\%$ & RESPOSTA* $^{*}$ \\
\hline 1 & ALSJ & $77063780 \mathrm{~F}$ & $\mathrm{~F}$ & 33 & Doença de Cushing & 23,0 & 29,3 & 27,3 & 155 & 369 & 138,0 & + \\
\hline 2 & GCV & $13470027 \mathrm{C}$ & $\mathrm{F}$ & 33 & Doença de Cushing & 20,6 & 21,0 & 1,9 & 52 & 71 & 36,5 & - \\
\hline 4 & JMS & $13471132 G$ & $\mathrm{~F}$ & 30 & Doença de Cushing & NR & NR & NR & NR & NR & NR & NR \\
\hline 5 & NMSS & 3387096D & $\mathrm{F}$ & 53 & Doença de Cushing & NR & NR & NR & NR & NR & NR & NR \\
\hline 6 & CRS & $13569682 \mathrm{H}$ & M & 30 & Doença de Cushing & NR & NR & NR & NR & NR & NR & NR \\
\hline 7 & CNCL & 13585880J & $\mathrm{F}$ & 34 & Doença de Cushing & NR & NR & NR & NR & NR & NR & NR \\
\hline 8 & ITS & 77066954J & $\mathrm{F}$ & 47 & Doença de Cushing & NR & NR & NR & NR & NR & NR & NR \\
\hline 9 & MAS & $1359030 \mathrm{~F}$ & $\mathrm{~F}$ & 35 & Doença de Cushing & NR & NR & NR & NR & NR & NR & NR \\
\hline 10 & JAMO & 13591449J & $\mathrm{F}$ & 16 & Doença de Cushing & NR & NR & NR & NR & NR & NR & NR \\
\hline 11 & ECM & 13608704E & $F$ & 30 & Doença de Cushing & 20,4 & 28,2 & 38,2 & 194 & 455 & 134,5 & + \\
\hline 12 & ASM & 13614617F & $\mathrm{F}$ & 34 & Doença de Cushing & 27,2 & 26,0 & 0 & 49 & 51 & 4,0 & - \\
\hline 13 & MNL & 13579367D & $\mathrm{F}$ & 38 & Doença de Cushing & 23,0 & 30,2 & 31,3 & 91 & 154 & 69,2 & + \\
\hline 14 & JOQ & 13624608B & $M$ & 32 & Doença de Cushing & 25,0 & 31,1 & 24,4 & 195 & 308 & 57,9 & + \\
\hline 15 & PPS & $13619831 \mathrm{~F}$ & $\mathrm{~F}$ & 32 & Doença de Cushing & 24,0 & 21,9 & 0 & 38 & 33 & 0 & - \\
\hline 16 & MLMS & $13624633 \mid$ & $\mathrm{F}$ & 46 & Doença de Cushing & 14,7 & 18,5 & 25,9 & 26 & 32 & 23,0 & - \\
\hline 18 & RMS & $55379444 G$ & $\mathrm{~F}$ & 24 & Doença de Cushing & 22,7 & 24,4 & 7,5 & 39 & 53 & 35,9 & - \\
\hline 19 & ZFS & $13569560 \mathrm{I}$ & $\mathrm{F}$ & 48 & Doença de Cushing & 22,9 & 24,8 & 8,3 & 125 & 138 & 10,4 & - \\
\hline 20 & MAMA & 13630788J & M & 15 & Doença de Cushing & 21,0 & 34,2 & 62,9 & 137 & 747 & 445,2 & + \\
\hline 21 & VBJ & $13576967 \mathrm{~F}$ & $\mathrm{~F}$ & 18 & SEA & 33,8 & 35,8 & 5,9 & 450 & 478 & 6,2 & - \\
\hline 22 & JCJ & $13620365 \mathrm{H}$ & M & 26 & SEA & 63,5 & 62,6 & 0 & 517 & 499 & 0 & - \\
\hline
\end{tabular}

№ número do paciente; Idade, anos; SEA, Secreção Ectópica de ACTH; F, cortisol sérico $800 \mathrm{~h}$ em $\mu \mathrm{g} / \mathrm{dL}$ (VN: 5-25 $\mu \mathrm{g} / \mathrm{dL}) ; \%$, porcentagem de incremento do valor de pico em relação ao valor basal (0); ACTH, ACTH plasmático em pg/mL (VN: < $60 \mathrm{pg} / \mathrm{mL}) ;+$, positivo; -, negativo; NR, não realizado; *Resposta + (pico vs. basal): Cortisol > 14\% e ACTH > 50\% (modificado de Newell-Price et al., 2002) 


\section{REFERÊNCIAS}

Adams EF, Huang B, Buchfelder M, Howard A, Smith RG, Feighner SD, van der Ploeg LH, Bowers CY, Fahlbusch R. Presence of growth hormone secretagogue receptor messenger ribonucleic acid in human pituitary tumors and rat $\mathrm{GH} 3$ cells. J Clin Endocrinol Metab. 1998;83:638-42.

Altschule MD. Occasional notes. A near miss-Osler's early description of Cushing's syndrome with, regrettably, no post-mortem examination. $N$ Engl $\mathrm{J}$ Med. $1980 ; 302: 1153-5$

Ambrosi B, Dall'Asta C, Cannavo S, Libe R, Vigo T, Epaminonda P, Chiodini I, Ferrero S, Trimarchi F, Arosio M, Beck-Peccoz P. Effects of chronic administration of PPAR-gamma ligand rosiglitazone in Cushing's disease. Eur $\mathrm{J}$ Endocrinol. 2004;151:173-8.

Antonini SR, Fragoso MC, Lacroix A. Clinical and molecular aspects of the ACTHindependent bilateral macronodular adrenal hyperplasia. Arq Bras Endocrinol Metabol. 2004;48:620-36.

Arlt W, Dahia PL, Callies F, Nordmeyer JP, Allolio B, Grossman AB, Reincke M. Ectopic ACTH production by a bronchial carcinoid tumour responsive to desmopressin in vivo and in vitro. Clin Endocrinol (Oxf). 1997;47:623-7. 
Arnaldi G, Angeli A, Atkinson AB, Bertagna X, Cavagnini F, Chrousos GP, Fava GA, Findling JW, Gaillard RC, Grossman AB, Kola B, Lacroix A, Mancini T, Mantero F, Newell-Price J, Nieman LK, Sonino N, Vance ML, Giustina A, Boscaro M. Diagnosis and complications of Cushing's syndrome: a consensus statement. J Clin Endocrinol Metab. 2003a;88:5593-602.

Arnaldi G, Mancini T, Kola B, Appolloni G, Freddi S, Concettoni C, Bearzi I, Masini A, Boscaro M, Mantero F. Cyclical Cushing's syndrome in a patient with a bronchial neuroendocrine tumor (typical carcinoid) expressing ghrelin and growth hormone secretagogue receptors. $J$ Clin Endocrinol Metab. 2003b;88:5834-40.

Aron DC, Findling JW, Tyrell JB. Glucocorticoid \& adrenal androgens. In: Greenspan FS, Gardner DG. Basic \& Clinical Endocrinology. New York: McGrawHill Companies; 2004. p.362-413.

Arvat E, Giordano R, Ramunni J, Arnaldi G, Colao A, Deghenghi R, Lombardi G, Mantero F, Camanni F, Ghigo E. Adrenocorticotropin and cortisol hyperresponsiveness to hexarelin in patients with Cushing's disease bearing a pituitary microadenoma, but not in those with macroadenoma. J Clin Endocrinol Metab. 1998;83:4207-11.

Arvat E, Maccario M, Di Vito L, Broglio F, Benso A, Gottero C, Papotti M, Muccioli G, Dieguez C, Casanueva FF, Deghenghi R, Camanni F, Ghigo E. Endocrine activities of ghrelin, a natural growth hormone secretagogue (GHS), in humans: comparison and interactions with hexarelin, a nonnatural peptidyl GHS, and GH-releasing hormone. J Clin Endocrinol Metab. 2001;86:1169-74. 
Arvat E, Ramunni J, Giordano R, Maccagno B, Broglio F, Benso A, Deghenghi R, Ghigo E. Effects of the combined administration of hexarelin, a synthetic peptidyl GH secretagogue, and hCRH on $\mathrm{ACTH}$, cortisol and $\mathrm{GH}$ secretion in patients with Cushing's disease. J Endocrinol Invest. 1999;22:23-8.

Bailey RE. Periodic hormonogenesis: a new phenomenon. Periodicity in function of a hormone-producing tumor in man. J Clin Endocrinol Metab. 1971;32:317-27 apud Newell-Price et al. 1998, p.647-72.

Barbaro D, Lapi P, Orsini P, Pasquini C, Ciaccio S. Pioglitazone treatment in Cushing's disease. J Endocrinol Invest. 2005;28:388-9.

Barbetta L, Dall'Asta C, Tomei G, Locatelli M, Giovanelli M, Ambrosi B. Assesment of cure and recorrence after pituitary surgery for Cushing's disease. Acta Neurochir (Wien). 2001;143:477-82.

Barlier A, Zamora AJ, Grino M, Gunz G, Pellegrini-Bouiller I, Morange-Ramos I, Figarella-Branger D, Dufour $H$, Jaquet $P$, Enjalbert A. Expression of functional growth hormone secretagogue receptors in human pituitary adenomas: polymerase chain reaction, triple in-situ hybridization and cell culture studies. J Neuroendocrinol. 1999;11:491-502.

Barrou Z, Guiban D, Maroufi A, Fournier C, Dugue MA, Luton JP, Thomopoulos P. Overnight dexamethasone suppression test: comparison of plasma and salivary cortisol measurement for the screening of Cushing's syndrome. Eur J Endocrinol. 1996;134:93-6.

Beauregard C, Dickstein G, Lacroix A. Classic and recent etiologies of Cushing's syndrome: diagnosis and therapy. Treat Endocrinol. 2002;1:79-94. 
Beuschlein F, Hammer GD. Ectopic pro-opiomelanocortin syndrome. Endocrinol Metab Clin North Am. 2002;31:191-234.

Bochicchio D, Losa M, Buchfelder M. Factors influencing the immediate and late outcome of Cushing's disease treated by transsphenoidal surgery: a retrospective study by the European Cushing's Disease Survey Group. J Clin Endocrinol Metab. 1995;80:3114-20.

Borges MH, DiNinno FB, Lengyel AM. Different effects of growth hormone releasing peptide (GHRP-6) and $\mathrm{GH}$-releasing hormone on $\mathrm{GH}$ release in endogenous and exogenous hypercortisolism. Clin Endocrinol (Oxf). 1997;46:713-8.

Bowers CY, Chang J, Momany F, Folkers K. Effect of the enkephalins and enkephalin analogs on release of pituitary hormones in vitro. In Maclntyre I, Szelke M, eds. Molecular Endocrinology. Amsterdam: Elsevier Science; 1977. p.287-92 apud Korbonits et al. 2004, p.27-68.

Brown WH. A case of pluriglandular syndrome. "Diabetes of bearded women". Lancet 1928;2:1022-3 apud Beuschlein and Hammer 2002, p.191-234.

Cannavo S, Ambrosi B, Chiodini I, Vigo T, Russo A, Milici C, Barbetta L, Dall'Asta C, Adda G, Arosio M. Baseline and $\mathrm{CRH}$-stimulated ACTH and cortisol levels after administration of the peroxisome proliferator-activated receptor-gamma ligand, rosiglitazone, in Cushing's disease. J Endocrinol Invest. 2004;27:8-11.

Carney JA, Gordon H, Carpenter PC, Shenoy BV, Go WLV. The complex of myxomas, spotty pigmentation, and endocrine overactivity. Medicine (Baltimore). $1985 ; 64: 270-83$. 
Casanueva FF. Physiology of growth hormone secretion and action. Endocrinol Metab Clin North Am. 1992;21:483-517.

Castro M, Elias LL, Elias PC, Moreira AC. A dose-response study of salivary cortisol after dexamethasone suppression test in Cushing's disease and its potential use in the differential diagnosis of Cushing's syndrome. Clin Endocrinol (Oxf). $2003 ; 59: 800-5$

Catalano RD, Kyriakou T, Chen J, Easton A, Hillhouse EW. Regulation of corticotropin-releasing hormone type 2 receptors by multiple promoters and alternative splicing: identification of multiple splice variants. Mol Endocrinol. 2003;17:395-410.

Catargi B, Rigalleau V, Poussin A, Ronci-Chaix N, Bex V, Vergnot V, Gin H, Roger P, Tabarin A. Occult Cushing's syndrome in type-2 diabetes. J Clin Endocrinol Metab. 2003;88:5808-13

Chabot V, de Keyzer Y, Gebhard S, Uske A, Bischof-Delaloye A, Rey F, Dusmet M, Gomez F. Ectopic ACTH Cushing's syndrome: V3 vasopressin receptor but not $\mathrm{CRH}$ receptor gene expression in a pulmonary carcinoid tumor. Horm Res. $1998 ; 50: 226-31$.

Chen $\mathrm{R}$, Lewis KA, Perrin MH, Vale WW. Expression cloning of a human corticotropin-releasing-factor receptor. Proc Natl Acad Sci U S A. 1993;90:8967-71.

Chiodini I, Torlontano M, Scillitani A, Arosio M, Bacci S, Di Lembo S, Epaminonda P, Augello G, Enrini R, Ambrosi B, Adda G, Trischitta V. Association of subclinical hypercortisolism with type 2 diabetes mellitus: a case-control study in hospitalized patients. Eur J Endocrinol. 2005;153:837-44. 
Coiro V, Volpi R, Capretti L, Caffarri G, Chiodera P. Desmopressin and hexarelin tests in alcohol-induced pseudo-Cushing's syndrome. $\mathrm{J}$ Intern Med. 2000;247:667-73.

Colao A, Faggiano A, Pivonello R, Giraldi FP, Cavagnini F, Lombardi G; Study Group of the Italian Endocrinology Society on the Pathophsiology of the Hypothalamic-Pituitary-Adrenal Axis. Inferior petrosal sinus sampling in the differential diagnosis of Cushing's syndrome: results of an Italian multicenter study. Eur J Endocrinol. 2001;144:499-507.

Colao A, Pivonello R, Spiezia S, Faggiano A, Ferone D, Filippella M, Marzullo P, Cerbone G, Siciliani M, Lombardi G. Persistence of increased cardiovascular risk in patients with Cushing's disease after five years of successful cure. J Clin Endocrinol Metab 1999;84:2664-2672.

Colombo P, Dall'Asta C, Barbetta L, Re, T, Passini E, Faglia G, Ambrosi B. Usefulness of the desmopressin test in the postoperative evaluation of patients with Cushing's disease. European J Endocrinolol. 2000;143:227-34.

Corcuff JB, Tabarin A, Rashedi M, Duclos M, Roger P, Ducassou D. Overnight urinary free cortisol determination: a screening test for the diagnosis of Cushing's syndrome. Clin Endocrinol (Oxf). 1998;48:503-8.

Cushing HW. The basophil adenomas of the pituitary body and their clinical manifestations (pituitary basophilism). Bull Johns Hopkins Hosp. 1932;50:137-95 apud Newell-Price et al. 1998, p.647-72.

Dahia PL, Aguiar RC, Honegger J, Fahlbush R, Jordan S, Lowe DG, Lu X, Clayton RN, Besser GM, Grossman AB. Mutation and expression analysis of the p27/kip1 gene in corticotrophin-secreting tumours. Oncogene. 1998;16:69-76. 
Dahia PL, Ahmed-Shuaib A, Jacobs RA, Chew SL, Honegger J, Fahlbusch R, Besser GM, Grossman AB. Vasopressin receptor expression and mutation analysis in corticotropin-secreting tumors. J Clin Endocrinol Metab. 1996;81:1768-71.

de Keyzer Y, Lenne F, Auzan C, Jegou S, Rene P, Vaudry H, Kuhn JM, Luton JP, Clauser E, Bertagna X. The pituitary V3 vasopressin receptor and the corticotroph phenotype in ectopic ACTH syndrome. J Clin Invest. 1996;97:1311-8.

de Keyzer Y, Lenne F, Bertagna X. Widespread transcription of the growth hormone-releasing peptide receptor gene in neuroendocrine human tumors. Eur J Endocrinol. 1997;137:715-8.

de Keyzer $\mathrm{Y}$, Rene $\mathrm{P}$, Beldjord C, Lenne F, Bertagna X. Overexpression of vasopressin (V3) and corticotrophin-releasing hormone receptor genes in corticotroph tumours. Clin Endocrinol (Oxf). 1998;49:475-82.

DeBold CR, Sheldon WR, DeCherney GS, Jackson RV, Alexander AN, Vale W, Rivier J, Orth DN. Arginine vasopressin potentiates adrenocorticotropin release induced by ovine corticotropin-releasing factor. J Clin Invest. 1984;73:533-8.

Dieterich KD, Gundelfinger ED, Ludecke DK, Lehnert H. Mutation and expression analysis of corticotropin-releasing factor 1 receptor in adrenocorticotropin-secreting pituitary adenomas. J Clin Endocrinol Metab. 1998;83:3327-31.

Estrada J, Garcia-Uria J, Lamas C, Alfaro J, Lucas T, Diez S, Salto L, Barcelo B. The complete normalization of the adrenocortical function as the criterion of cure after transsphenoidal surgery for Cushing's disease. J Clin Endocrinol Metab. 2001;86:5695-9. 
Etxabe J, Vazquez JÁ. Morbidity and mortality in Cushing's disease: an epidemiological approach. Clin Endocrinol (Oxf). 1994;40:479-84.

Findling JW, Raff H. Diagnosis and differential diagnosis of Cushing's syndrome. Endocrinol Metab Clin North Am. 2001;30:729-47.

Findling JW, Raff H. Screening and diagnosis of Cushing's syndrome. Endocrinol Metab Clin North Am. 2005;34:385-402.

Fletcher TP, Thomas GB, Willoughby JO, Clarke IJ. Constitutive growth hormone secretion in sheep after hypothalamopituitary disconnection and the direct in vivo pituitary effect of growth hormone releasing peptide 6. Neuroendocrinology. 1994;60:76-86.

Gardner DG. Multiple endocrine neoplasia. In: Greenspan FS, Gardner DG. Basic \& Clinical Endocrinology. New York: McGraw-Hill Companies; 2004. p.829-41.

Gaytan F, Barreiro ML, Caminos JE, Chopin LK, Herington AC, Morales C, Pinilla L, Paniagua R, Nistal M, Casanueva FF, Aguilar E, Dieguez C, Tena-Sempere M. Expression of ghrelin and its functional receptor, the type 1a growth hormone secretagogue receptor, in normal human testis and testicular tumors. J Clin Endocrinol Metab. 2004;89:400-9.

Gaytan F, Morales C, Barreiro ML, Jeffery P, Chopin LK, Herington AC, Casanueva FF, Aguilar E, Dieguez C, Tena-Sempere M. Expression of growth hormone secretagogue receptor type $1 \mathrm{a}$, the functional ghrelin receptor, in human ovarian surface epithelium, mullerian duct derivatives, and ovarian tumors. J Clin Endocrinol Metab. 2005;90:1798-804. 
Ghigo E, Arvat E, Muccioli G, Camanni F. Growth hormone-releasing peptides. Eur J Endocrinol. 1997a;136:445-60.

Ghigo E, Arvat E, Ramunni J, Colao A, Gianotti L, Deghenghi R, Lombardi G, Camanni F. Adrenocorticotropin- and cortisol-releasing effect of hexarelin, a synthetic growth hormone-releasing peptide, in normal subjects and patients with Cushing's syndrome. J Clin Endocrinol Metab. 1997b;82:2439-44.

Ginzinger DG. Gene quantification using real-time quantitative PCR: an emerging technology hits the mainstream. Exp. Hematol. 2002;30:503-12.

Giordano R, Picu A, Broglio F, Bonelli L, Baldi M, Berardelli R, Ghigo E, Arvat E. Ghrelin, hypothalamus-pituitary-adrenal (HPA) axis and Cushing's syndrome. Pituitary. 2004;7:243-8.

Giulietti A, Overbergh L, Valckx D. Decallonne B, Bouillon R, Mathieu C. An overview of real-time quantitative PCR: applications to quantify cytokine gene expression. Methods. 2001;25:386-401.

Gnanapavan S, Kola B, Bustin SA, Morris DG, McGee P, Fairclough P, Bhattacharya S, Carpenter R, Grossman AB, Korbonits M. The tissue distribution of the mRNA of ghrelin and subtypes of its receptor, GHS-R, in humans. J Clin Endocrinol Metab. 2002;87:2988.

Grottoli S, Arvat E, Gauna C, Maccagno B, Ramunni J, Giordano R, Maccario M, Deghenghi R, Ghigo E. Effects of alprazolam, a benzodiazepine, on the ACTH-, GHand PRL-releasing activity of hexarelin, a synthetic peptidyl GH secretagogue (GHS), in patients with simple obesity and in patients with Cushing's disease. Pituitary. 1999;2:197-204. 
Heaney AP, Fernando M, Yong WH, Melmed S. Functional PPAR-gamma receptor is a novel therapeutic target for ACTH-secreting pituitary adenomas. Nat Med. 2002;8:1281-7.

Howard AD, Feighner SD, Cully DF, Arena JP, Liberator PA, Rosenblum Cl, Hamelin M, Hreniuk DL, Palyha OC, Anderson J, Paress PS, Diaz C, Chou M, Liu KK, McKee KK, Pong SS, Chaung LY, Elbrecht A, Dashkevicz M, Heavens R, Rigby M, Sirinathsinghji DJ, Dean DC, Melillo DG, Patchett AA, Nargund R, Griffin PR, DeMartino JA, Gupta SK, Schaeffer JM, Smith RG, Van der Ploeg LH. A receptor in pituitary and hypothalamus that functions in growth hormone release. Science. 1996;273:974-7.

Howlett TA, Drury PL, Perry L, Doniach I, Rees LH, Besser GM. Diagnosis and management of ACTH-dependent Cushing's syndrome: comparison of the features in ectopic and pituitary ACTH production. Clin Endocrinol (Oxf). 1986;24:699-713 apud Wajchenberg et al. 1994, p.752-87.

Hull SS, Sheridan B, Atkinson AB. Pre-operative medical therapy with rosiglitazone in two patients with newly diagnosed pituitary-dependent Cushing's syndrome. Clin Endocrinol (Oxf). 2005;62:259-61.

Invitti C, Giraldi FP, de Martin M, Cavagnini F. Diagnosis and management of Cushing's syndrome: results of an Italian multicentre study. Study Group of the Italian Society of Endocrinology on the Pathophysiology of the HypothalamicPituitary-Adrenal Axis. J Clin Endocrinol Metab. 1999;84:440-8.

Isidori AM, Kaltsas GA, Pozza C, Frajese V, Newell-Price J, Reznek RH, Jenkins PJ, Monson JP, Grossman AB, Besser GM. The ectopic adrenocorticotropin syndrome: clinical features, diagnosis, management, and long-term follow-up. J Clin Endocrinol Metab. 2006;91:371-7. 
Jansson JO, Svensson J, Bengtsson BA, Frohman LA, Ahlman H, Wangberg B, Nilsson $\mathrm{O}$, Nilsson M. Acromegaly and Cushing's syndrome due to ectopic production of $\mathrm{GHRH}$ and $\mathrm{ACTH}$ by a thymic carcinoid tumour: in vitro responses to GHRH and GHRP-6. Clin Endocrinol (Oxf). 1998;48:243-50.

Kaltsas GA, Giannulis MG, Newell-Price JD, Dacie JE, Thakkar C, Afshar F, Monson JP, Grossman AB, Besser GM, Trainer PJ. A critical analysis of the value of simultaneous inferior petrosal sinus sampling in Cushing's disease and the occult ectopic adrenocorticotropin syndrome. J Clin Endocrinol Metab. 1999;84:487-92.

Kaye TB, Crapo L. The Cushing syndrome: an update on diagnostic tests. Ann Intern Med. 1990;112:434-44.

Kelly W. Exophthalmos in Cushing's syndrome. Clin Endocrinol (Oxf). 1996;45:167-70.

Kim K, Arai K, Sanno N, Osamura RY, Teramoto A, Shibasaki T. Ghrelin and growth hormone $(\mathrm{GH})$ secretagogue receptor (GHSR) mRNA expression in human pituitary adenomas. Clin Endocrinol (Oxf). 2001;54:759-68.

Kim K, Sanno N, Arai K, Takano K, Yasufuku-Takano J, Teramoto A, Shibasaki T. Ghrelin mRNA and $\mathrm{GH}$ secretagogue receptor mRNA in human $\mathrm{GH}$-producing pituitary adenomas is affected by mutations in the alpha subunit of $\mathrm{G}$ protein. Clin Endocrinol (Oxf). 2003;59:630-6.

Kojima M, Hosoda H, Date Y, Nakazato M, Matsuo H, Kangawa K. Ghrelin is a growth-hormone-releasing acylated peptide from stomach. Nature. 1999;402:656-60. 
Korbonits M, Bustin SA, Kojima M, Jordan S, Adams EF, Lowe DG, Kangawa K, Grossman $A B$. The expression of the growth hormone secretagogue receptor ligand ghrelin in normal and abnormal human pituitary and other neuroendocrine tumors. $J$ Clin Endocrinol Metab. 2001;86:881-7.

Korbonits M, Goldstone AP, Gueorguiev M, Grossman AB. Ghrelin- a hormone with multiple functions. Front Neuroendocrinol. 2004;25:27-68.

Korbonits M, Jacobs RA, Aylwin SJ, Burrin JM, Dahia PL, Monson JP, Honegger J, Fahlbush R, Trainer PJ, Chew SL, Besser GM, Grossman AB. Expression of the growth hormone secretagogue receptor in pituitary adenomas and other neuroendocrine tumors. J Clin Endocrinol Metab. 1998;83:3624-30.

Lacroix A, N'Diaye N, Tremblay J, Hamet P. Ectopic and abnormal hormone receptors in adrenal Cushing's syndrome. Endocr Rev. 2001;22:75-110.

Lania A, Ballare E, Corbetta S, Filopanti M, Persani L, Spada A. Growth hormonereleasing hexapeptide (GHRP-6) increases intracellular calcium concentrations in cultured cells from human pituitary adenomas of different types. Eur J Endocrinol. 1998;139:343-8

Leal-Cerro A, Pumar A, Garcia-Garcia E, Dieguez C, Casanueva FF. Inhibition of growth hormone release after the combined administration of GHRH and GHRP-6 in patients with Cushing's syndrome. Clin Endocrinol (Oxf). 1994;41:649-54.

Leal-Cerro A, Torres E, Soto A, Dios E, Deghenghi R, Arvat E, Ghigo E, Dieguez C, Casanueva FF. Ghrelin is no longer able to stimulate growth hormone secretion in patients with Cushing's syndrome but instead induces exaggerated corticotropin and cortisol responses. Neuroendocrinology. 2002;76:390-6. 
Lebrethon MC, Grossman AB, Afshar F, Plowman PN, Besser GM, Savage MO. Linear growth and final height after treatment for Cushing's disease in childhood. J Clin Endocrinol Metab. 2000;85:3262-5.

Lefournier V, Gatta B, Martinie M, Vasdev A, Tabarin A, Bessou P, Berge J, Bachelot I, Chabre O. One transient neurological complication (sixth nerve palsy) in 166 consecutive inferior petrosal sinus samplings for the etiological diagnosis of Cushing's syndrome. J Clin Endocrinol Metab.1999;84:3401-2.

Lefournier V, Martinie M, Vasdev A, Bessou P, Passagia JG, Labat-Moleur F, Sturm $\mathrm{N}$, Bosson JL, Bachelot I, Chabre O. Accuracy of bilateral inferior petrosal or cavernous sinuses sampling in predicting the lateralization of Cushing's disease pituitary microadenoma: influence of catheter position and anatomy of venous drainage. J Clin Endocrinol Metab. 2003;88:196-203.

Leibowitz G, Tsur A, Chayen SD, Salameh M, Raz I, Cerasi E, Gross DJ. Preclinical Cushing's syndrome: an unexpected frequent cause of poor glycaemic control in obese diabetic patients. Clin Endocrinol (Oxf). 1996;44:717-22.

Leinung MC, Zimmerman D. Cushing's disease in children. Endocrinol Metab Clin North Am. 1994;23:629-39.

Lengyel AM. From growth hormone-releasing peptides to ghrelin: discovery of new modulators of GH secretion. Arq Bras Endocrinol Metabol. 2006;50:17-24.

Liaw CW, Lovenberg TW, Barry G, Oltersdorf T, Grigoriadis DE, de Souza EB. Cloning and characterization of the human corticotropin-releasing factor-2 receptor complementary deoxyribonucleic acid. Endocrinology. 1996;137:72-7. 
Lida S, Nakamura Y, Fujii H, et al. A patient with hypocortisolism and Cushing's syndrome-like manifestations: cortisol hyperreactive syndrome. J Clin Endocrinol Metab. 1990;70:729-37.

Liddle GW, Island DP, Nicholson WE, Shimizu N, Ney RL. An Unexpected cause of Cushing's syndrome: Carcinomas that secrete "ACTH". Trans Am Clin Climatol Assoc. 1962;74:92-101 apud Beuschlein and Hammer 2002, p.191-234.

Lindholm J, Juul S, Jorgensen JO, Astrup J, Bjerre P, Feldt-Rasmussen U, Hagen C, Jorgensen J, Kosteljanetz M, Kristensen L, Laurberg P, Schmidt K, Weeke J. Incidence and late prognosis of cushing's syndrome: a population-based study. $J$ Clin Endocrinol Metab. 2001;86:117-23.

Lindsay JR, Nieman LK. Differential diagnosis and imaging in Cushing's syndrome. Endocrinol Metab Clin North Am. 2005;34:403-21.

Liu H, Crapo L. Update on the diagnosis of Cushing's syndrome. The Endocrinologist. 2005;15:165-79.

Livak KJ, Schmittgen TD. Analysis of relative gene expression data using real-time quantitative PCR and the 2(-Delta Delta C(T)) Method. Methods. 2001;25:402-8

Losa M, Mortini P, Dylgjeri S, Barzaghi R, Franzin A, Mandelli C, Giovanelli M. Desmopressin stimulation test before and after pituitary surgey in patients with Cushing's disease. Clin Endocrinol. 2001;55:61-8.

Magiakou MA, Mastorakos G, Oldfield EH, Gomez MT, Doppman JL, Cutler GB Jr, Nieman LK, Chrousos GP. Cushing's syndrome in children and adolescents. Presentation, diagnosis, and therapy. N Engl J Med. 1994;331:629-36. 
Malerbi DA, Mendonca BB, Liberman B, Toledo SP, Corradini MC, Cunha-Neto MB, Fragoso MC, Wajchenberg BL. The desmopressin stimulation test in the differential diagnosis of Cushing's syndrome. Clin Endocrinol (Oxf). 1993;38:463-72.

Martinez-Fuentes AJ, Moreno-Fernandez J, Vazquez-Martinez R, Duran-Prado M, de la Riva A, Tena-Sempere M, Dieguez C, Jimenez-Reina L, Webb SM, Pumar A, Leal-Cerro A, Benito-Lopez P, Malagon MM, Castano JP. Ghrelin is produced by and directly activates corticotrope cells from ACTH-secreting adenomas. J Clin Endocrinol Metab. 2006;Mar 21 [Epub ahead of print]

Matsuno A, Okazaki R, Oki Y, Nagashima T. Secretion of high-molecular-weight adrenocorticotropic hormone from a pituitary adenoma in a patient without Cushing stigmata. Case report. J Neurosurg. 2004;101:874-7.

Matsuzaki LN, Canto-Costa MH, Hauache OM. Cushing's disease as the first clinical manifestation of multiple endocrine neoplasia type 1 (MEN1) associated with an R460X mutation of the MEN1 gene. Clin Endocrinol (Oxf). 2004;60:142-3.

McAndrew J, Paterson AJ, Asa SL, McCarthy KJ, Kudlow JE. Targeting of transforming growth factor-alpha expression to pituitary lactotrophs in transgenic mice results in selective lactotroph proliferation and adenomas. Endocrinology. $1995 ; 136: 4479-88$

Meador CK, Liddle GW, Island DP, Nicholson WE, Lucas CP, Nuckton JG, Luetscher JA. Cause of Cushing's syndrome in patients with tumors arising from "nonendocrine" tissue. J Clin Endocrinol Metab. 1962;22:693-703 apud Beuschlein and Hammer 2002, p.191-234. 
Mericq V, Cassorla F, Bowers CY, Avila A, Gonen B, Merriam GR. Changes in appetite and body weight in response to long-term oral administration of the ghrelin agonist GHRP-2 in growth hormone deficient children. J Pediatr Endocrinol Metab. 2003;16:981-5.

Nagesser SK, van Seters AP, Kievit J, Hermans J, van Dulken H, Krans HM, van de Velde CJ. Treatment of pituitary-dependent Cushing's syndrome: long-term results of unilateral adrenalectomy followed by external pituitary irradiation compared to transsphenoidal pituitary surgery. Clin Endocrinol (Oxf). $2000 ; 52: 427-35$

Nanzer AM, Khalaf S, Mozid AM, Fowkes RC, Patel MV, Burrin JM, Grossman AB, Korbonits M. Ghrelin exerts a proliferative effect on a rat pituitary somatotroph cell line via the mitogen-activated protein kinase pathway. Eur J Endocrinol. 2004; 151:233-40.

Newell-Price J, Morris DG, Drake WM, Korbonits M, Monson JP, Besser GM, Grossman AB. Optimal response criteria for the human $\mathrm{CRH}$ test in the differential diagnosis of ACTH-dependent Cushing's syndrome. J Clin Endocrinol Metab. $2002 ; 87: 1640-5$

Newell-Price J, Trainer P, Besser M, Grossman A. The diagnosis and differential diagnosis of Cushing's syndrome and pseudo-Cushing's states. Endocr Rev. 1998;19:647-72.

Newfield RS, Kalaitzoglou G, Licholai T, Chilton D, Ashraf J, Thompson EB, New MI. Normocortisolemic Cushing's syndrome initially presenting with increased glucocorticoid receptor numbers. J Clin Endocrinol Metab. 2000;85:14-21. 
Nielsen S, Mellemkjaer S, Rasmussen LM, Ledet T, Astrup J, Weeke J, Jorgensen JO. Gene transcription of receptors for growth hormone-releasing peptide and somatostatin in human pituitary adenomas. $J$ Clin Endocrinol Metab. 1998;83:2997-3000.

Nieman LK, Oldfield EH, Wesley R, Chrousos GP, Loriaux DL, Cutler GB Jr. A simplified morning ovine corticotropin-releasing hormone stimulation test for the differential diagnosis of adrenocorticotropin-dependent Cushing's syndrome. J Clin Endocrinol Metab. 1993;77:1308-12.

Odell W, Wolfsen A, Yoshimoto Y, Weitzman R, Fisher D, Hirose F. Ectopic peptide synthesis: a universal concomitant of neoplasia. Trans Assoc Am Physicians. 1977;90:204-27 apud Terzolo et al. 2001, p.S83-7.

Ohta K, Shichiri M, Kameya T, Matsubara O, Imai T, Marumo F, Hirata Y. Thymic hyperplasia as a source of ectopic ACTH production. Endocr J. 2000;47:487-92.

Oldfield EH, Doppman JL, Nieman LK, Chrousos GP, Miller DL, Katz DA, Cutler GB Jr, Loriaux DL. Petrosal sinus sampling with and without corticotropin-releasing hormone for the differential diagnosis of Cushing's syndrome. $N$ Engl $\mathrm{J}$ Med. 1991;325:897-905.

Oliveira JH, Vieira JG, Abucham J, Lengyel AM. GHRP-6 is able to stimulate cortisol and $\mathrm{ACTH}$ release in patients with Cushing's disease: comparison with DDAVP. $J$ Endocrinol Invest. 2003;26:230-5.

Papanicolaou DA, Yanovski JA, Cutler GB Jr, Chrousos GP, Nieman LK. R A single midnight serum cortisol measurement distinguishes Cushing's syndrome from pseudo-Cushing states. J Clin Endocrinol Metab. 1998;83:1163-7. 
Pecori Giraldi F, Invitti C, Cavagnini F; Study Group of the Italian Society of Endocrinology on the Pathophysiology of the Hypothalamic-pituitary-adrenal axis. The corticotropin-releasing hormone test in the diagnosis of ACTH-dependent Cushing's syndrome: a reappraisal. Clin Endocrinol (Oxf). 2001;54:601-7.

Pecori Giraldi F, Marini E, Torchiana E, Mortini P, Dubini A, Cavagnini F. Corticotrophin-releasing activity of desmopressin in Cushing's disease: lack of correlation between in vivo and in vitro responsiveness. J Endocrinol. 2003;177:373-9.

Petersenn S, Rasch AC, Penshorn M, Beil FU, Schulte HM. Genomic structure and transcriptional regulation of the human growth hormone secretagogue receptor. Endocrinology. 2001;142:2649-59.

Petersenn S. Structure and regulation of the growth hormone secretagogue receptor. Minerva Endocrinol. 2002;27:243-56.

Pfaffl MW. A new mathematical model for relative quantification in real time RTPCR. Nucleic Acids Research. 2001;29:2002-7.

Popovic V, Miljic D, Micic D, Damjanovic S, Arvat E, Ghigo E, Dieguez C, Casanueva FF. Ghrelin main action on the regulation of growth hormone release is exerted at hypothalamic level. J Clin Endocrinol Metab. 2003;88:3450-3.

Rabadan-Diehl C, Makara G, Kiss A, Lolait S, Zelena D, Ochedalski T, Aguilera G. Regulation of pituitary $\mathrm{V} 1 \mathrm{~b}$ vasopressin receptor messenger ribonucleic acid by adrenalectomy and glucocorticoid administration. Endocrinology. 1997;138:5189-94.

Rasmussen RP. Quantification on the LightCycler. In: Meuer S, Wittwer CT, Nakagawara K, eds. Rapid Cycle Real-time PCR, Methods and Applications. Heidelberg: Springer Press; 2001, 21-34. 
Rix M, Hertel NT, Nielsen FC, Jacobsen BB, Hoejberg AS, Brixen K, Hangaard J, Kroustrup JP. Cushing's disease in childhood as the first manifestation of multiple endocrine neoplasia syndrome type 1. Eur J Endocrinol. 2004;151:709-15.

Rocheville M, Lange DC, Kumar U, Sasi R, Patel RC, Patel YC. Subtypes of the somatostatin receptor assemble as functional homo- and heterodimers. J Biol Chem. 2000;275:7862-9.

Scott LV, Medbak S, Dinan TG. ACTH and cortisol release following intravenous desmopressin: a dose-response study. Clin Endocrinol (Oxf). 1999;51:653-8.

Silva SRC, Nascif SO, Lengyel AMJ. ACTH and cortisol responses to ghrelin and GHRP-6 after one month of ketoconazole treatment in Cushing's disease. Arq Bras Endocrinol Metab. 2006;50:S62.

Skinner MM, Nass R, Lopes B, Laws ER, Thorner MO. Growth hormone secretagogue receptor expression in human pituitary tumors. J Clin Endocrinol Metab. 1998;83:4314-20.

Smith RG, Van der Ploeg LH, Howard AD, Feighner SD, Cheng K, Hickey GJ, Wyvratt MJ Jr, Fisher MH, Nargund RP, Patchett AA. Peptidomimetic regulation of growth hormone secretion. Endocr Rev. 1997;18:621-45.

Stratakis CA, Kirschner LS, Carney JA. Clinical and molecular features of the Carney complex: diagnostic criteria and recommendations for patient evaluation. $\mathrm{J}$ Clin Endocrinol Metab. 2001;86:4041-6.

Sugimoto T, Saito M, Mochizuki S, Watanabe $\mathrm{Y}$, Hashimoto S, Kawashima H. Molecular cloning and functional expression of a cDNA encoding the human $\mathrm{V} 1 \mathrm{~b}$ vasopressin receptor. J Biol Chem. 1994;269:27088-92. 
Suri D, Weiss RE. Effect of pioglitazone on adrenocorticotropic hormone and cortisol secretion in Cushing's disease. J Clin Endocrinol Metab. 2005;90:1340-6.

Tamura H, Kamegai J, Sugihara H, Kineman RD, Frohman LA, Wakabayashi I. Glucocorticoids regulate pituitary growth hormone secretagogue receptor gene expression. J Neuroendocrinol. 2000;12:481-5.

Terzolo M, Reimondo G, Ali A, Bovio S, Daffara F, Paccotti P, Angeli A. Ectopic ACTH syndrome: molecular bases and clinical heterogeneity. Ann Oncol. 2001;12:S83-7.

Tomlinson JW, Draper N, Mackie J, Johnson AP, Holder G, Wood P, Stewart PM. Absence of Cushingoid phenotype in a patient with Cushing's disease due to defective cortisone to cortisol conversion. $J$ Clin Endocrinol Metab. 2002;87:57-62.

Trainer PJ, Grossman A. The diagnosis and differential diagnosis of Cushing's syndrome. Clin Endocrinol (Oxf). 1991;34:317-30.

Tsagarakis S, Tsigos C, Vasiliou V, Tsiotra P, Kaskarelis J, Sotiropoulou C, Raptis SA, Thalassinos $\mathrm{N}$. The desmopressin and combined $\mathrm{CRH}$-desmopressin tests in the differential diagnosis of ACTH-dependent Cushing's syndrome: constraints imposed by the expression of V2 vasopressin receptors in tumors with ectopic ACTH secretion. $\mathrm{J}$ Clin Endocrinol Metab. 2002;87:1646-53.

Utz AL, Swearingen B, Biller BM. Pituitary surgery and postoperative management in Cushing's disease. Endocrinol Metab Clin North Am. 2005;34:459-78. 
Vale W, Spiess J, Rivier C, Rivier J. Characterization of a 41-residue ovine hypothalamic peptide that stimulates secretion of corticotropin and beta-endorphin. Science. 1981;213:1394-7.

Valero R, Vallette-Kasic S, Conte-Devolx B, Jaquet P, Brue T. The desmopressin test as a predictive factor of outcome after pituitary surgery for Cushing's disease. Eur J Endocrinol. 2004;151:727-33.

van den Ouweland AM, Kioschis P, Verdijk M, Tamanini F, Toniolo D, Poustka A, van Oost BA. Identification and characterization of a new gene in the human Xq28 region. Hum Mol Genet. 1992;1:269-73.

van der Lely AJ, Tschop M, Heiman ML, Ghigo E. Biological, physiological, pathophysiological, and pharmacological aspects of ghrelin. Endocr Rev. 2004;25:426-57.

Vergès B, Boureille F, Goudet P, Murat A, Beckers A, Sassolas G, Cougard P, Chambe B, Montvernay C, Calender A. Pituitary disease in MEN type 1 (MEN1): Data from the France-Belgium MEN1 multicenter study. J Clin Endocrinol Metab. $2002 ; 87: 457-65$

Wajchenberg BL, Mendonca BB, Liberman B, Pereira MA, Carneiro PC, Wakamatsu A, Kirschner MA. Ectopic adrenocorticotropic hormone syndrome. Endocr Rev. $1994 ; 15: 752-87$

Watzinger F, Lion T. Multiplex PCR for quality control of template RNA/cDNA in RTPCR assays. Leukemia. 1998;12:1984-6. 
Weinstein LS, Shenker A, Gejman PV, Merino MJ, Friedman E, Spiegel AM. Activating mutations of the stimulatory $\mathrm{G}$ protein in the McCune-Albright syndrome. N Engl J Med. 1991;325:1688-95.

Yanovski JA, Cutler GB Jr, Chrousos GP, Nieman LK. Corticotropin-releasing hormone stimulation following low-dose dexamethasone administration. A new test to distinguish Cushing's syndrome from pseudo-Cushing's states. JAMA. $1993 ; 269: 2232-8$

Yap LB, Turner HE, Adams CB, Wass JA. Undetectable postoperative cortisol does not always predict long-term remission in Cushing's disease: a single centre audit. Clin Endocrinol (Oxf). 2002;56:25-31. 